\title{
Dynamic ellipsometry, biochemical and biomedical applications
}

Citation for published version (APA):

Cuypers, P. A. (1976). Dynamic ellipsometry, biochemical and biomedical applications. [Doctoral Thesis, Maastricht University]. Rijksuniversiteit Limburg. https://doi.org/10.26481/dis.19760507pc

Document status and date:

Published: 01/01/1976

DOI:

$10.26481 /$ dis. $19760507 p c$

Document Version:

Publisher's PDF, also known as Version of record

\section{Please check the document version of this publication:}

- A submitted manuscript is the version of the article upon submission and before peer-review. There can be important differences between the submitted version and the official published version of record.

People interested in the research are advised to contact the author for the final version of the publication, or visit the DOI to the publisher's website.

- The final author version and the galley proof are versions of the publication after peer review.

- The final published version features the final layout of the paper including the volume, issue and page numbers.

Link to publication

\footnotetext{
General rights rights.

- You may freely distribute the URL identifying the publication in the public portal. please follow below link for the End User Agreement:

www.umlib.nl/taverne-license

Take down policy

If you believe that this document breaches copyright please contact us at:

repository@maastrichtuniversity.nl

providing details and we will investigate your claim.
}

Copyright and moral rights for the publications made accessible in the public portal are retained by the authors and/or other copyright owners and it is a condition of accessing publications that users recognise and abide by the legal requirements associated with these

- Users may download and print one copy of any publication from the public portal for the purpose of private study or research.

- You may not further distribute the material or use it for any profit-making activity or commercial gain

If the publication is distributed under the terms of Article $25 \mathrm{fa}$ of the Dutch Copyright Act, indicated by the "Taverne" license above, 


\begin{abstract}
DYNAMIC ELL IPSOMETRY
BIOCHEMICAL ANO BIOMEDICAL APPLICATIOHS
\end{abstract}

$$
\text { P R O E F S C H R I F T }
$$

TER VERKRIJGING VAN DE GRAAD VAN DOCTOR IN DE GENEESKUNDE AAM DE RIJKSUNIVERSITEIT LIMBURG, OP GEZAG VAN DE RECTOR MAGNIFICUS OR.H.A.TIDDENS, HOOGLERAAR IN DE FACULTEIT DER GENEESKUNDE, VOLGENS BESLUIT WAN HET COLLEGE VAN DEKANEN TE VERDEDIGEN OP 7 MEI 1979 TE KLOKKE 15.00 UUR

D $\quad 0 \quad 0 \quad R$

PETER ANTONY CUYPERS

GEBOREN TE GRAFT IN 1948 
Thekeningen: Mej. A. B. Multer

lay-aut: Mewn. Hermeer-knulst

Produktie : Boo/nW Centrum, Rijksuniversiteit Limburg

Druk : Rijksuniversiteit Limburg, afd. Reprografie 
Promotor: Prof.Dr.H.C.Hemker

Dit proefschrift werd bewerkt in het Laboratarium voor Cardiobiochemie en Bloedstollingsbiachemie van het Academisch Ziekenhuis te Leiden en het Laboratorium vaor Biochemie van. de Rijksuniversiteit Limburg, onder leiding van Dr. W. Th. Hermens en Prof.or.H.C. Hemker. 
Aan mijn ouders 
CHAPTE Imtroduction

Literature references

The automatized llipsometer

Principles of the method

Light source

Aligment of the ellipsometer

3.2 .1 .2

Light detector

3.2 .1 .4 Amplifier correction unit

$3,2.2$

Meter amplifier

$\begin{array}{ll}3.2 .2 .2 \text { Timing circuit } & 27\end{array}$

3.2 .2 .3 Decoder 27

3.2 .2 .4 Stepping motor print 27

3.2 .2 .5 5tepping motor 28

4 Ellipsometer steering computer program 28

4.1 Introduction 28

4.2 Principle of the steering procedure 28

4.3 Steering method of the stepping motars 29

4.4 The computer programs 
4.4.1 Core restitent programs

4. 4.1. system $y$

4.4.1.2 Arithmetic routines

4.4.1.3 Interrupt and service routines 31

4.4.1.4 Montitor 31

4.4.2 Calibration program 31

4.4.3 Processing program; it re regroduction prograta 34

Literature references 42

CHAPTER III Optical basis of the method 43

1.1 Defintions and basic principles of polarized light 43

1.2 Complex notation 45

1.3 The reflection and refraction of light an a boundary between two isotropic dielectrics 47

1.4 Phise conditions 49

1.5 Amplitude conditions (Fresnel's formulat) 50

2.1 Total phase difference by reflection of a monochromatic light wave on an isotropic adsorioing substrate cowered by a thin adsorbing layer 51

2.2 Mulutiple reflection (Drude equation) 53

2.3 System of several layers 55

2.4 Influence of wery thin transitional films

3 Determination of $\psi$ and $\Delta$ from ellipsometer scale readings 59

3.1. Introduction 59

3.2 The relationship of $p_{,} a_{p}$ and $a_{5}$ to the $p$ and $A$

4 Determination of $m$ and $k$ on a clean surface 66

5 Ellipsometric theories in the submonolayer range 67

$\begin{array}{lll}5.1 & \text { Introduction } & 67\end{array}$

5.2 Short review of the ellipsometer theories 68

5.2.1 General equations (macrascapic theary) 69

5.2 .1 a clean surface 69

5.2. Ib Surface covered with one layer 69

5.2.1c Surface covered with several iayers 70

$5.2 .1 d$ Inversion in of Drudes exact ellipsometric equation 71

5.2 .2 Approximations (macroscopic theory) 73

5.2 .2 a Approximated Drude equation for thin film $(50-100 \AA) \quad 73$

$5.2 .2 b$. Multiple film systems 74

5.2 .3 Theories for the submonolayer rangle 75

5.2.3a Drude model (extrapolated) 75 


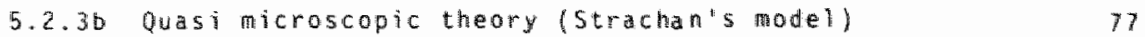

$5.2 .3 \mathrm{c}$ Aicroscopic theory (Sivukthos model)

6 Computation methods for some inhomageneous fillas? 79

6.1 Maxwell differential equation 9

6.2 An inhomogemeous film replaced by a plle of homo-

geneaus ones 81

Literature peferences

CHAPIER IV Calculations of thickness and refractive index from analyzer and polarizer data 85

1 Intoduction 85

2 Computer program 85

2.1 Vimgin 85

2.2 El1is 86

2.3 EIIP 89

3 Applications 89

3.1 The grawth of layers of different real parts

of refractive index onto a silicon surface 89

3.2 The influence of the aptical properties of the reflecting surface 91

3.3 Influence of the angle of incidence 93

3.4 The influence of wavelength on the sensitivity of $n=1.47$ layers on chromium

3.5 The influence of varying real parts of refractive index of the immersion medium an the chromium barium stearate system

CHAPTER V Experimental calibrations 97

1 Introduction 97

1.1 Preparation of monolayers 97

1.2 Tramsfer of the monolayers to solid surfaces 98

1.2.1 Piston 0il method 98

1.2.2 Automatic recording Langmuir trough 99

2 Experimenta? catibrations 100

2.1 Determination of the angle of incidence 100

2.2 Wariations of the angle of incidence ion

2.3 Calibration of the ellipsometer with monalayers of barium steatrate on chromin in air 101

2.3 .1 Procedure and results 102

\begin{tabular}{ll}
3 & Discussion \\
\hline
\end{tabular}

4 Calibration in the curet 107

Literature references 112 
CHAPTER VI

1

2

3

3. 1

3. 2

3. 3

3.4

4

5

5.1

5.2

6

6.1

6.2

7

B

Appliteations

113

Introduction

113

Haterials

13

Adsorption of fibrinogen

113

Hydrophlitic chromium surface

113

115

120

122

122

122

122

126

126

Albuinin-antialbumin interaction

Displacement of albumin by fibrinogen in a chromium surface

Displacement of the serun proteims by fibrinogen on a chromium surface

Relation between thickness and refractive index in

a monolayer of protein

Discussion

134

Literature references

135

137

139

141

143

145

146 
CHAPTER I

Introduction

The meed for a better understanding of enzynatic reactions at interphases has been rased by recent developments in cell biochemistry and cell biology. However, a number of difficulties is imherent to the study of biological surfaces. Perhaps the greatest difficulty is the complex organization of biological systems and the functional continuity between various components. The living cell represents a complex of membranes and organelles, whose structural and functional properties are maintained by reactions accurrimg at multiple interrelated solid-gel, solid-liquid, and liquid-gel interphases. The whole cell in turn interacts with the envimonment by means of a highly complex outer surface. Consequently, there are both conceptual and practical difficulties in defining the precise nature and spatial limits of many interphases. If we add to this that biologicali systems are gaverned by dynamic, rather than static conditions, one can admit that identifying the properties of even the simplest biological interphase poses considerable problems.

Almast all reactions of biochemical interest at interphases studied thus far, took place at 1iquid-air interphases (1-23). The results have not been too encouraging, altogether, partly due to the physicochemical behaviour of proteins. When spread at a water-air interphase, they loose part or all their biological activities $(15,17,20,21)$. If instead a (lipid) substrate is spread at the surface and the protein (enzyme) is in the bulkphase, film penetration and unequal distributian of enzyme between the liquid phase and the film can interfere. In addition a liquid-air interphese cannot be a proper madel for the natural conditions inside or on the surface of a living cell. A 1iquidsolid interphase would be a much better model. For instance, if the solid is a lipid or a protein, acting as a substrate, and if the enzyme is dissolved in the adjacent liquid phase, conditions might be very similar to those found in the intestinal tract. Whem the enzyme is on the surface of a solid phase and the substrate is dissolved in the adjacent liquid phase, the conditions resemble closely those inside and around the organelles of a living cell.

Only rather recently different physico-chemical methods have been abie to study reactions at interphases which have been applied to biological systems. As we want to discuss an extension af the arsenal in this thesis, we will first briefly mention the other methods, currently available. 
SPECTROSCOPIC TECHUIQUES have been applied to the study of lipid-protein interactions in membranes. Dne af them being MMR spectroscopy (24). The fundamentals of NMR spectroscopy are that certain nuclei 6.9 . $H$ and 15 b) behave ine minute magnetic bars and can be lined up in the presence of a magnetic field. The adsorption of radiation energy can cause the manets to flip from one energy level to another. There exists a characteristic resonance energy for each nucleus, depending on its surroumdings, e.g. Whether a proton is in a methylene group. an amino group or attached to a double bond carbon, or whether the direct environment of the atom is hydrophobic or hydrophilic by nature. Interactions between lipids and proteins can be investigated by comparing spectra of mixtures, with thase of lipid and protein separately. Chapman (1968) (24) and associates $(25,26)$ have reported NMR spectra from phospholipid, bille salts, serum lipoproteins and red blood cell ghosts. Serum lipoproteins have been studied with this method by steim et a 1. (27).

These studies indicate that interactions between proteins and lipids. result in restriction of the mobility of the hydrocarbon chains. Interactions between lipids and proteins are beliewed to be of a hydrophobic character.

Other spectroscopic techniques include optical rotation dispersion (ORD) and circular dichroism (CD). The optical rotation in a protein solution iscaused by the added effects of each of the optically active centers of the amino acid residues and of the three dimensional folding of the protein chain. When the rotation is measured as a function of the wavelength, one can e.g. calculate the helix content of the protein.

In the circular dichroism technique one uses two light beams, a left and a right handed circularly polarized one. These beams are unequally adsorbed by optically active materials and the difference in adsarption as a function of the wavelength gives the co spectrum. This technique makes it also possible to evaluate conformational properties of biopolymers.

Both ORO and CD spectra of a variety of lipid-protein membranes have been reported (28-3i). They suggest, an the basis of their measuremerts, that the membrane proteins investigated, all contain a-heltcal regions.

More recently, the so-called spin labelling technique has been extemded to the study of biological membranes $(32,33)$. The spin labelling 
technique is based on the fact that a tag molecule ( 5 pin labeli). when attached to a macromolecule such as a protein, gives off a signal in the ESR spectrometer. that is dependent on its immediate surroundings and in this way the signals allow canclusions on (changes in) these surroundings. Spin labels wsed thus far include nitroxide type free radicals such as di-t-butyl nitroxide and 2.2 .6 .6 -tetramethyl piperidine-1-oxyl.

Except in the detecting instrumentation, the use of a spin label is very similiar to that of introducing dye into a biological material. The advantages of spin labels are their sensitivity to the local enviromment and their ability to measure very rapid mollecular motion (33). Today, the spin label technique has been used on rabbit nerve - excitable membrames, bovine red blood cell ghosts, and artificial bilayer membrane models.

Gelfiltration has been used by Scamu et al. (34) and by Fleischer et $1 .(35,36)$ to investigate interactions of the lipid and protein components of high density lipoproteins and the interactions of $\gamma$-lipoproteins with phospholipids. This method is of walue in determining binding stoichiometry between lipids and proteins. Dialysis against a non-aqueous medium will provide information about the nature of lipid-protein interaction. This technique involves the partition of a lipid in a non-aqueous solvent and an aqueous protein solution separated by a dialyzing membrame. Materials isolated from chlaroplast lamellae were studied in this way (37). Interactians between fatty acids and serum albumin were thus investigated by spectar (38) and Arvidson and Belfrage (39).

Differential scanning calorimetry (OSC) is a classical method, in contrast with the application to biological systems, which is a recent development $(25,27)$.

The principle of DSC is that the temperature of the sample and of a thermally inemt reference materlal in the same thermal environment are compared while the temperature of the enwironment is programmed. The adsorption or generation of thermal energy by the sample causes its temperature to lag momentarily or to lead the reference temperature. This difference is recorded as a function of the program or of the sample temperature, and produces a curve consisting of negative or positive peaks. These peaks indicate the existence of endothermic or exothermic thermal changes at the corresponding temperature. Phase transitions like this obserwed can be correlated with changes in biological properties. 
For instance. Steim et a $1 .(27)$ observed that the transition tenperature of intact membranes of M. Loddowail was equal to that of the extracted lipids in aqueous dispersions. Using the same technique, Ladbrooke et a l.(25) studied the effect of cholesteral on phase transitions in phospholipids.

Heat burst calorimetry has been used for the first time in biochemistry by kitzinger and Benzinger (40). The technique was applied by Lovrien and Anderson (41) to study the interaction between sodium dodecyl sulfate and y-lactoglobulin and by klopfenstein (42) to determime the enthalpy change on binding of lysolecithin to bovine serum albumin. This technique is of potential walue in providing quantitative thermodynamic data, useful in the understanding of the nature of binding forces between the lipid and protein.

Another approach of the problem of lipid-protein interaction is the use of MODEL SYSTEMS. Today, only a few studies have been examining the effect of proteins on the untrinsic properties of bilayer lipid membranes (BLM). The first BLM protein interaction experiments were reported by Mueller et al. $(43-44)$. Protein material was found to lower the restistance of a brain ipid 8 LM from $10^{7}-10^{8}$ to $10^{3}-10^{4}$ ohms $/ \mathrm{cm}^{2}$. A1bumin modified BLMs have been studied by two different groups of investigators, yielding conflicting results. Hanai et al. (45) have investigated 1ecithin BLM in the presence of egg-albumin, insulin, or bovine serum albumin and did not find any effect on the BLM capacitance, unlike Tsofina et a 1. (46) who have found that the electrical properties of BLM are significantiy altered in the presence of albumin.

Del Castillo et ál. (47) developed an interesting technique to detect antigen-antibody reactions on BLMs. The interaction of BLM with bovine erythrocyte proteins was investigated by Maddy et a 1.(48) and by Van den Bergh (49). By adding bovine protein extract to the bathing solution, the latter reported a sudden reduction in BLM resistence.

Smek 1 and Tien (5l) studied the interaction of a variety of proteins with oxidized cholesterol BLM using the reflectance technique of Tien and Howard. In the case af alcohol-dehydrogenase, the thickness of the membrane increased from 50 to appraximately $100 \&$.

The results obtained recently with fluorescent probes, in studying BLM-protein interaction should also be mentioned (51). Recently, Azzi et a 1 (52) and Rubalcana et a 1. (53) used 8-anilino-1-maphtalene sulfonate (ANS) in studies of biological membranes. 
It is known that the fluorescent properties of Ans and its derivatives are dependent on the polarity and threedimesustonal structure of the environment ( 55 ). In aqueous solutions ANS is practically non-fluorescent, out it fluoresces with an apreciable quantumyield when dissolved in organic solvents and when associated with proteins (55). These properties make Alls an ideal probe for inuestigating BLA protein interactions.

These techniques all allow a considerable insight into lipid-protein interactions to be gained, and have substantially contributed to our knowledge of the biochemical reactions, accurring at lipidwater interphases. Yet they are largely indirect. This, together with the fact that many of the main unsolved problems in biochemistry, involwe processes accurring at interphases. like oxydative phosphorylation, cell recognition, antibody synthesis, membrane transport, blood coagulation, enzymatic breakdown of insoluble substrates (collagen etc.) caused us to try a more direct approach.

In the study of 1 iquid solid interphases described in this thesis, we used the ELLIPSOMETER TECHNIQUE. This technique was already known for the first time in 1895 by $P$ aul arude and has been reported ever since under several names $(56,57)$ among which "ellipsometry" and "polarization spectrometry".

The theoretical basis of the method as formulated by Drude amounts to the idea that the optical properties of a bare surface can be calculated from al change in the state of polarization of a reflecting light-oeam. Once these optical properties are known, it is possible to apply a similar procedure ta a dielectric film on top of the surface.

Using the Maxwel1 theory for electromagnetic waves, Drude obtained exact equations for the interrelationship between the wavelength used, the optical constants of the systern, the thicknesses of the layers and the angle of incidence. However, because these equations are hardiy applicable in experimental practice, they cannot be solved in clased form for the desired parameters (refractive index and thickness of the $f i 7 m$ ) in terms of the measured changes in the state of polarization. Thus trial and error and iteration methods had to be used, and routine application of the exact equations was almost impossible before the computer became available.

This is why orude and subsequently many other workers only used the first linear terms in the Taylar expansion of the exact arude equation and these approximating equations are often referred to as 
"the Drude equations" "This approximation limited application of the Drude theory to films which are very thin with respect to the wavelength of the used light beam. This is anyhow one order of magnitude smaller than can be studied by other means as interferometry or electron microscopy. Since the introduction of modern computers. the use of the exact Drude equations is a matter of routine, and the technique can be applied to flims of ary thickness. Normally, each measurement, by hand, on an ellipsometer, takes 5 minutes. This is too long to follow adequately most biological adsorption processes. Only in 1952, when Trurnit $(58,59)$ introduced an autamatized socalled recording ellipsameter it became possible to follow changes in polarization relatively rapidy. As this instrument recorded the amount of light transmitted by the apparatus, the gain had to be paid for by the exchange of two interpretable parameters (An and Pol) for one, interpretable only under restrictive assumptions.

Some important contributions in the field of ellipsometry in biological systems have been made by Trurnit and Vroman. In 1952 , Trurnit $(58,59)$ studied the proteolytic activituy of chymotrypsin at a liquidsolid interphase, the substrate bowine serum albumin constituting the solid phase. Depending upon buffer concentration and pH of the enzyme both adsorbed to the substrate and/or removed substrate from the solid phase. Subsequently, he studied the adsarption kinetics of chymotrypsin on solid surfaces from a theoretical point of view. on this basis he was able to describe the initial phase of the reaction qualitatively as well as quantitatively. Trurnits experiments also showed umequivocally that the recording ellipsometer could be used to measure diffusion coefficients rapidly in extremely diluted solutions. Moreover, interphasial enzyme reaction studies of this type permit one to investigate the initial reaction phase more easilly and in a finer detail than by studying bulk reactions.

The work of Wromam deals wh the field of blood coagulation. He and his colleagues have been using a recording ellipsometer to monitor the amount and rate of protein adsorption from citrated plasma at a solid-liquid interphase, using optically sensitive hydrophilic and hydrophobic surfaces of anodized tantalum sputtered glass slides and polished slices of silicom crystalls $(60,61)$. Vromans work has shown that exposure, of the slides to normall intact and activated plasma and various factor-deficient plasmas for only a few seconds, resulted in the adsorption of detectable material. 
Elipsometric studies have also shown that fibrinogen is an important major component of the plasma films adsorbed onto surfaces. This was demonstrated by the ability of plasma films ta bind antiserum against fibrinogen $(62)$.

The scarce literature avallable shows that ellipisometry is a very useful technique to study biochemical reactions at interphases (63) but that it suffers from one major drawback. Either one obtains correct walues for analyzer and polarizer positions from which thickness (d) and refractive index (n) can be computed, but then the data acquisition is too slow for biochemical experiatents, or one gains speed by measuring light transmission at the expense of the interpretability of the results. This brought us to develop a dynamic ellipsometer, suitable for the exact evaluation of biochemical experiments. 
1. Harkins, W. D. and Bayd, G.E. (1941) J.Phys.Chem. 45, 20

2. Bu71, H.B. (1947) Adyances in Protein Chemistry 3,116

3. Cadenhead, D.A. and Phillips, M.C. (1968) Advanced Cher. Ser.84.131

4. Davies, d.T. and Rided, E. (1963) Interfacial phenomena. Acad. Press, Hew York

5. Blank, M. (1968) B101. Interfaces. Flows and Exchanges. Litcle Brown, Baston

6. Sma 1. D.M. (1968) J.Ami.011 Chem.50c.45, 108

7. Adamson. A. W. (1967) Physical Chemistry of Surfaces. Hiley intersic. New Vork

B. Gurd, F.R.N. (1960) in Lipid Chemistry. Ed. D. W. Hamahan. Wiley Intersc. New York 135

9. Dawson, R.M.C. (1968) Blological Membranes. Ed.O.Chapman.Acad. press New York, 203

10. Colacicco, G. and Rapport, M.M. (1968) Adv.Chem.Ser. 84, I57

11. Matalon, R. and Schulman, J.H. (1949) Discuss.Faraday Soc. 6, 27

12. Knaiat, A. and Miller, H.R. (1969) Bioch. Biaph.Acta 183, 309

13. Lucy, J.A. (1968) In Bialogical Membranes. Ed.D.Chapman. Acad. Press New York, 233

14. whosh, 5. and Bull, H. B. (1962) Biach.Bioph.Acta 66, 150

15. Galnes, G.L. (1965) Insoluble monolayers at liquid-gas interfases. Intersci.Publ. Willey.Lamdon

16. Colacicco, G. (1969) J.Colloid Interface Sci. 29,345

17. James, L.K. and Augenstein, L.G. (1966) Adv.Enzymol. 28, 1

18. Vilallonga, $F$, Altschul, R., Fernandez, M.S. (1967) Bioch. Bioph. Acta 135, 406

19. Werger, K., Mieras, C.E., and De Has, G.H., (1973) J.Biol.Chem. $24.8,4023$

20. Trurnit, H. J. (1960) J.Colloid Interface Sci.15,1

21. Skou, J.C. (1959) Bjoch. Bioph. Acta 31, 1

22. Suzuki, A. and Goto, S. (1972) Btoch.Bioph. Acta 255,734

23. Popiel, w... (1970) Sci.prog. Oxf. 58,237

24. Chapnan, D. (1968) Lipids 4, 251

25. Ladbrooke, B. U., Williams, R.M. and Chapman, D. (1968) Bioch. Bioph. Acta 150,333

26. Leslie, R.B. and Chapman, 0. (1969) Chem.Phys.Lipids 3, 152

27. Steim, J.M. (1968) Adv.Chem.Ser. 84, 259

28. Lenard,J. and Singer, S.J. (1966) Proc. Mat).Acad.Sci.U.S.A. 56,1828

29. Wallach, D.F.H. and Zahler, P. (1966) Proc. Nat1.Acad.Sci.U.S.A. 
30. Urry, D.w., Mednieks, il. and Bejnarowicz, E. (1967) Proc. Nati. head. Sci.U.S.A. 57,1043

31. Steim, J.W. and Fleischer, S. (1967) Proc. Nat?.Acad.Sci.U.S.A. 58,1292

32. Hubbell, W. L. and McConnell, H.M. (1968) Proc.Nat A.Acad.Sci.U.5.A. 61,12

33. Griffith, 0.H. and Waggoner, A. S. (1969) Accounts Chem. Res. 2.17

34. Scanu, A., Pollard, H., Hirz, R. and Kothary, K. (1969) Proc. Natl. Acad.Sci.U.S.A. 62, 171

35. Fieisther, S., Fleischer, B. and stockenius, W. (1967) J.Cell.Biol. $32,1.93$

36. Fleischer, S., Brierley, G., Klouwen, H. and Slautterback, D.B. (1962) J.Biol.Chem. 237, 3264

37. Ji, T.H., Hess, J.L. and Benson, A.A. (1968) Bioch.Bioph.Acta 150. 676

38. Spector,A.A.,John,K., and Fletcher, J.E. (1969) J.Lipid Res. 10,56

39. Arwidson, E.0. and Belfrage, P. (1969) Acta Chem.Scand. 23,232

40. Kitzinger, C. and Benzinger, T.H. (1960) In Methods of Biochemical Analysis. Ed.D. Gilick. Vol. 8 Intersci. Wlley. Wew rork

41. Lovrien, R. and Anderson, W. (1969) Arch.Bioch.Biophys. 131,139

4.2. Klopfenstein, W.E. (1969) Bioch.Bioph.Acta 181, 323

43. Mueller, P., Rudin, D.0.. Tien, H.T. and Wescott, W.C. (1962) Nature (London) 194,979

44. Mueller, P., Rudin, D.0., Tien, H.T. and Wescott, W.C. (1964) Rec.Progr. Surface Sci. 1, 379

45. Hanai, T. Haydon, D.A. and Taylor, J. (1965) d.Theor.Biol. 9,422

46. Tsofina, L.M. Liberman, E.A. and Babakov, A.V. (1966) Nature (London) 212,681

47. Del Castil10, J., Rodriguez, A., Remero, C.A. and Sanchez, $V$. (1966) Science 153, 185

48. Maddy, A.H. (1966) Int.Rev.Cytol. 20,1

49. Van den Bergh, H.j. (1968) Adv.Chem.Ser. 84, 99

50. Tien. H. T. and Howard, R.E. (1971) In Techniques of Surface Chemistry and Physics. R.d.Good, R.R.Stromberg and R.L.Patrick, eds. Vol. 1. Marcel Dekker. Wew York

51. Smeka1,E. and Tien, H.T. (1971) In Techniques of Surface Chemistry and Physics. R.J.Good, R.R.Stromberg and R.L.Patrick, eds. Woll. 1. Warcel Dekker, New York

52. Azzi, A., Chance, B., Radda, G.K. and Lee, C.P. (1969) Proc. Nat1. Acad.Sci. U.S.A.62, 612 
53. Rubalcana, B., De Munoz, D.M. and Gitler, C. (1969) Biochemistry 8. 2742

54. Edelman, G.M. and Mc.Clure, .0 . (1968) Accounts Chem. Res. 1,65

55. Stryer, L. (1968) Science 162,526

56.. Urude, P. (1889) Ann. Physic. 36,532

57. Drude, P. (1889) Amn.Physic. 36, 865

58. Trurntt, H.J. (1953) Arch.8iach.Btoph. 47, 251

59. Trurnit, H.J. (1954) Arch.Bioch.Bioph. 51, 176

60. Vromam, L. In Blood Clotting Enzymology. W. H. Seegers, ed. (1967) Acad.Press, Wew York, 279

61. Vroman, L. (1963) Thrombos.Diathes.haemorrh. 10,455

62. Adam, A.L. and Vroman, L. (1965) Thrombos.Diathes.haemorrh. 12,387

63. Fenstermaker, C.A., Grant, W.H., Morpissey, B.W., Smith, L.E. and Stromberg, R.R. (1974) N.B. S.I.R. 74-470 Nat.Bur. of Standards, Wân sington. 


\section{CHAPTER II}

The automatized ellipsoneter

\section{Principles of the method}

An ellipsometer is a device that measures the change in the polarization state of a light beam upon reflection. It comsists of an array of a light saurce, a polarizer, a quarter wave plate, the reflecting surface (sample), an analyzer and a light detectimg device. The place of the quarter wave plate is arbitrarilly between the polarizer and the surface or between the analyzer and the surface. The light has ta be monochromatic. Collimating lenses, diaphragms and filters are added where necessary to modify the light and guide the light beam (fig. II. I).

The plane of polarization of the incident light beant can be varied by changing the polarizer position. In general the light will have its ellipticity and azimuth changed by reflection from the sample (fig. II.I, for precise definition see Chapter III). The analyzer will not completely extinguish elliptically polarized light but will do so with plane polarized light. By varying the plane of polarization with the polarizer and subsequently passing the beam through the fixed quarter wave plate, the ellipticity of the light incident to the reflecting surface can be adjusted in such a way that after reflection it will be plane polarized.

Whether the light is extinguished by the analyzer it is consequently a function of the position of both the analyzer and the polarizer. These two positions together with the known fixed position of the quarter wave late will completely define the change of ellipticity on the reflecting surface. On a bare surface, this change is a function of the complex refraction index of the reflecting surface, the refraction index of the surrounding medium and the (fixed) angle of inclidence. When a dielectric (i.e. a translucent) layer is deposited on the surface the thickness and refractive index of the layer will contribute to the change in ellipticity. With wavelength, angle of incidence and refractive index of the reflecting surface given, the change in ellipticity will be a function of thickness and refractive index of the dielectric layer only. 


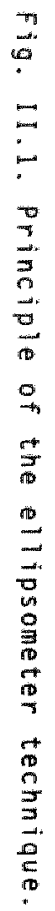

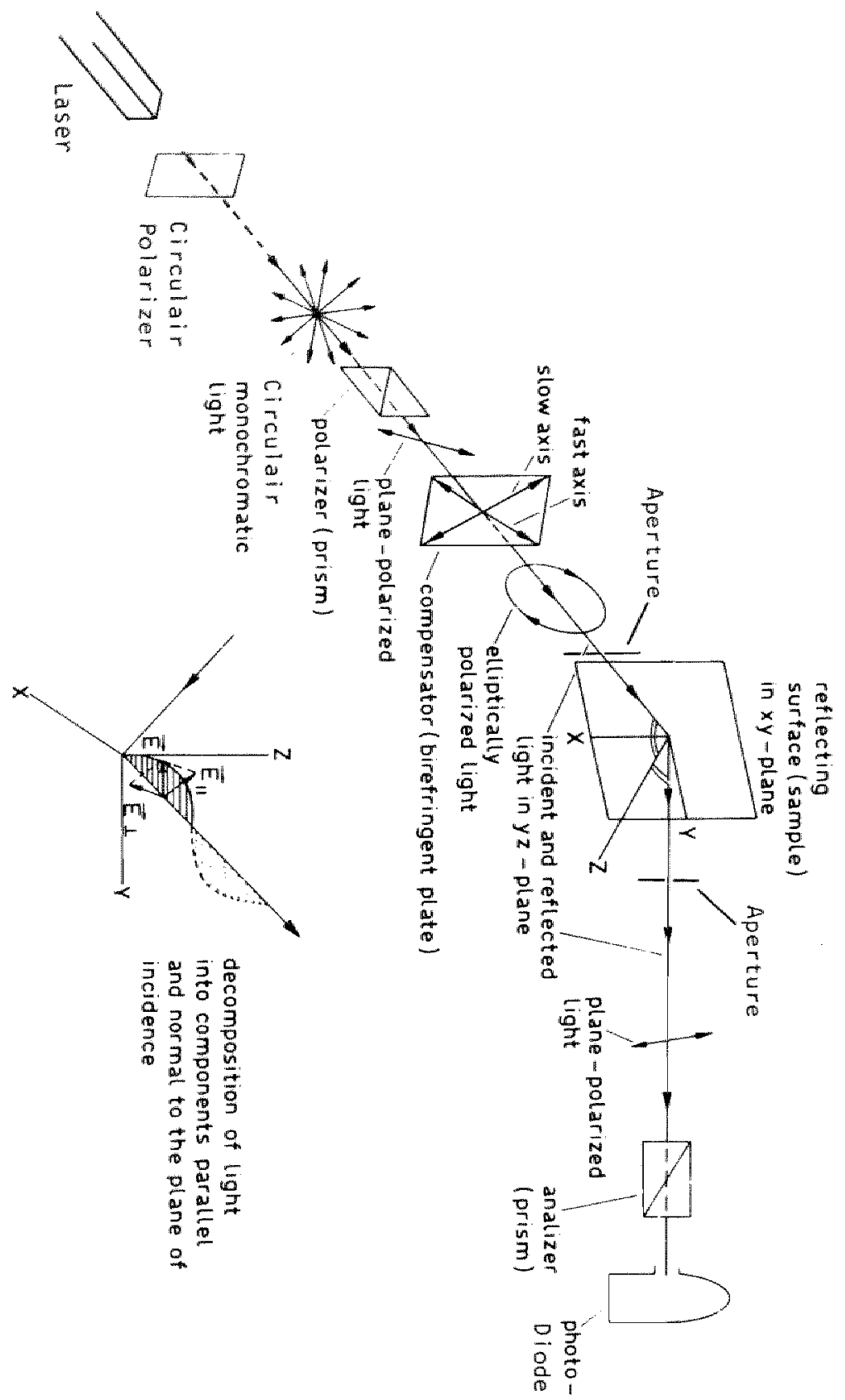


Reactions of biachemical interest at an interphase like adsorption of proteins or lipids, protein-protein-, and protein-lipid interactions, will cause deposition af and changes in the dielectric layers which can be monttored by ellipsometry. The fact that ellipsometry is only dependent on the polarization changes of light and not on adsorption causes the method to be sensitive to changes in thickness wich are several orders of magnitude below the wawelength used. It also causes the method not to be restricted by constraints upon the wavelength used (Chapter III). To follow the changes in the properties of the dielectric layer with a time resollution acceptable for biom chemical purposes we had to autamatize the adjustment to a minimum light tramsmission (fig. II.2). The rest of this chapter contains a detailed description of the instrument we used.

2. Description of the instrument

2.1 optical bank

The basic setup, consisting of a light source, palarizer, analyzer, quarter wave plate, sample mount and light detecting device mounted on optical banks is commercially available (thin film ellipsometer. type 43303-200E Ser. Mo. 3801, 0.C.Rudolph and Sons, Fairfield, N.J. U.S.A.). I世 can also be realized with standard optical components. our automated ellipsometer was basically an adaptation of the Rudolph instrument. The light source and quarter wave plate were replaced as well as the 1 ight detecting device and the sample mount (see below). The instrument was placed at a $100 \times 80 \times 4 \mathrm{~cm}$ marble slab on an ordinary laboratory table. For high precision calibration experiments a set of optical banks * were mounted on a stone slab which had a deviatiom

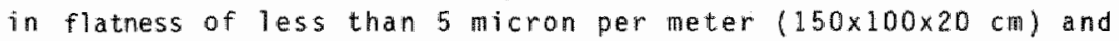
was provided with polaroid high precision optical components.

Physik Instr.P. I. U.m.b.H. D-8 Munchen

Polaroid Corporation Cambridge, Mass. U.S.A. 


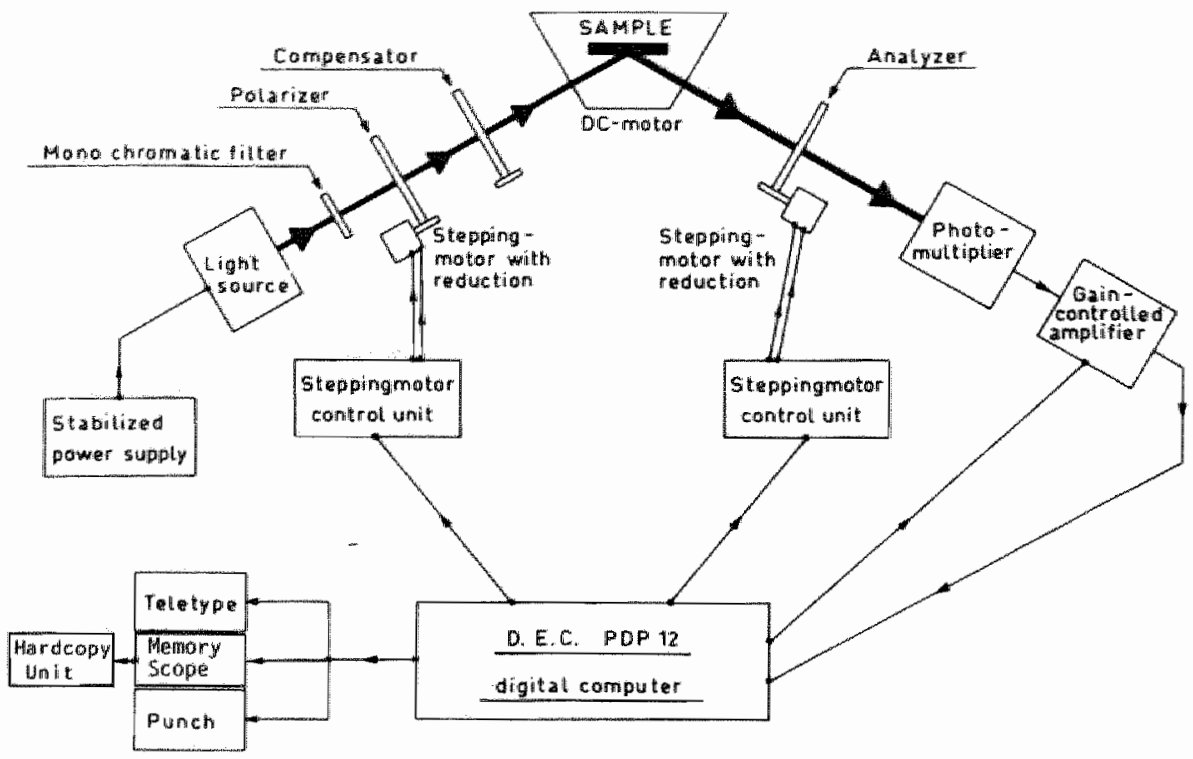

Fig. 11.2. Schematic representation of the automated ellipsometer.

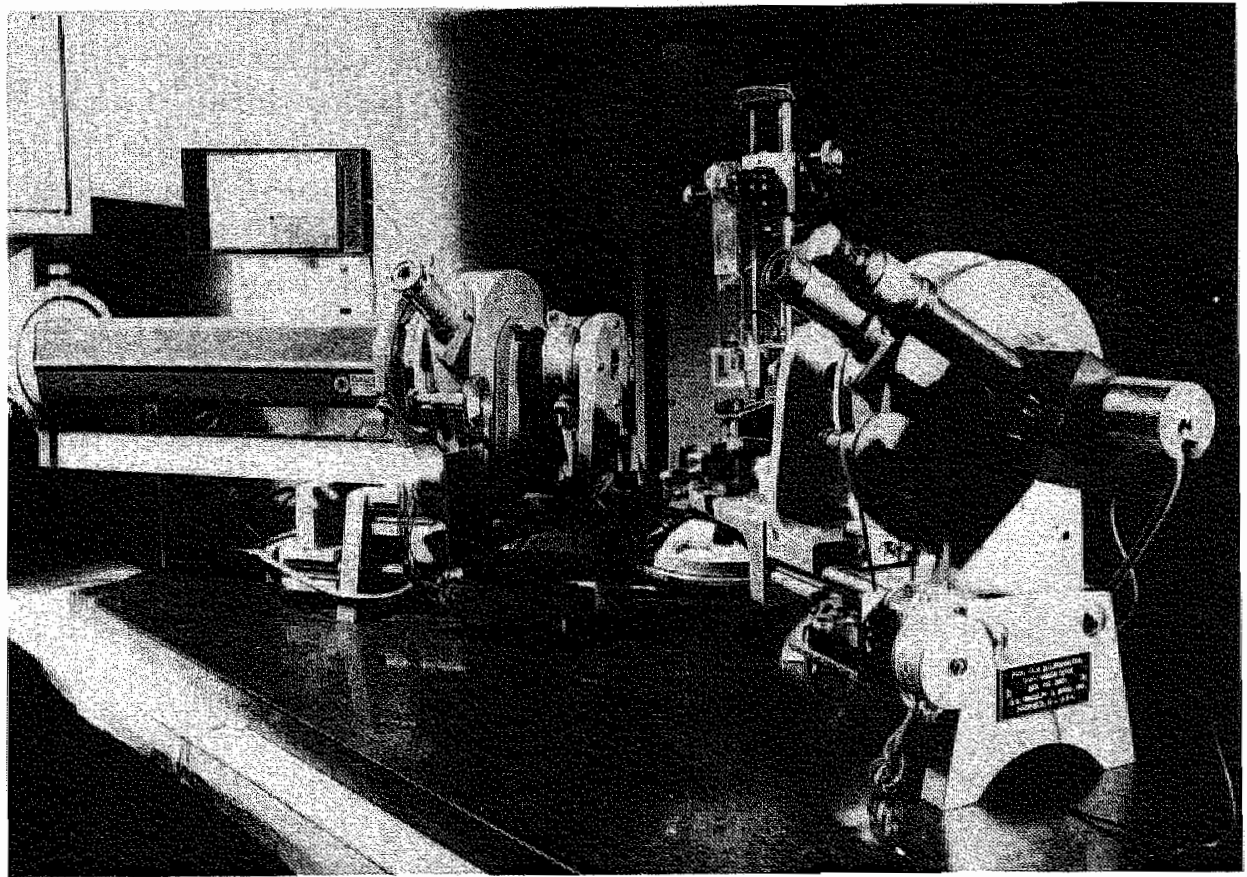

Fig. II.3. The automated ellipsometer. 

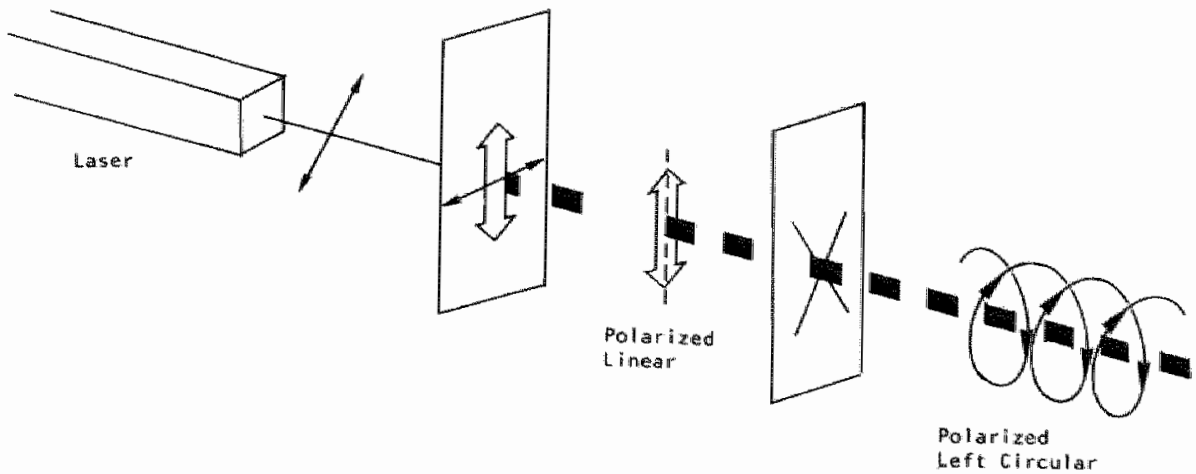

Fig. II.4. A circular polarizer is a "sandwich" consisting of a piece of lineap polarizer bonded to a quarter-wave retardation sheet oriented at an angle of $45^{\circ}$ to the transmission direction of the polarizer. This schematic diagram shows what happens as light passes through.

\subsection{Light source}

The use of a laser as a light source improved the signal to noise ratio by a factor 20 as compared to the conventional $\mathrm{Hg}$ lamps with filter setup. A helium neon laser (Spectra Physics) was used in our experiments. This source produced plane polarized monochromatic $7 \mathrm{ight}$ of $632.8 \mathrm{~nm}$. The laser was fixed to the support in a 6 point suspension system that allowed perfect alignment with the optical axis (fig. II, 3).

\subsection{Circular polarizer}

As it is necessary to bring about controlled variations of the plane of polarization, the laser beam is first circularly polarized. This is done by inserting a sheet of material into the polarized beam, that selectively retards light, polarized along the slow axis of the material whereas light polarized along the fast axis at $90^{\circ}$ to the slow axis is less retarded (circular polarizer HR CP 7 Red of the Polaroid Carparation). The thickness of this retardation 
sheet is such that the retarded beam is $1 / 4$ of a cycle out of phase with the non retarded sheet. The sheet is called $1 / 4$ wawe retardation plate and is bonded to a polarizing sheet (fig. II.4). The slow axis of the retarding sheet is placed at $45^{\circ}$ to the cransmission axis of the polarizer sheet. If the tramsmission axis of the polarizer is in the plane of the laser light, maximum intensity of circularly polarized light is obtaned. If the polarizing sandwich is rotated by $90^{\circ}$, zero intensity is obtained. So by the rotatable circularly pollarizing sandwich one can obtain circularly polarized 1 tght of any desired intensity.

2. The polarizer

The polarizer, a Nicol prism mounted in a graduated circle serves to polarize the light, passing the circular polarizer. By this rotatable pollarizer, plane polarized light of any desired plane can be obtained. The rotation is dome by hand in the conventional setup and by stepping motors (see page 27) in the dutomated version.

2.5 The compenstor

The compensator also in araduated circle consists of a biaxial crystal which devides the incident beam into two perpendicular companents orientated in the principal directions of the device, and "retards" one component with respect to the other. The introduced phase difference is also called the compensation. In our case the compensator retards $90^{\circ}$, so we have a quarter wave compensator. If the compensator is not quarter wave, the calculation of thickness and refractive index is still possible but becomes mare complicated (Chapter III).

In our ellipsometer the compensator is used to convert the limearly polarized light into elliptically polarized light. The 7 ight incidentupon the sample has an azimuthal angle and an elipticity predictable from the settings of the polarizer and compensator (see Chapter III). The compensator going with the Rudolph instrument is quarter wave for the $5461 \AA \mathrm{Hg}$ line. A compensator that was quarter wave for the He-ite laser was purchased from Lasermetrics, U.S.A.

\section{6 The apertures}

The aperture is an adjustable opening allowing a wariation in the area of surface examined, and the amount of light reaching the photodiode.

\subsection{Sample nolder}

The sample holder is shown in detail in fig. II.5. 


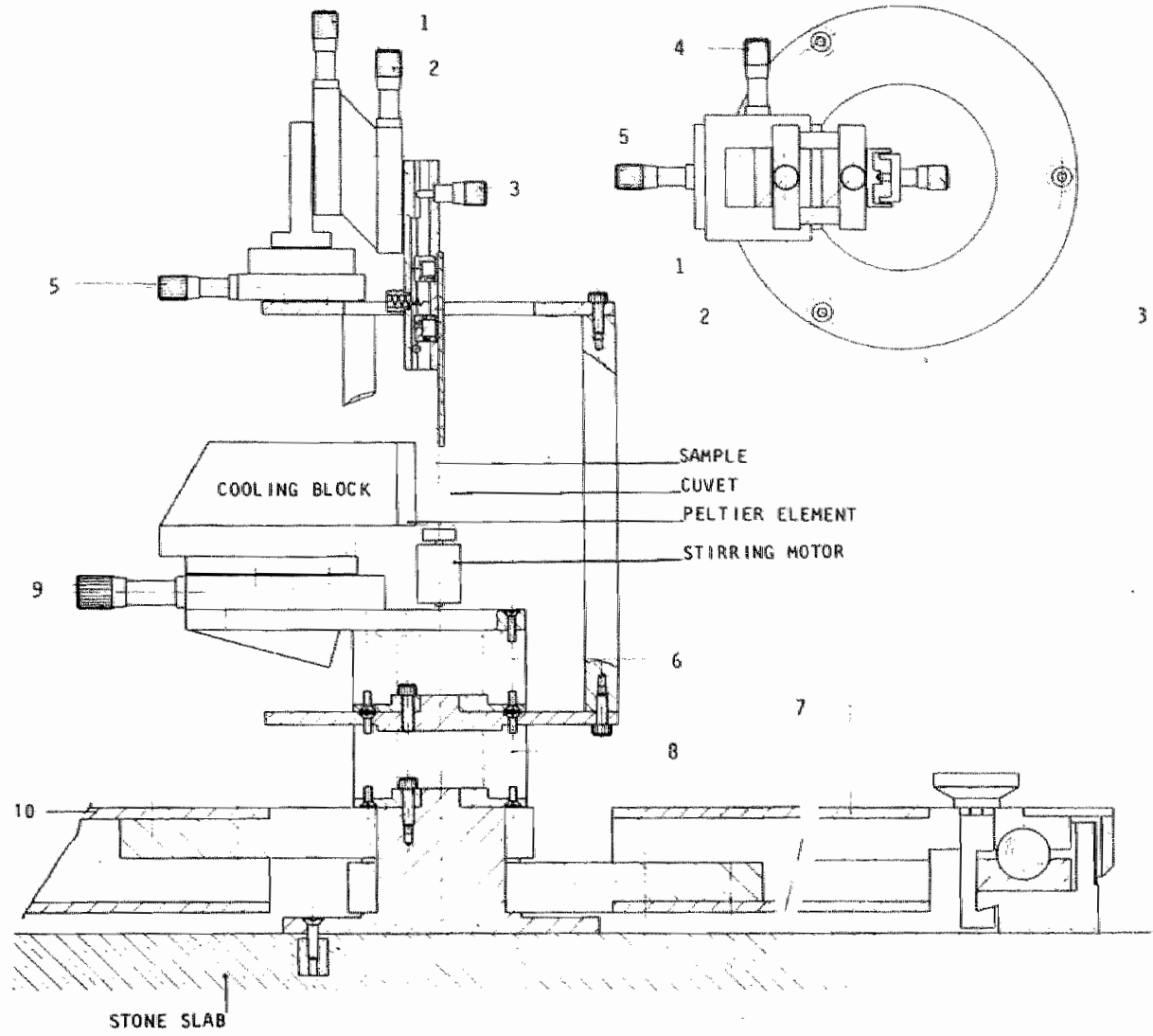

Fig. II.5 The sample holder

If the optical rails are situated in the $X Y$ plane, the role of the different micrometers can be described as follows:

number 1,2 allow movement alang the $Z$ axis (height ajustment)

3 is necessary to adjust the sample parallel to the $Z$ axis

4,5 allow movement of the sample in the $X Y$ plane

6 allows movement of the cuvet around the $Z$ azis

7 revolving optical rail

8 allows rotation of the complete sample holder around the $z$ axis

9 allows movement of the cuvet in the $x y$ plane

10 fixed optical rail. 


\subsection{Thermoregulation of the cuvet}

For bochemical experiments it is necessary to be able to place the sample in a fluid medium of controlled temperature. The medium must be continuously stirred. Because in the study of lipids it is inaportant to convey the range of possible transition temperatures which extends to below room temperature, cooling as well as heating is necessary. So for themostation we chose a Peltier element. With this device it is possible to cool and heat with the same element if one side of the element is connected to a mass of high heat capacity.

A Peltier element creates a heat current which is difrectiy proportional to the electric current passing through the element. To make efficient use of the peltier element it is necessary to steer it by a "constant current" circuit. When the temperature of the cuwet was more than $5^{\circ} \mathrm{C}$ from the desired temperature, it is corrected by a switching regulation i.e. maximal heating or cooling capacitiy is used. Within the range of approximately $5^{\circ} \mathrm{C}$ from the desired temperature proportional regulation was applied in order to prevent oscillations j.e. the cooling or heating current is in proportion to the temperature gap to be bridged. With our circuit the temperature covered ranges from $0-50^{\circ} \mathrm{C}$. The capacity is sufficient to neat the curet from $0-50^{\circ} \mathrm{C}$ within. 2 minutes. The stability of the temperature in the cuvet is very high. The temperature varies less than $0.05^{\circ} \mathrm{C}$. Smal1 variations of temperature brought about by additions etc. are corrected in less than 20 secands. By means of LEDS on the instrument panel it is indicated whether the right temperature is reached or nöt. The desired temperature is chosen by the setting of a reference voltage. The reference wollage can be given via the duol unit of the computer or via a potentiometer on the thermaregulation itself. The block scheme (fig. II.6) shows the elements of the thermoregulation.

2.8.1 oifference amplifier (fig. II.6)

This part detects the difference between the reference woltage and the temperature information from the thermotransducer. Wia an absolute value circuit and a switching circuit which detects whether the difference is positive or negative, and a multiplier. a voltage is obtained which in sign and magnitude is proportional to the temperature gap ta be bridged. 
D

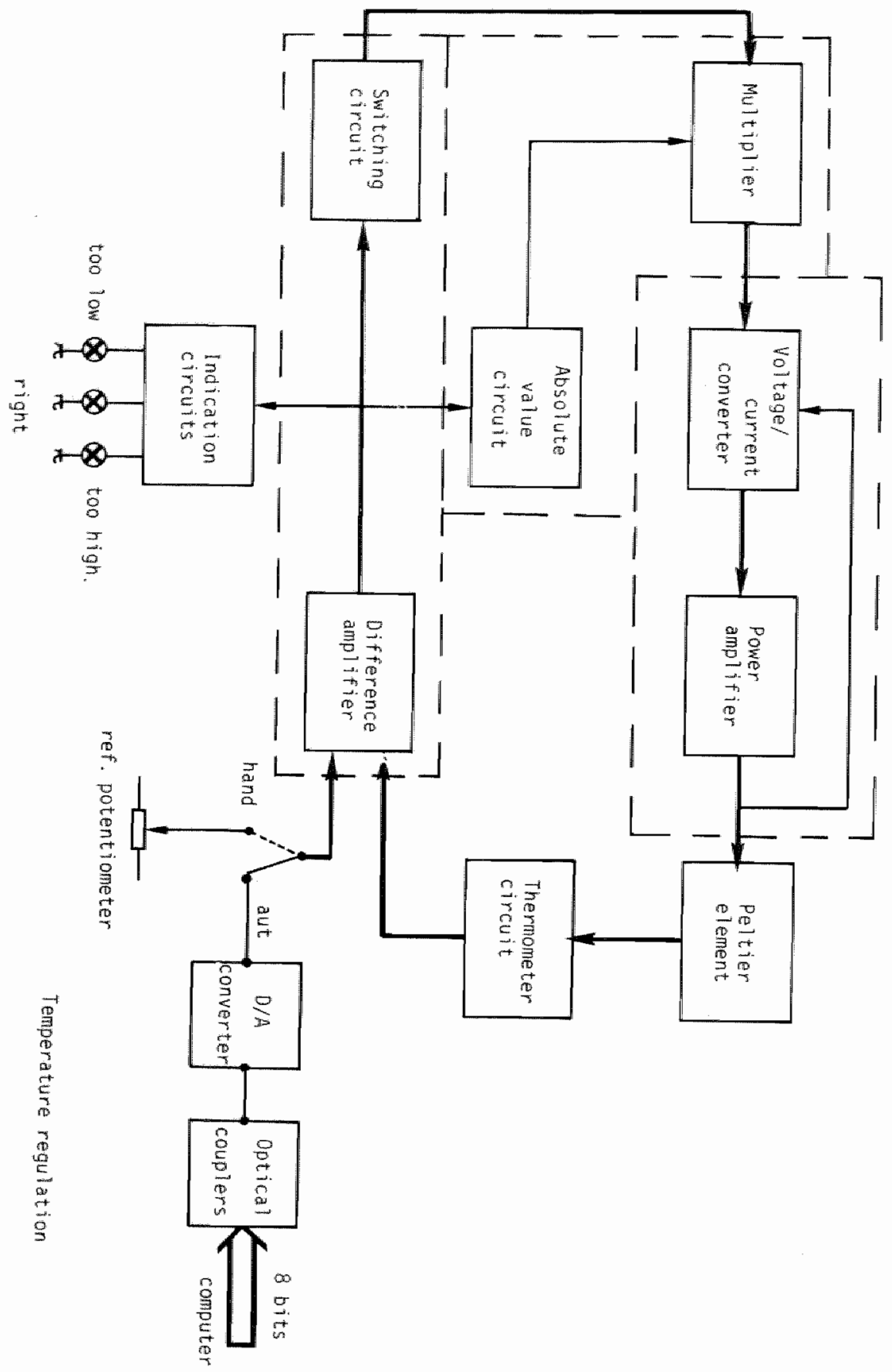


2.8 .2 Controlled current 5 tabilizer (Fig. 11.6 )

This circuit consists of a power amplifier with symmetric Darlington output transistors. Via a resistor of 0.5 onh a curment is abtained which is in proportion to the input voltage. This circuit gan give a current of approximately 5 amperes.

2.8.3 Thermometer circuit (Fig. 11.6)

A bridge circuit with a negative temperature coefficient mesistor. 2.8.4 Indication circuit (Fig. II.6)

Indicates whether the temperature differs more than $0.25^{\circ} \mathrm{C}$ with the selected ane.

2.9 Apertures necessary for the alignment of the sample and cuvet. 2.10 The analyzer, the second prism in a rotatiwe graduated circle, like the polarizer (2.4) also steered by a stepping motor.

2.11 Photadiode will be described in details together with the electronic circuits of the photodiode channal.

\subsection{Alignment of the ellipsometer}

The optical axis of the instrument shows an angle at point I where the reflecting surface is met (fig. II.1). The plane through the broken axis, the point I and the incident light beam define a rectangular coordinative system. The position of the polarizer, analyzer and compensator relative to this coordinative system must be exactly known. This is abtained by aligmment of the ellipsometer. To obtain accurate walues of the aptical constants of surfaces, the alignment of the ellipsometer is very critical. The procedure for aligning the ellipsometer is typical of that generally used in aptical instruments except for the adjustment of the analyzer (A) and polarizer $(P)$, the scales of which when well aligned must read zero when the planes of transmission of the prisms are parallel to the plane af incidence. In principle, the adjustment is relatively simple. With the compensator removed and the polarizer and analyzer arms in the straight-through position, the polarizer and analyzer prisms are adjusted in their respective scales until extinction is achieved when the scale readings differ by $90^{\circ}$. The arms ame then set for reflection from metal surface. A minimum in the photometer reading is sought through which the scale readings differ by $90^{\circ}$. The planes of transmission of the two prisis should then be in the plane of incidence and normal to it. 
In practice, small imparfections cause a nom-ideal wehaviour. After hawing first crassed the prisins when reflecting from the surface, - minimum my be achiewed ejther by fixing $P$ and adjusting $A$ or vice versa. When the light issuing from the polarizer is accurately plane polarized then the minimum achieved, by either of these two means and with the $P$ and $A$ scales crossed, occurs at a single walue of pand A independent of the procedure followed. However, if the light issuing from the polarizer has some slight ellipticity due to imm perfections in the polarizer, there are then two postions at which the prisms are crossed and minimum photometer readings are obtained depending upon whether the minimum is achieved by fixing p and adJusting A or vice versa. Moreover, the deepest minimum or most complete extinction of the reflected light now occurs at a third point where line scales are not crossed.

with certin assumptions even in this case alignment may be achieved quite accurately (Mc.crackin (B)).

A step by step procedure for alignment of the ellipsometer is as follows: First remove the quarterwave plate. Set the arms to the "straight through" pasition. Set the P scale to read zero or any convenient value. Adjust $A$ until minimum transmission is achieved. The $A$ scale will now in generall read $\left(P \pm 90^{\circ}\right)+E$. $E$ being the error in the setting. Rotate the $A$ prism in its holder untile is zero. In this way we eliminate a difference in setting between $P$ and $A$. The $P$ and $A$ scales are now crassed when the prisms are crossed. The scales should track within appraximately 0.02 degrees throughout ane revolution. The remaining error in the $P$ and $A$ settings is $e l i m-$ inated in the following way. With a metal surface set for reflection, place the arms to an angle ensuring high sensitivity (about $70^{\circ}$ ). Set A in such a way that the plane of transmission of the analyzer is approximately in the plane of the surface. The minimum of extinction 15. sought. In the ideal case $P=A \pm 90^{\circ}$. In this case the plane of transilission of the prism is in the plane of incidence and the plane of transmission of the A prism is in the plane of the surface. however, the scale readings will in general not differ $90^{\circ}$. Let the values of $P$ and $A$ at minimum postition, be for example $0^{0}+E^{\text {and }}$ $90^{\circ}+E^{\prime}$. respectively. The quantitiy $\varepsilon^{\prime}$ is now the amount by which both scalles are displaced from the true zero azimuth. In this way the abolute errors of $P$ and $A$ are deternined. Adjust the $P$ prism in its 
holder until $\varepsilon^{\prime}$ is zero by turning the prism a small anount in its holder and again adjusting the $p$ scale for minimum transmission. This will require series of adjustments. It is imperative that the A scale and prism are not moved at this stage, and that the adjustment is done in this order. If the $\mathbb{P}$ scale was fixed and A ajusted. the ellipsometer would be aligned to the value of $\mathrm{P}=\mathrm{A} \pm 90^{\circ}$. Haying adjusted $\varepsilon$ " to zero, remove the reflecting surface and place the arms to the "straight through" position. Set the $p$ scale at zero and adjust the A scale for minimum. The A scale will now read $90^{\circ}+E^{\prime}$. Turn the A prism in its holder until $E^{\prime}$ is zero. The e 1 ipsometer $P$ and A scales are now alligned.

Alignment of the compensator: Next we place the quarter wave plate between the crossed prisms. When the quarter wave plate is placed with its fast or slow axis in the plane of the polarizer, the extinction has to remain the same as without the quarter wave plate. In these positions the values on the graduated scales have to read $0^{\circ}$ and $90^{\circ}$, respectivelly. If this is achieved, the ellipsometer is aligned. For most of the experiments the $1 / 4 \times \mathrm{plate}$ is placed at $\pm 45^{\circ}$. If the $1 / 4 \lambda$ plate is mot placed in a graduated circle, the exact $\pm 45^{\circ}$ positions can be obtained by placing the polarizer at $+45^{\circ}$ and the analyzer at $135^{\circ}$. The position of the compensator giving minimal extinction is the exact $\pm 45^{\circ}$ position.

3. The electronic automatization

\subsection{Introduction}

As explained above, the polarizer and the analyzer positions have to be changed at short interwals in order to monitor biochemical reactions in the sample. In principle this can be done by various methods (1-5).

a. Electrically; o) By an analogue circuit and servomotoms; and c) by a digital circuit and stepping motors.

The principle of the system is always the same, the signal from the light detection dewice is coupled back to devices changing the state of polarization of the incident beam c.q. extinguishing the reflected beam to obtain a minimal output. Together with the Department of Electrotechnics of the Technological University, Delft, Halland, we did elaborate experiments in analogue and electrical automatization (9).

a. Electrically the plane of polarization can be changed by faraday cails, ar Pockel cells. In both devices the optical changes are directly dependent upon the electrical emergy applied to them. This 
in principle opens the possibility to construct an autonated ellipsometer without mowing parts (10). Also in favour of this approach is the extreme welocity of the measuring cycle (up to milliseconds). The drawback of this method lies in the fact that it remains difficult to assess precisely the angles of polarization and compensation achieved. Further work along this line is in progress.

u. fin analogue circuit and serwomotor system hawe the advantage of being relatively quick when using a custom bullt ellectronic optimalization dewice instead of a digital computer. We experimented with a setup in wich polarization and compensation were phase modulated by a Faraday coil arid a Packell cell. With us the system had a tendency to be unstable and very sensitive to optical noise. Again it was difficult to obtain reliable figures for polarizer and analyzer position with the desired degree of accuracy.

c. A digital circult and stepping motors have the disadwantage of being relatively slow ta minimal cycle time of approximately 2 seconds cam be reached) and therefore requiring a digital computer. In our hands the system worked reliably and in the very act of setting polarizer and analyzer measured the positions accurately within 0.01 of a degree. Moreover, the computer when present can be used to great advantage for other components of the system: gain controlled amplification of the light detector signal, calculations based on the exact Drude equations, time measurement etc.

3.2 The electronic steering system

Black schemes of the electronic circuits for coupling tme ellipsometer and the PDP-12 computer are given in Figs. II.7 and II.8.

The electronic circuits can be separated into two independent parts:

1. the photodiode channel (Fig. II.7)

2. the stepping motor steering circuits (Fig. II.8).

3.2.1 Photodiode channel

This circuit is designed to obtain an electric signal proportional to the light intensfty. The electric signal is filtered and intensified until the right level is reached to steer the analog/digital converters of the computer. The photodiode channel consists of the following parts $(F+g .11 .7)$ :

1. light detector; 2 . photometeramplifier; 3 . amplifier correction unit; 4. filter unit, and 5. meter amplifier.

3.2 .1 .1 Light detector

As a light detector we used an integrated photodiode operational amplifier combination (united Detector UDT 500). We did not use a highly 


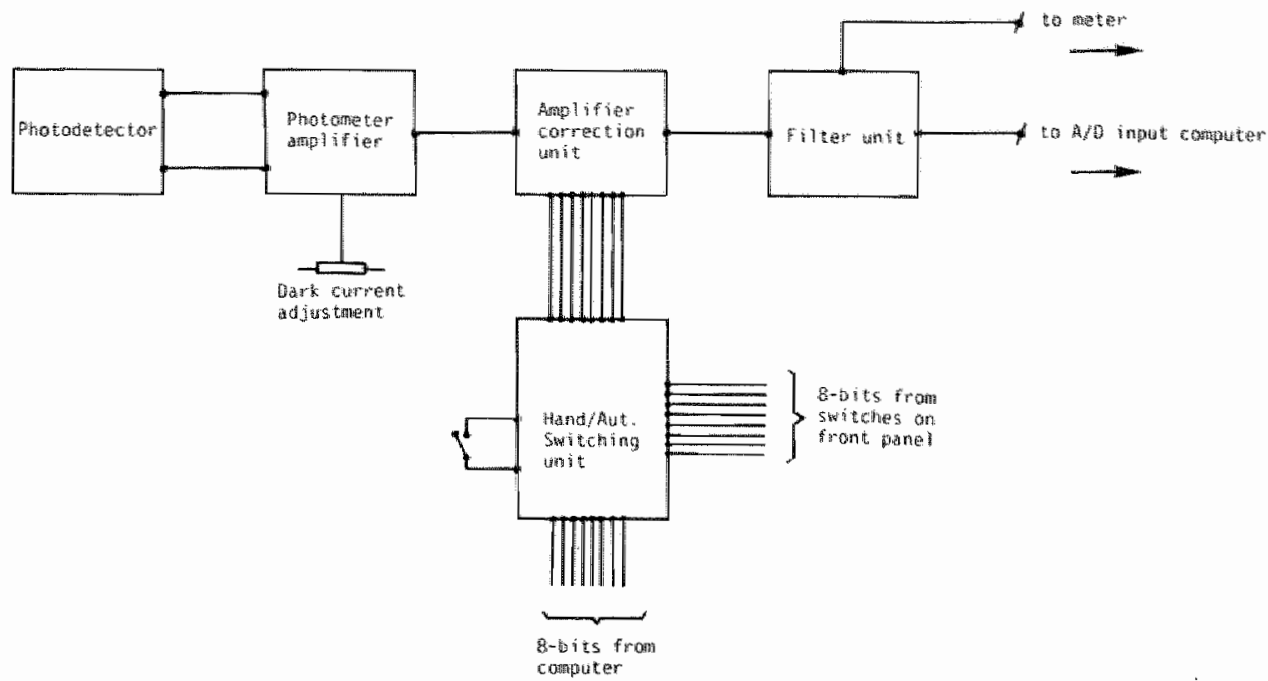

Fig. II.7. Blackscheme of the photodiade channel.

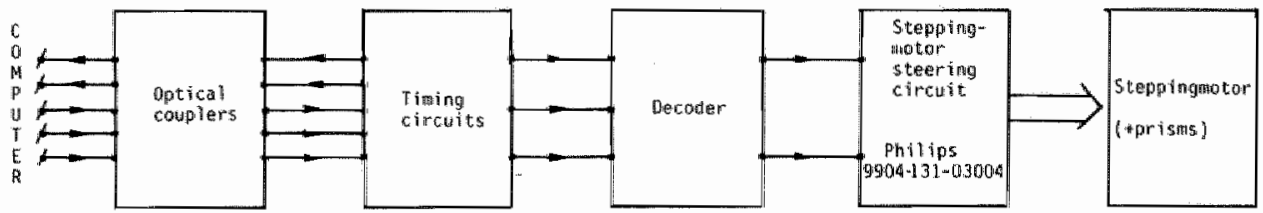

Fig. II.8. Blockscheme of the hardware motordriving and timing logic. 
Sensitive photomultiplier tube because of the considerable noise in this combination and of the high light intensity awallable. Especially the very low frequent secondary enission noise of the photomultiplier tube was very inconvenient during the measuring process (Fig. II, 7 ).

3.2.1.2 The photometeramplifier

This amplifier consists of two pairs: first a differential input to suppress the "jick up signals". Because of the low signal level a high common mode rejection (CMR) ( $80 \mathrm{~dB}$ ) is necessary. The input cables have to be a twisted pair of coaxial cables. The total amplification is about 4 a 5 fold. Second, an amplifier with the passibility to change the dark current. The dark current can be changed about 1 Volt.

\subsubsection{The amplifier correction unit}

In general a change in the analyzer position will not cause the same variation in the. light intensity as the same change in the polarizer. The amplifier correction unit is designed to eliminate the difference in sensitivity between analyzer and polarizer angle change. In this way an optimal sample speed is achieved. The changes in sensitivity because of changes in adsorption during the measuring time are also eliminated in this way. The signal for the desired lewel of amplification is generated in the computer as will be explained later on. It comes out of the computer in the form of an eight bits word which is transfarmed by a digitalfanalag converter into a direct current. This direct current is connected to the $r$ input of a multiplexer. The photometer sighal is connected wia an amplifier with the $x$ input of the multiplexer. The result is a signal, on the $z$ output which is of the same form as the photometer signal and which is proportional to the voltage from the $A / D$ converter and thus to the computer signal.

Filter unit: the bandpass filter serves to limit the bandwidth of the measuring system. The bandwidth is chosen twice the bandwidthwich caused an extension of the sample time by ten percents. The filter is a third order Butterworth filter with $f_{0}=100 \mathrm{~Hz}$, flank steepness 18 dB/octave.

\section{2 .1 .4 Meteramplif ter}

During the initiation of the ellipsometer by hand it is necessary ta have direct indication of the light intensity. This is obtained from a voltmeter served by a separate amplifier. The amplification of this. unit is 15 fold. The maximum current through the meter is limited to $1.2 \mathrm{IMA}$. 
3. L.2 Hardware motordriving and timing logic (Fig. 11.8)

The stepping motors (PD 12) are steered wia philips steering prints (type nuber 9904-131-03004). To steer, one motor needs a steppulseand a direction bit. There is also the possibility of neglecting atep order by means of an "inhbit bit". This inhibit bit is transmuted to the steering print via a decoder. The pulses and bits are generated by the computer as will be described later an. The computer can give pulses much faster than the motors are able to execute their steps. Therefore, a timing circuit is included between the stepping motor equipment and the computer. After receiving a signal from the computer this circuit will generate a "non-done" signal that causes the computar not to give further pulses during a period adequately for executing the step. In order to prevent noise from pick up pulses it was meces. sary to disconnect the computer and the mator systen electrically by means of optocouplers. The stepping motor systen consequently consists of (Fig. II.B):

\subsubsection{Optocouplers}

As opto isolators we used the Hewlett Packard high speed optically coupled isolators type $5082-43.50$.

3.2 .2 .2 Timing circuit

This circuit consists of a momostable multivibrator (SH 74121 N) which is started by the steppulse. The length of the steppulse is adjustable between 4 and 20 isec. A potentioneter adjusts the length of the "non done" block on about 3 msec. In this way the stepping rate is 320 steps/ second.

3.2.2.3 Decoder

This circuit consists of a gate circuit which has the following properties:

1. the inhibit pulse $=0$, the steppulse does not reach the stepping motor;

2. the intibit pulse $=1$, the steppulse reaches to the motor.

The switching of the inhibit cannot cause a steppuls.

3.2 .2 .4 stepping motar print

This print is manufactured by Philips (type number 9904-131-03304). It is designed for steering the eight phase stepping motors. This print only receives the step order and a direction signal. To give an uncoupling of the power supply and because of the pull-in frequency. it is necessary to enlarge the mator steer voltage to 20 and to introduce RC networks. 
3.2 .2 .5 The stepping motor

The stepping motor is a Philips PD 12, the transission of the motarsteps to the prism holder is constructed in such a way that one motorstep gives an angle change of about $0.01^{\circ}$ of the prism. It is very important that the transmission is of a very high quality and that the backlash has to be reduced as much as possible. The remaining backlash is corrected by the computer program.

\section{Ellipsometer steering computer program}

\section{1 Introduction}

The ellipsometer steering computer program is designed to control the measuring process of the ellipsometer, it is carried out by aidigital PDP 12 computer, which drives the polarizer and the analyzer of the ellipsameter by means of stepping motors. Both the polarizer and the analyzer have to be steered to the position where a minimum light intensity is achiewed on the photodiode behind the amalyzer. At the same time the postion of the prisms is recorded.

\subsection{Principle of the steering procedure}

The light intensity at the photodiode is a parabolic function of both the polarizer and analyzer position (Fig. I1.9) (Chapter III). We want to find the coordinates of the point in the andyzer-polarizer plane of minimal light intensity and to follow its changes in time. Seeking the minimum light intensity is done by moving the analyzer at a fixed polarizer value, next by fixing the analyzer at the value foumd and changing the polarizer again to find a minimum then again moving the analyzer etc. When one starts at a position mot too far from the minimum, the real minimum is usually found after a few iterations. When the position of the minimum changes, the procedure will follow the changing minimum $(6,7)$.

so first two polarizer positions of equal intensity are sought. and then this prism is steered to the middle in between these positions being the minimum of the parabolic function. Next the program repeats the same procedure with the motor which drives the analyzer. When the analyzer is steered to the minimum position of the function one whole measuring cycle is completed. This cycle is repeated continuously.

At the end of the measuring cycle one can optionally obtain a printout of the momentary values of the polarizer position, analyzer position, time, temperature and $p H$ in the cuwet. At the end of each motorcycle, during the running back of each motor to the minimum, on the 


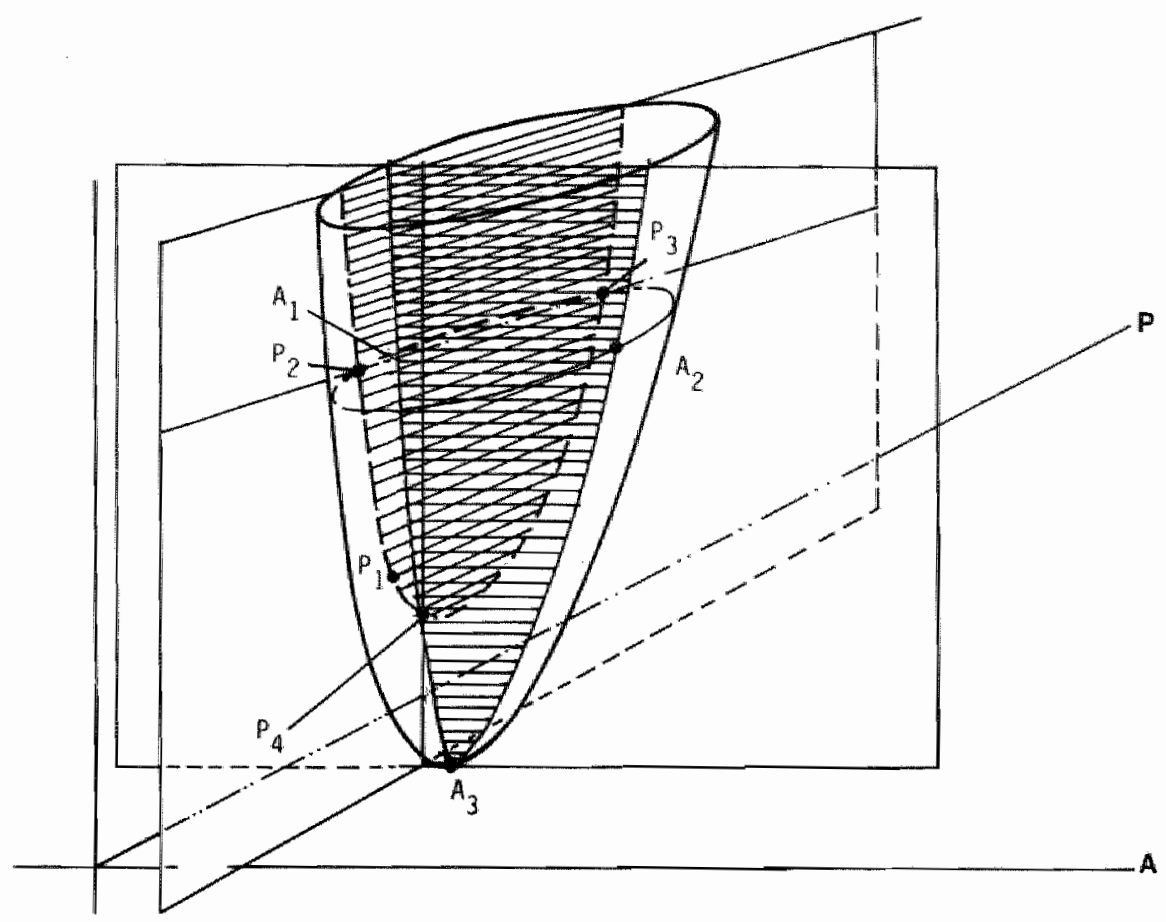

Fig. II. $9^{\circ}$ seeking procedure

Starting position $P_{1}$. With fixed analyzer position the light intensity will follow the intersection $P_{2} P_{2} P_{1} P_{3} P_{4}$. From positions $P_{2}$ and $P_{3}$ the middle $P_{4}$ is calculated. Starting position $P_{4}$ : with fixed polarizer position the 1 ight intensity will follow intersection $P_{4} A_{1} P_{4} A_{2} A_{3}$. If necessary the procedure is repeated from starting position $A_{3}$.

computer display two curves are visible. These curves consist of all the stored previous positions of polarizer and analyzer versus time. There is also a possibility to replace these curves with curves of the temperature and/or pH versus time. With a sense switch setting one transfers the computer display to a memary scope which is connected to a hard copy unit which can produce a photocopy of the displayed curve.

4.3 steering method of the stepping motors

Technical details

The stepping motors which drive the polarizer and analyzer are 
steered by the computer via the Du0l multiplexer. This unit gives command pulses via the "pulse 1-" and "pulse 2-" output channel of M730 module to the hard ware motardriving and timing logic. The logic answers after about $2.5 \mathrm{msec}$. This logic also receives a 12-bits dataword via the same output module M730 in channel 0 of the multiplexer. By means of bit settings in this data word an indication is made which motor should be steered forwards or backwards. If bitt $1=0$ then the polarizer should be steered forwards, if bit $1=1$ then this motor should be steered backwards. The ane holds for bit 2 with the alyzer. The 12-bits dataword which goes via the M730 module of the oud unit to the ellipsometer, contains besides the motor steering bit 0,1 , and 2 , also a digital steering of the amplifier which is coupled to the photodiode. With the sewen least significant bits the gain of this amplifier is determined. The variable gain control is used to optimize the measuring time, in the cases where a big difference in sensituivity between polarizer and analyzer exists and when the sensitivity changes during the adsorption process. The whole program is contralled by a monitor program which is core resident together with a number of routines for general purpose.

4. 4 The computer programs

PROGRAMA DATA "ELLIPSOMETER PROGRAM"

THE ELLIPSOMETER-PROGRAM CONSISTS OF THE FOLLOWING PARTS

PART 1: BINARY ASSEMBLING OF:

SYSTEM V2

+ ARITHMETIC ROUTINES

+ INTERRUPT \& SERVICE ROUTINES

+ MON ITOR

(CORE RESIDENT TOGETHER)

THIS TO LOAD WITH "0700/0000; LMODE; I/O PRESET; DO; START2O

PART 2: LOGIN-PROGRAM ON LINCTAPE

PART 3: CALIBRATION PROGRAM IDEM

PART 4: PROCESSING PROGRAM IDEM

PART 4: FILE REPRODUCTION IDEM MONITOR COMMANDS

(ALL COMMANDS TERMINATED BY "KETURN")

"LO" LOAD THE LOGIN PROGRAM

"YK": LOAD THE CALIBRATION PROGRAM

"PR":LOAD THE PROCESSING PROGRAM

"FR": LOAD THE FILE REPRODUCTION

"FN": LOAD THE FILE NAME LISTING 
"CTRL/C" WURING ANY PROGRAM: LO TO MONITOR

"CO" CONT INUE THE CURRENT PROGRAM, INTERRUPTED BY "CTRL/C"

\subsubsection{Core resident programs}

The total of core resident programs consists of:

4.4.1.1 System $V 2$ with routines for teletype printer, teletype keyboard, ingh speed puncher, scope subroutine, decimal conversion, and the master interrupt control.

4.4.1.2 Arithmetic routimes with subroutines for double length division, mutiplification, addition, subtraction and scaling.

4.4.1.3 Interrupt and service routines for the servicing of the KW $12 \mathrm{~A}$ clack, the stepping motors via the ouol unit and keyboard input routine.

4.4.1.4 Manitor for guiding, steering and watching as described sub II. 4.3 .

4.4.2. Calibration program (Fig. II.10, 10a)

Wth this progran the values of the starting pasition of both the polarizer and the analyzer are entered in the program. Secand, the calculation factor is determined which transforms the number of steps of a stepping motor inta the position change of a prism in degrees.

First we minimize the photodiade output, positioning the prism by hand; this gives the starting position. From this starting position of the polarizer, the polarizer motor is steered forward 4096 steps. The position which is reached thereupon is read in 0.01 degrees (see below) and this value is typed on the keyboard in five figures. Wext the motor goes back to his starting position, this position is also read and typed on the keyboard. From the difference of both values the correction factor is calculated. The motor number is increased to motor no $=1$ and the same routine is done for the analyzer position. 10

FILE NAME $=B E N \mid / 75 / 2$

- $Y K$

CALIBRATION OF POLARIZER

1ST POSITION IN 0.01 DEGREES $=13912$

2ND POSITION IN 0.01 DEGREES $=08042$

CAL IBRATION OF AMALYZER

IST POSITION IN 0.01 DEGREES $=06460$

2ND POSITION IN 0.01 DEGREES $=02104$ 


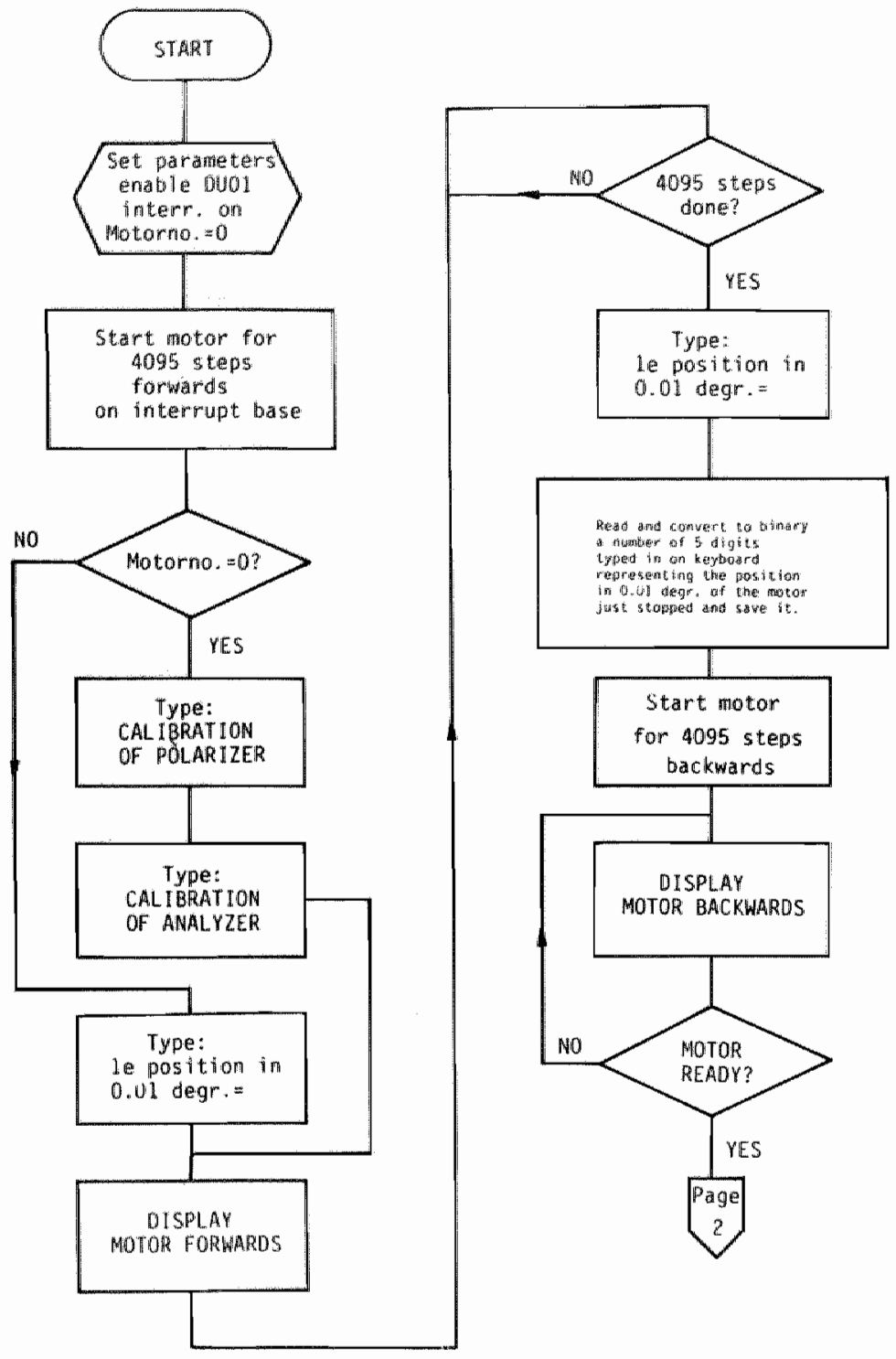

Fig. N10. Calibration program. 


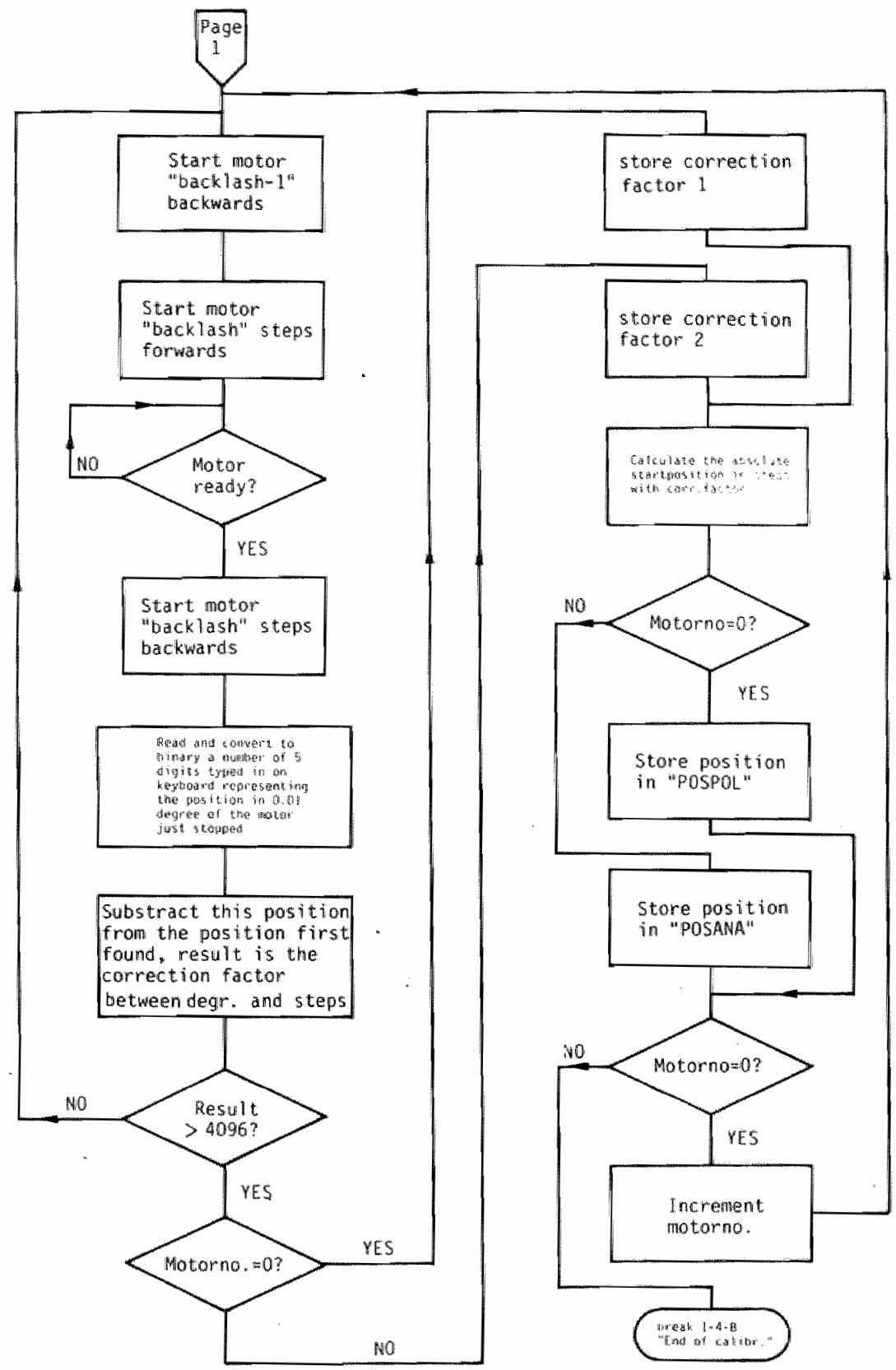

Fig. I.10a. Calibration program continued. 


\subsubsection{Processing program}

Before zero time in each experiment, the polarizer and analyzer are placed in the minimum postions via the calibration programo These minlmum postions are the starting positions in the processing program. The processing program starts steering forwardsthe polarizer motor. Meanwhle the output of the photodiade is sampled via an analogdigital converter input. When a saple value of 200 or more is reached the motor is stopped. After stopping for about 40 msec, 8 samples are taken, averaged and stored as the reference light intensity. The notor position is stored too. Hext the motor is steered back. After a fixed number of steps, sampling of the photodiode output is started again. A buffer zone without sampling is needed becaluse it is to be avolded that fluctuations in the phatodiode output cause that the reference light level is reached again thus measuring two times the same intensity at one site of the minimum position. The samples are continuously compared to the reference light level. If this value is reached, the motor is steered further several steps. How the motor is stcpped about $40 \mathrm{msec}$, and started again in the rewerse (forward) direction. The stop of $40 \mathrm{msec}$ is necessary because the big angular acceleration in case of a sudden change of the motor direction would damage the mechanism. Without stopping the motor will slip and this causes a loss of motor steps. As the prism posttion is monitored by counting the steps, this would bring about an inaccuracy in the assessment of this position.

Running forward the samples of the photodiode are compared again with the first position. When this sample value is the sala or less than the first position the motor is stopped and the second position is found. This pasition is added to the first position and devided by two. This value gives the minimum position of the function and is stored. Subtraction of motor position and the minimum pasition of the function gives the number of steps the motar still has to do to reach the minifium position. The polarizer measuring cycle is finished now with MOTOR $\mathbb{N}=0$. Next the polarizer position in steps is transformed ta 0.01 degrees and stored.

During the time the motor goes to the minimulin position the display routine displays the built file. When the motor is meady, motor $N=1$ is set and the whole process starts with the analyzer motor. In this case the minimum position is calculated and stored. After this cycle it is checked whether the ight amplification ensures maximal efficiency. To do this the distance between the two points of maximal intensity is determined. If this value is bigger than a fixed number 
of steps, the codeword for the gaincontrol of the photodiode amplifier is lowered by 1 bit. In this way the amplification is increased. Whem the distance is too small, the codeward is enlarged by 1 and the amplification is lowered. Values of temperature and pH in the cuvet can also be measured. Both values are stared binary. The locations of the prisms, time, temperature and pH form together a data sample block of 10 words which is added to datafile in the memory at the end of the analyzer cycle. The time is measured via the real time clock (KW 12) in the computer. During the measurement these five values can be printed out on the teletype by a sense switch aptian. When the fije is as big as 15 memory blocks = 3840 locations, the whole memory field is stored on the tape labeled with the filename. After 10 measuring cycles of polarizer and analyzer the 611 memory scope is automatically enabled and displays the process. The 611 memory scope is coupled with a hardcopy unit which can give a photocopy of the display.

PROCESSING PROGRAM (Fig. I I. 11 a, b, $c, d$ )

OPTIONS AFTER TYPINIG "CTRL/C":

"CL": CLEAR ALL DATA AMD TIME, RESTART PROCESS

"rI":FINISH THE PROCESS AND STORE THE DATA

1

FOR CUIRVE SELECTION:

"C1": SELECT CURVE 1

"C2":SELECT CURVE2

THAN: "PO", "AN" "TE", OR "PH"

FOR RESP.POLARIZER-, ANALYZER-, TEMPERATURE- OR ACIDITY CURVE

SENSE SWITCH OPTIONS:

5.5. O HORIZDNTAL CALIBRATION

S. S. 1 VERTICAL CALIBRATIONS I

S.S. 2 VERTICAL CALIBRATIONS 2

S. S.3 PRINTER DUTPUT

S.S. 4 CONTINUE DISPLAY

S.\$.5 REFRESH MEMORY SCOPE (AUTO)

" 5 " IN RIGHT SWITCHES: 5 OEGR. VERTICAL MOVING WINOOW,

ELLSE 2.5 DEGR.

KNOB 0: SHIFT OF $X$-AXIS

(ALWAYS FULLY CLOCKWISE ON START OF PROCESS)

KNOB 4: SCALTNG OF $X$-AXIS

RNOBS 185: $Y$-SHIFT OF CURVE I (MOVING WINDON)

KNOBS 286: $Y$-SHIFT OF CURVE 2 (MOVING WINOOW) 
File reproduction program

Handing of the data filles is carried out by the file reproduction program described below.

FILE REPRODUCTION PROGRAM

DURING THE DISPLAY OF A FILE:

TYPING "*

THE DISPLAY SHIFTS 5 TAPEBLOCKS FORWARO (INCREASING TIHE)

TYP 1 NG "

THE DISPLAY SHIFTS 5 TAPEBLOCKS BACKWARD (AS FAR AS STARTINGBLOCK)

$/$

$/$

OPTIONS AFTER TYPING "CTRL/C":

$/$

"LS" :

THE PART OF CURYE DISPLAYED IS PRINTED OUT BY TELETYPE

"HS":

THE PART OF CURVE DISPLAYED IS PUNCHED OUT BY H.S. PUNCHER

$/$

FOR CURVE SELECTION:

"C1" : SELECT CURVE1

"C2" : SELECT CURVE?

THAN: "P0", "AN" "TE", OR "PH"

FOR RESP.POLARIZER-, ANALYZER-, TEMPERATURE- OR ACIDITY-CURVE

1

SENSE SNITCH OPTIONS:

5.\$.0 HORLZONTAL CALIBRATION

S.S.1 VERTICAL CALIBRATIONS 1

S.S. 2 VERTICAL CALIBRATIONS 2

S.S.5 REFRESH MEMORY SCOPE (AUTO)

"I" IN RLGHT SWITCHES: 5 DEGR. VERTIC. MOVING WINDOW, LLSE 2.5 DEGR.

l

KNOB 0: SHIFT OF $X$-AXIS

(ALWAYS FULLY CLOCKWISE ON START OF PROGRAM)

KNOB 4: SCALING OF X-AXIS

KNOBS 1:5: $\gamma$-SHIFT OF CURVE 1 (MOVING WINOOW)

KNOBS 286: $\gamma$-SHIFT OF CURVE 2 (MOVING WINDOW) 
CLEAR TIME

List of program command codes

List of routine start addresses

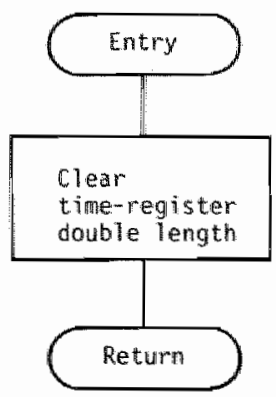

CLEAR DATA BUFFER

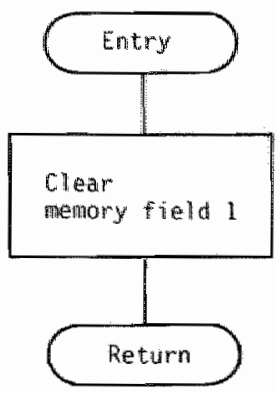

Working up of the particular progrant options executed by the MONITOR after "GTRL/C"

typing a command codie.

CLEAR DATA.

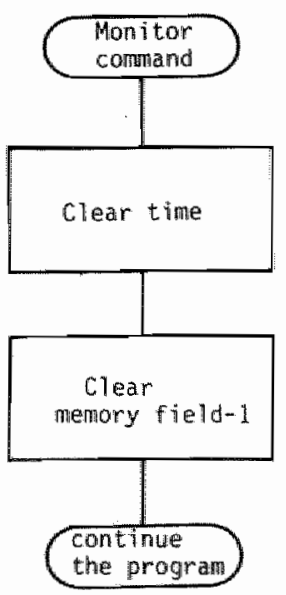

PRCRV1

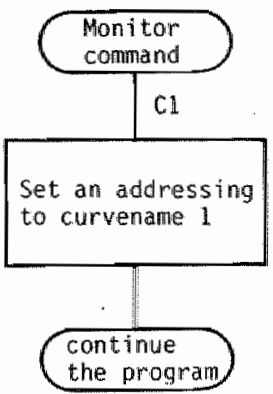

PRPOL

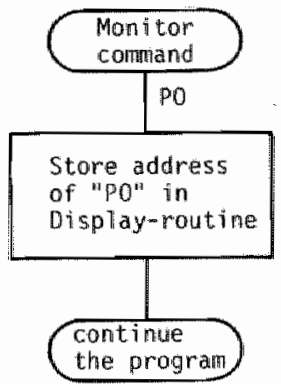

Fig. I1.11. Processing program 
PRTEMP

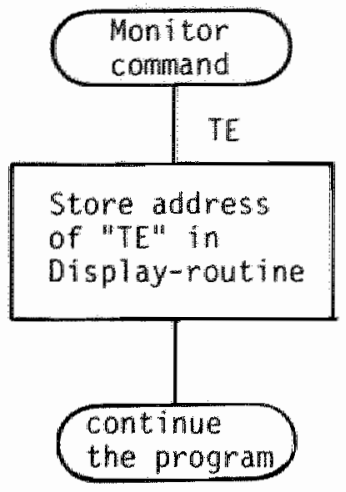

PRANA

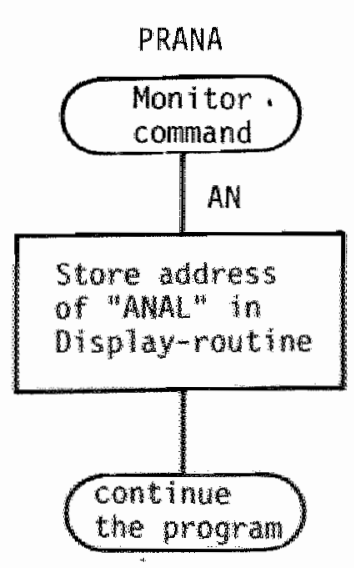

FINISH

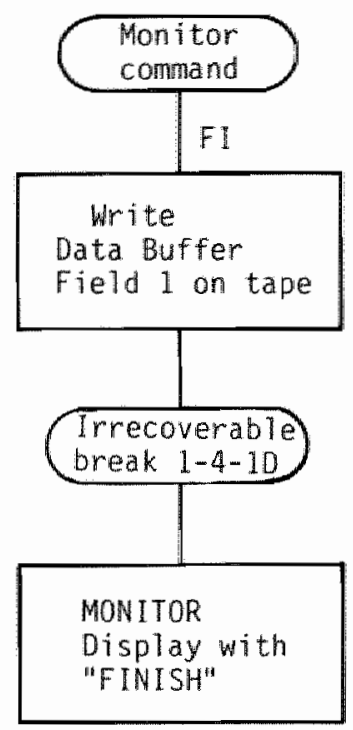

PRACID

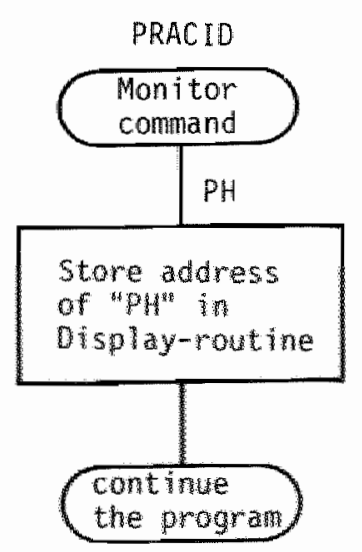

PRCRV2

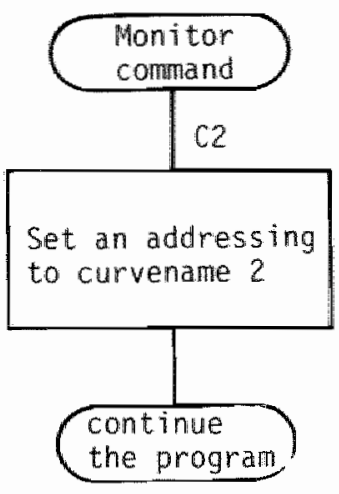

Fig. H.11a. Processing program (continued) 


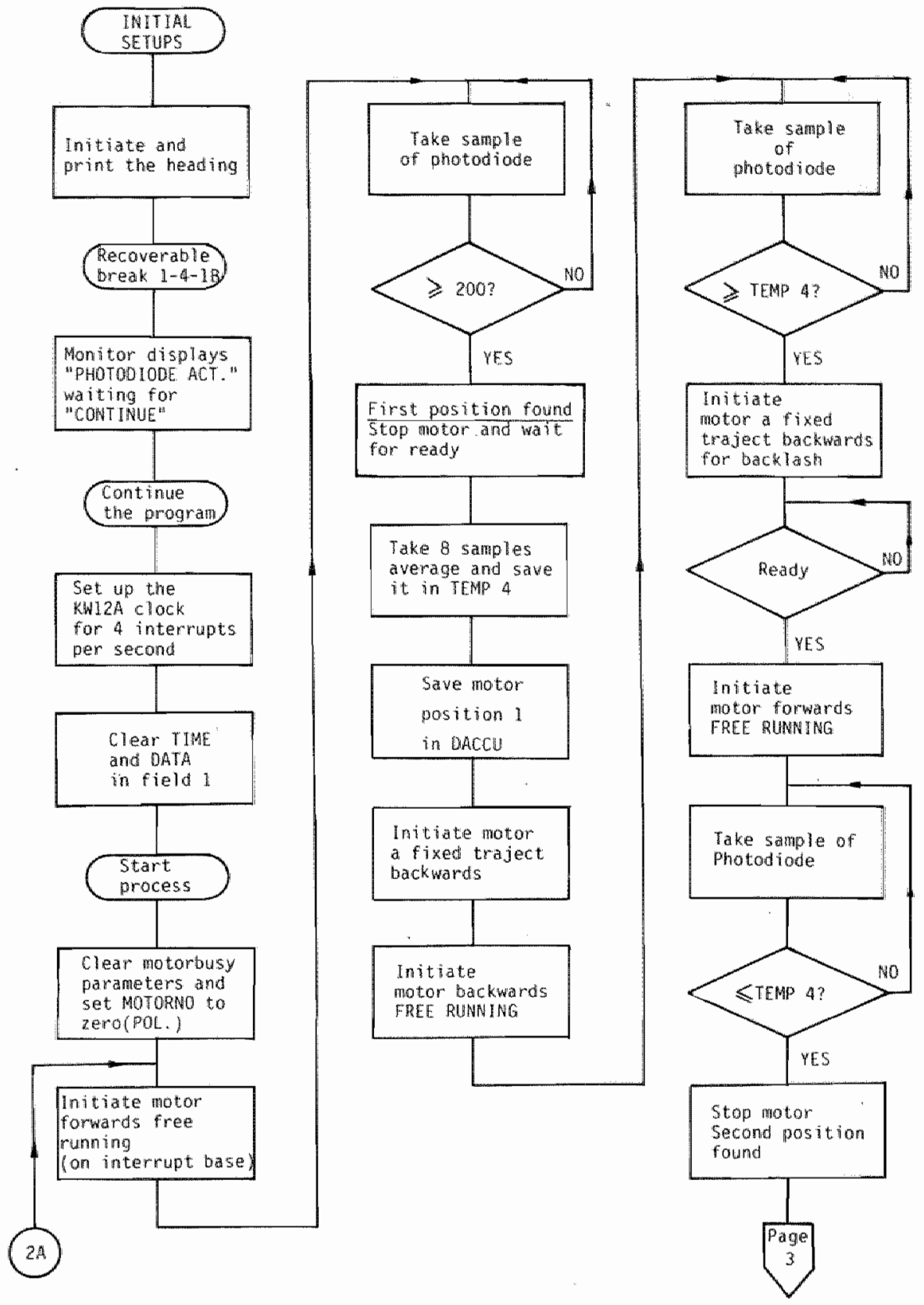

Fig. Il $11 b$. Processing program (continued) 


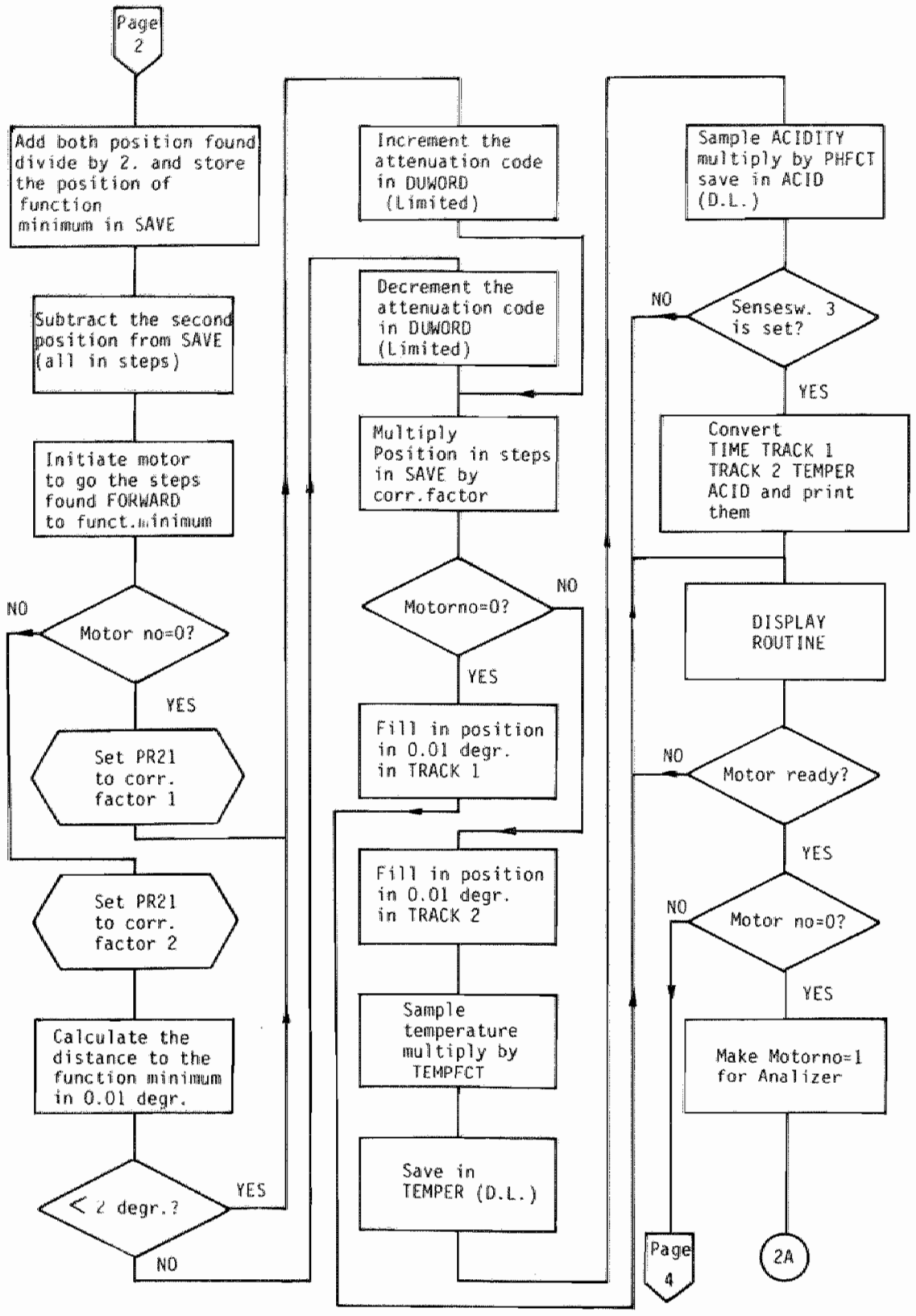

Fig. II.11c. Processing program (continued) 


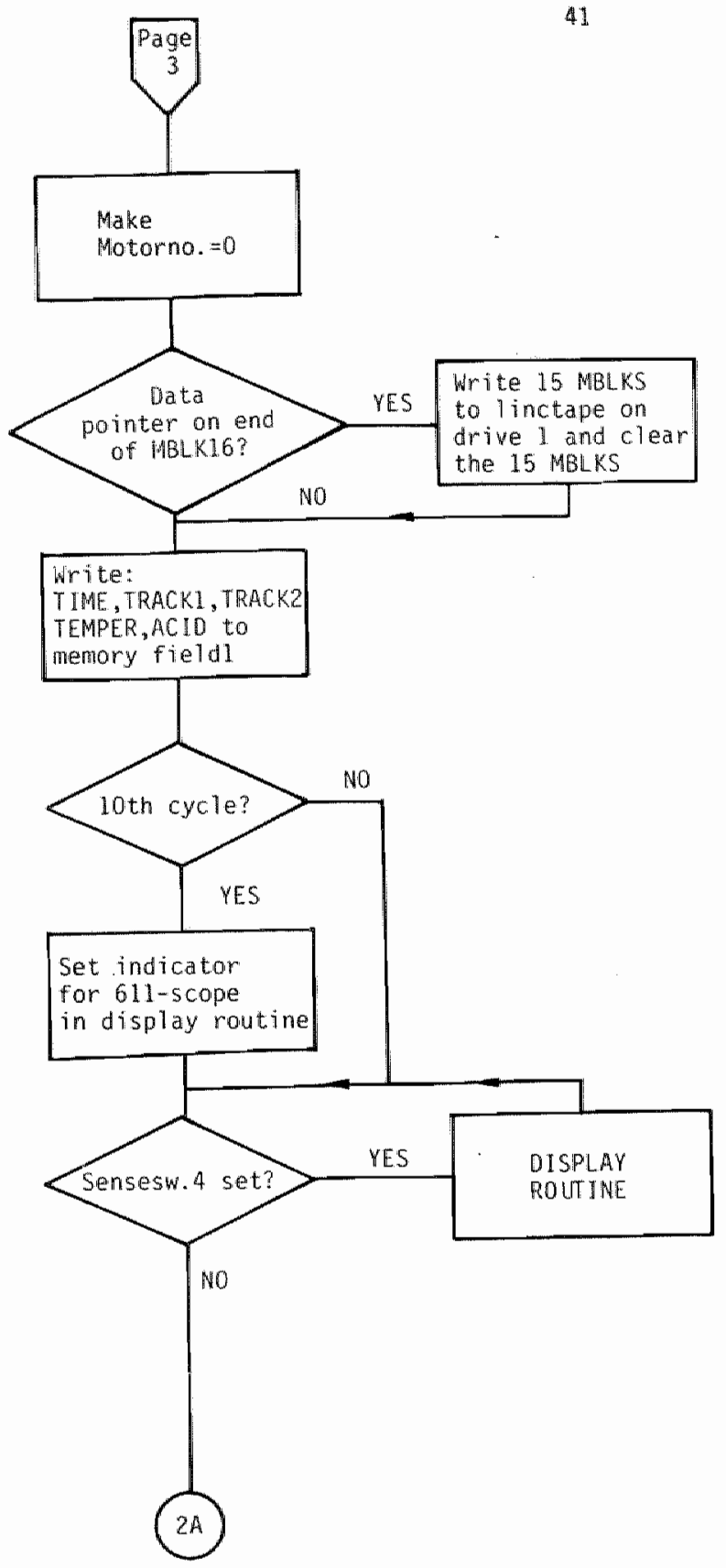

Repeat for Analyzer

Fig. II.11d. Processing program (continued) 
Literature references

1. Layer, H.P. (1969) Surface Science 16,177

2. Cahan, B.u. and spanier, R.F. (1969) Surface Science 16, 166

3. Ord, J.L. (1969) Surface Science 16, 155

4. Wilmanns, I. (1969) Surface science 16, 147

5. alerard, H. G. (1969) Surface science 16, 137

6. Fletcher, R. and Reeves, C.M. (1964) Comp.J.7, 149

7. Fletcher, F. and Powe11, M.J.0. (1963) Comp.J.6,163

8. Mc.Crackin, F. and Passaglia, E. (1963) J.Res.Nat.Bur.Stand. 67 A, 363

9. De Haan, P.C.H., Hemker, P.W. Unpublished results

10. Winterbottom, A.B. (1946) Trans.Famaday Sac. $41,487$. 


\section{CHAPTER III}

optical basis of the method

1. 1 Definitions and basic principles of polarized light

Interpretation of ellipsoneter data, trouble shooting in the instrument and recognition of possible artefacts is not well possible without understanding the working principles. We therefore give here the relevant parts of the optical theary on polarized light.

tllipsometry is based on the analysis of plane polarized light mesulting from the reflection of incident elliptically polarized lught from a metal surface. The concept of elliptically pollarized light is best understood when it is considered as resulting from the interaction of two beams of plane polarized light.

Consider a light wawe travelling along the $z$-axis of a coordinate system. The electric vector of the wave can be given by:

$$
\begin{aligned}
& E_{x}=A \cos \left(\pi+\hat{b}_{1}\right) \\
& E_{y}=B \cos \left(\pi+\hat{\sigma}_{2}\right)
\end{aligned}
$$

where $t=w\left(t-\frac{z}{w}\right)$, w and vare the angutar frequency and linear velocity of the light, mespectively, and the tatal amplitude is the vectorsum of $A$ and $B$.

The polarization can be described by the amplitudes $A$ and $B$ and the phase difference $\delta=\delta_{1}^{-\delta}$, of the compoments.

Elimination of $\tau$ gives the following relation:

$$
\left(\frac{E x}{A}\right)^{2}+\left(\frac{E_{y} y}{B}\right)^{2}-2 \frac{E_{x} E_{y}}{A B} \cos \delta=\sin ^{2} \delta
$$

which is the equation of a conic section, an ellipse in this special case. From the equation one can see:

of $\delta=0$

$$
\begin{aligned}
& \left(\frac{E_{A}}{A}\right)^{2} \cdot\left(\frac{E y}{B}\right)^{2}-\frac{2 E_{x^{E} y}}{A B}=0 \\
& \frac{E_{X}}{H_{A}}=\frac{E_{y}}{B} \rightarrow \text { plane polarized light. }
\end{aligned}
$$

The same is true for $\delta=\pi, 2 \pi$ 
If $b=90^{\circ}, 270^{\circ}$

$\left(\frac{E_{x}}{A}\right)^{2}+\left(\frac{E_{y}}{B}\right)^{2}=1$

Only if $A=B$ we get $E_{x}{ }^{2}+E_{y}{ }^{2}=A^{2}$ which is the general formula for a circle. In the next picture all possible situations are given:

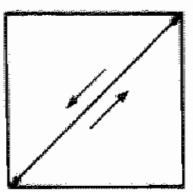

$\Delta=0$

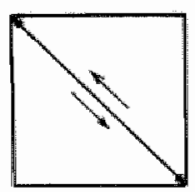

$\Delta=\pi$

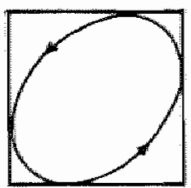

$0<\Delta<\frac{1}{2} \pi$

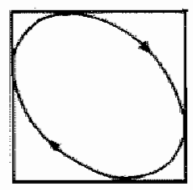

$\pi<\Delta<1$ 被 $\pi$

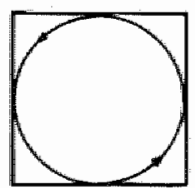

$\Delta=\frac{1}{2} \pi$

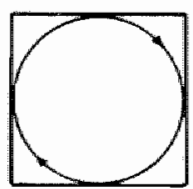

$\Delta=1 \frac{1}{2} \pi$

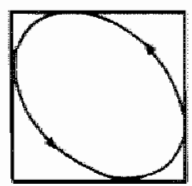

$\frac{1}{2} \pi<\Delta<\pi$

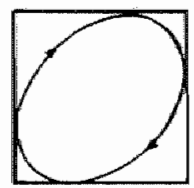

$1 \frac{1}{2} \pi<\Delta<2 \pi$

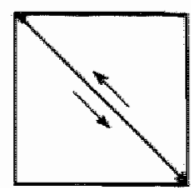

$\Delta=\pi$

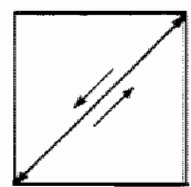

$\Delta=2 \pi$

Fig. III.1. Cases of polarization for variaus phase differences $\Delta$. From fig. III.1 we see that the ellipticity is a function of $\delta$. The relationship between an ellipse and its components in the reference planes is given below. 


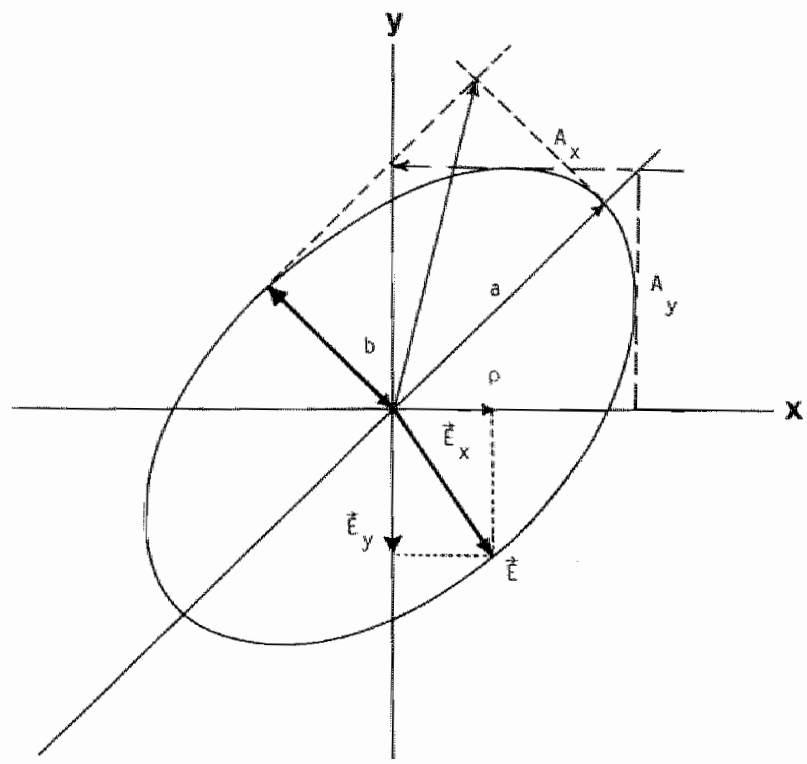

Fig. MI.2 Representation of monochromatic elliptically light

The components $E_{x}$ and $E_{y}$ of the electric vector $E$ have amplitudes $A_{x}$ and $A_{y}$. The relevant parameters are:

1. azimuth $\rho$ (angle formed by the positive $x$-axis and the long axis of the elips)

2. elipticity $x= \pm \arctan \left(\frac{b}{a}\right)$

The + sign denotes a clockwise orbit of the electric vectar

3. The ratio $\frac{A_{y}}{A_{x}}$ expressed by $a=\arctan \frac{A}{A_{x}}$

4. the phase difference between $E_{x}$ and $E_{y}$.

These quantities satisfy the equations of partington

$\tan 2 p=\tan 2 \alpha \cdot \cos 0^{\circ}$

$\sin 2 x=\sin 2 \alpha . \sin s$.

As seen from the last relation, plane polarized light is obtained for zero phase difference $(\delta=0)$ between $E_{x}$ and $E_{y}$.

1.2 Complex notation

To describe a lightwave, one can use the following notation:

$E_{x}=A \sin \left[\omega\left(t-\frac{z}{v}\right)+B_{1}\right], E_{y}=B \sin \left[\omega\left(t-\frac{z}{v}\right)+\delta_{2}\right]$ 
However, calculation with these quatities becomes clearer and simpler if a symolic expression by means of complex numbers is used. If we denote:

$$
\cos \left(t-\frac{2}{b}\right)=\tau
$$

then according to Euller's relation

$$
e^{i t}=\cos t \text { is int }
$$

it follaw that cost is the real part and sint the imaginary part of the complex expression $e^{i \tau}$. The real part of the final expression is understaod to represent the physical quantity in question (1).

The equations $E_{x}=A$ sinut $E_{y}=B s i n w r$ can then be written in the form

$$
E_{x}=\vec{A} e^{1 \tau} \quad E_{y}=\ddot{B} e^{1 t}
$$

where the amplitudes $\bar{A}$ and $\bar{B}$ cam be given generally by complex numbers, for instance the complex amplitude $\bar{A}$ can be written in the form:

$$
A=A^{\prime}+i A^{n}=\sqrt{A^{2}+A^{2}{ }^{2}} e^{i \delta} 1=A e^{i \delta} 1
$$

where

$$
\tan b_{1}=\frac{A^{\prime \prime}}{A^{\prime \prime}}
$$

Equations (eq. 5) can then be written in the form

$$
E_{x}=\bar{A} e^{i \tau}=A e^{i\left(\tau+\delta \delta_{1}\right)} \quad E_{y}=\bar{B} e^{i \tau}=B e^{i\left(\tau+\delta_{2}\right)}
$$

The method of witing

$$
\begin{aligned}
& E_{x}=A \sin \left[\omega\left(t-\frac{z}{v}\right)+\delta_{1}\right]=\bar{A}_{e} e^{i \tau} \text { and } \\
& E_{y}=B \sin \left[\omega\left(t-\frac{z}{v}\right)+\delta_{2}\right]=\bar{B} e^{i \tau} \text { shows that } E_{x} \text { and } E_{y} \text { are components }
\end{aligned}
$$

of the vector harmonic wave which are generally written in the form (1).

$$
\tilde{E}=\bar{E}_{0} e^{i \tau}
$$

where $\tilde{E}_{0}$ is the complex vector of amplitude which has the following components

$$
E_{0, x}=A e^{1 \delta_{1}}, E_{0, y}=B e^{1 \delta 2}, E_{0, z}=C e^{i \delta_{3}}
$$

The change from one form of polarized light to another is brought about by reflection and refraction of the light by particular materials. and the type of change is determined by the optical properties of these materials. In order to understand the measurements of thin films by ellipsometry it is necessary to cansider the changes in polarized light which occur on reflection and refraction. 
1.3 The reflection and refraction of light an a boundary between two isotropic dielectios

When studying the reflection and refraction of light on a boumary between two isotropic homogeneous dielectrics we orientate the coardinate system so that the $x y$ plane lies in the plane boundary of the two media. The $x$-axis is the projection af the plane boundary of the two dielectrics, while the $y$-axis is normal to the plane of drawing. The plate of incidence in which the incident reflected and refracted rays $l y$ is in the plane of drawing, i.e. in the $X 2$ plane. The medium from which a plane light wave is incident on the refracting boundary has refractive index $n_{0}$; similarly the other medium into which the light wave is refracted, has refractive index $n_{1}$. The vector piane wave of the incident light is written in the complex form

$$
\bar{E}_{0}^{d}=\bar{A}_{0} e^{i \tau} o^{d}
$$

similarly the vector reflected wave is given by

$$
E_{0} r=R_{0} e^{i \tau_{0} r}
$$

and the vector refracted wave by

$$
E_{1} d=A_{1} e^{i \tau_{1} d}
$$

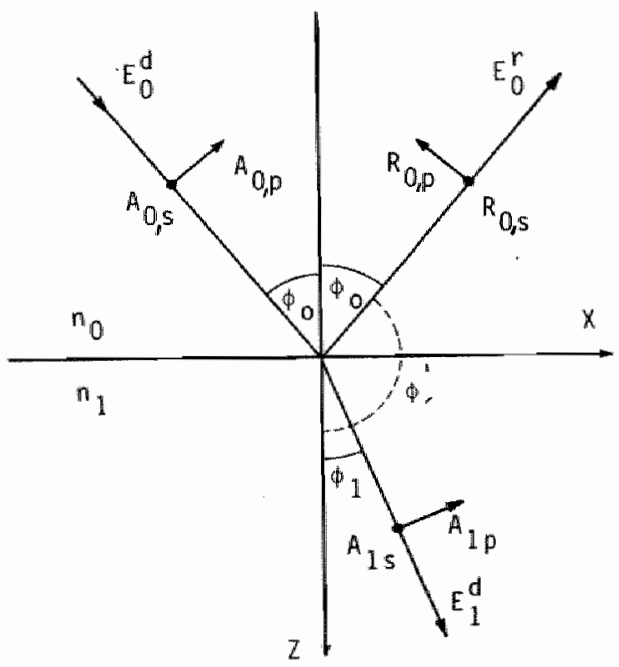

Fig. IIL.3 Reflection and refraction of light at plane boundary between two dielectrics with arientation of the vectors $\mathbb{E}_{0} d$. $\bar{E}_{0} r$, and $\bar{E}_{1} d$ and its component $A_{0, p}, A_{0,}, R_{0, p}, R_{0, s}, A_{1}, p, A_{1}, s$. 
In the above equations the expanent of the function e in the incident wave is:

$$
\tau_{a}^{d}=w_{0}\left(t-\frac{x \sin \theta_{0}+2 \cos p_{0}}{v_{a}}\right)
$$

in the reflected wave:

$$
\left.T_{0}^{r}=\frac{x \sin \rho_{0}+2 \cos \rho_{0}{ }^{s}}{v_{0}}\right)
$$

in the refracted wave:

$$
\tau_{1}^{d}=\omega\left(t-\frac{x \sin p_{1}+2 \cos p_{1}}{y_{1}}\right)
$$

where $t$ is the time and the circullar frequency of the light wave, $\rho_{0}$ the angle of incidence, $\rho_{0}$ ' the angle of reflection and $\rho_{1}$ the angle of refraction.

The vector of the amplitude of the imcident light wave $\bar{A}_{0}$ is diwided inta two components - the component $A_{0, p}$ lying in the plane of incidence, and the component $A_{0,}$ normal to the plane of incidence. Similarly in a reflected light wave the vector of the amplitude $\vec{R}_{0}$ is divided into the components $R_{0, p}$ and $R_{o, s}$ and in a refracted light wave the amplitude $\vec{A}_{1}$ is divided into $A_{1, p}$ and $A_{1,5}$.

If we write out the above vector light waves into components along the coordinate axes, the components of the amplitude s are normal to the plane of incidence and thus ly in the direction of the y-axis, white the components of $p$ ly in the plane of incidence, and have projections into the $x$ and $z$ axis. We thus obtain for the components of the light vectors:

for incident light:

$E_{0, x}^{d}=A_{0, p} \cos p_{0} e^{i \tau_{0}}$

for reflected light:

$E_{0, y}^{d}=A_{0,5} e^{i t} 0^{d}$

$E_{0, x}^{r}=R_{0, p} \cos \rho_{a}^{i} e^{i \tau}{ }^{r}$

$E_{0, z}^{d}=-A_{0, j} \sin p_{0} e^{i \tau} d$

$E_{0, y}^{r}=R_{0, s}{ }^{i t_{0}^{r}}$

$E_{0, Z}^{r}=-k_{0, p} \operatorname{sinp}^{\prime} e^{i \tau} a^{r}$

for pefracted light:

$E_{1, x}^{d}=A_{1, \beta} \cos \rho_{1} e^{i \tau_{1}^{d}}$

$E_{1, y}^{d}=A_{1, s} e^{i \tau}{ }_{1}^{d}$

$\mathrm{E}_{1, z}^{d}=-H_{1, p} \sin p_{1} \mathrm{e}^{i t} d$ 
On the boundary between the wa dielectrics the tangential components of the electric vector vary cantinuously. We thus have (2):

$E_{0, x}^{d}+E_{0, x}^{r}=E_{1, x}^{d}$

$E_{0, y}^{d}+E_{0, y}^{r}=E_{1}^{d}, y$

$E_{0, z}^{d}+E_{0, z}^{r}=E_{1, z}^{d}$

These conditions must be satisfied for the boundary $z=0$ in every time t. These boundary conditions are satisfied if two basic consitions are satisfied for the boundary $z=0$.

1.4 Phase conditions

The phase condition which leads to relations between the exponents

$$
\tau_{0}^{d}=\tau_{0}^{r}=\tau_{1}{ }^{t}
$$

From the phase condition for $z=0$ we obtain the first relation by comparing the coefficients of $x$

$$
\frac{\sin p_{0}}{v_{0}}=\frac{\sin p_{0}}{v_{0}} \quad \text { i.e. } \sin p_{0}=\sin o^{\prime}
$$

since the reflected and incident rays have different directions $\left(\rho_{0}{ }^{\prime} f \rho_{0}\right), \rho_{0}{ }^{\prime}=11-\rho_{0} \quad$ i.e. $\cos _{0}{ }^{\prime}=-\cos \rho_{a}$.

This is the law of reflection.

By further comparison of the coefficient of $x$ we abtain a secand rellation

$\frac{\sin p_{0}}{v_{0}}=\frac{\sin p_{1}}{v_{1}}$ or $\frac{\sin \rho_{0}}{\sin p_{0}}=\frac{v_{0}}{v_{1}}=\frac{n_{1}}{n_{0}}$

This is snell's law of refraction, normally writtem in the form

$n_{0} \sin p_{0}=n_{1} \sin p_{1}$

The amplitudes $\vec{A}_{a}, \bar{K}_{a}, \vec{A}_{1}$ are generally complex numbers 


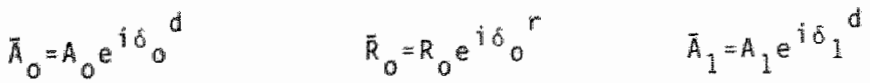

The phase condition then gives the following relations:

$b_{0}^{d}=b_{0}^{r}=b_{1}^{d}$

So the light reflected or refracted at the bourdary between two dielectrics has na change of phase or changes by \pm tr. When the

light incident on the boundary between two dielectrics is plane polartzed then the reflected or refracted light is also plane polarized.

If we writie the equations for the exponent more general: a d for the incident wave, $r$ for the reflected wave and $w_{1}$ for the refracted wave instead of $w$, then we have from the phase condition:

$\omega_{0}^{d}=w_{0}^{r}=\omega_{1}^{d}=w$

So on static boundary $z=0$ the frequency of the light at reflection and refraction does not vary.

1. 5 Amplitude conditions (Fresnel's formulae)

The anplitude conditions which lead to relations between the components of the amplitudes in incident, reflected and refracted light (cos $\left.\rho_{0} "=-\cos \rho_{0}\right)$ have the following form:

$\left(A_{o, p}-R_{a, p}\right) \cos p_{0}=A_{1, p} \cos \rho_{1}$

$\left(A_{o, p}+R_{o, p}\right) n_{0}=A_{1, p} n_{1}$

$A_{0,5}+R_{0,5}=A_{1,5}$

$\left(A_{0, s} \mathbb{R}_{0,5}\right) n_{0} \cos \rho_{0}=A_{1, s_{1}} \cos _{1}$

From the last four equations we can calculate Fresnel's formta which give the relations between the amplitudes of reflected and incident light and the relations between the amplitudes of refracted and incident light, both for the $p$ and the s component.

By calculation we obtain for the amplitude of reflected light: 


$$
\begin{array}{ll}
R_{0, p}=\frac{n_{1} \cos \rho_{0}-n_{0} \cos \rho_{1}}{n_{1} \cos \rho_{0}+n_{0} \cos \rho_{1}} & A_{0, p}=\frac{\tan \left(\rho_{0}-\rho_{1}\right)}{\tan \left(\rho_{0} \rho_{1}\right)} A_{0, p} \\
R_{0,5}=\frac{n_{0} \cos \rho_{0}-n_{1} \cos \rho_{1}}{n_{0} \cos \rho_{0}+n_{1} \cos \rho_{1}} & A_{0, s}=-\frac{\sin \left(\rho_{0}-\rho_{1}\right)}{\sin \left(\rho_{0}+\rho_{1}\right)} A_{0, s}
\end{array}
$$

and for the ratio of the reflected and incident amplitudes:

$$
\begin{aligned}
& r_{p}=\frac{R_{0, p}}{A_{0, p}}=\frac{n_{1} \cos p_{0}-n_{0} \cos p_{1}}{n_{1} \cos p_{0}+n_{0} \cos p_{1}}=\frac{\tan \left(\rho_{0}-p_{1}\right)}{\tan \left(p_{0}+p_{1}\right)} \\
& r_{5}=\frac{R_{0, s}}{H_{0, s}} \frac{n_{0} \cos \rho_{0}-n_{1} \cos p_{1}}{n_{0} \cos p_{0}+n_{1} \cos p_{1}}=-\frac{\sin \left(\rho_{0}-p_{1}\right)}{\sin \left(\rho_{0}+p_{1}\right)}
\end{aligned}
$$

Similarly one can calculate the amplitude of light transmitted through a boundary of dielectrics.

2.1 Total phase difference by reflection of a monochromatic lightwave on an isotropic adsorbing substrate covered by a thin absorbing layer

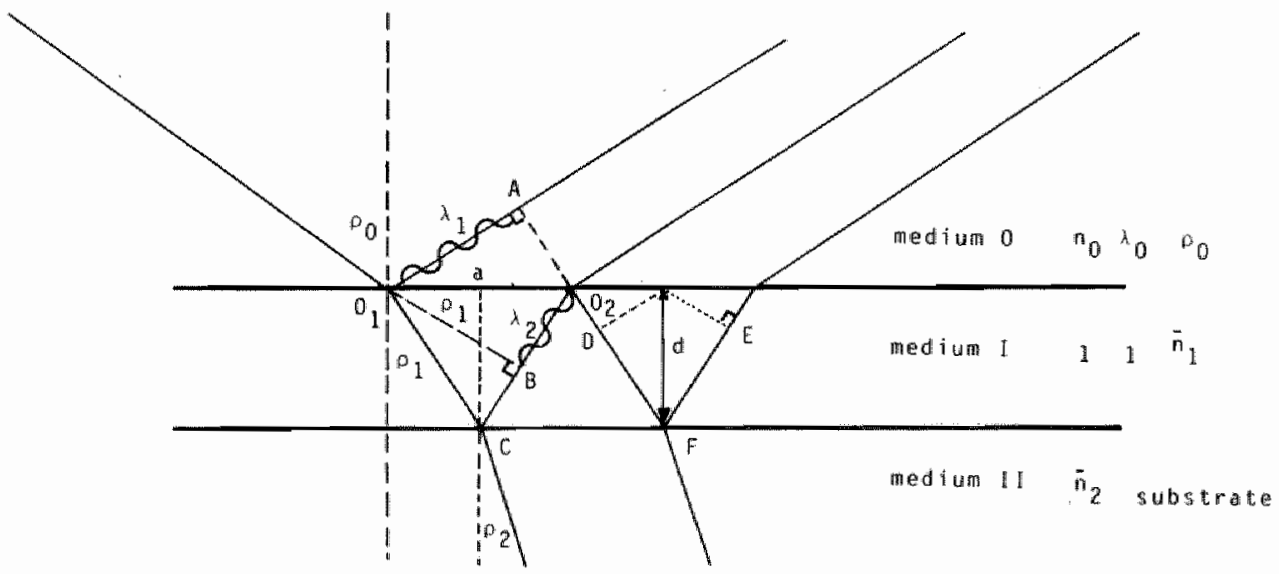

Fig. III.4. Phase difference introduced by reflection on a substrate covered by a thin layer.

Medium $D$ is the surrounding medium $n_{a}=1$ (air)

Medium 1 : thin absorbing Jayer, thickness $d_{1}$, optical constant $\vec{n}_{1}$

Medium 2 " substrate, optical constant $\vec{n}_{2}$ " 
The optical constant $\bar{n}_{j}$ is defined in the following way:

$\tilde{n}_{j}=n_{j}-1 k_{j}$

$\bar{n}_{j}=$ aptical constant medium $j$

$n_{y}=$ refractive index medium $j$

$k_{j}=a b s o r b i n g$ coefficient medium $j$.

In the figure you can see that the dffference in optical path between two successive reflected beams equals:

$\left|O_{1} C\right|+\left|O_{2} C\right|-|\underline{1}| \underline{1}$

The resulting phase difference introduced by this path is calculated below.

$\left|0_{1}\right|=\operatorname{asino}(\operatorname{lncm})=a / \lambda_{a} \operatorname{sing} p_{0}$ (in wave length)

$\lambda_{0}=$ wavelength in medium 0

$\left|0_{2} B\right|=\sin \rho_{1}($ in $\operatorname{con})=a / \lambda_{1} \sin _{1}$ (in wave length)

$\lambda_{1}=$ wavelength in medium 1

Upan reflection and refraction the frequency does not change, so

1) $v_{0}=f \lambda_{0}$

$v_{1}=f \lambda_{1}$

$v_{2}=f \lambda_{2}$

$\frac{v_{0}}{\lambda_{0}}=\frac{v_{1}}{\lambda_{1}}=\frac{v_{2}}{\lambda_{2}}$

2) $n_{0} \sin p_{0}=\bar{n}_{1} \sin p_{1}$ (sne $1 \pi " s$ law)

$n_{0} \lambda_{0}=\bar{n}_{1} \lambda_{1}=\bar{n}_{2} \lambda_{2}$

3) $n_{0} v_{0}=\bar{n}_{1} v_{1}=\bar{n}_{2} w_{2}$ (definition of $n$ )

$\frac{a}{\lambda_{1}} \sin \rho_{1}=\frac{n_{0}}{n_{1} \lambda_{1}} \sin \rho_{0}=\frac{a}{\lambda_{0}} \sin \rho_{0}$

so the optical path $\left|\mathrm{O}_{1} \mathrm{~A}\right|=\left|\mathrm{O}_{2} \mathrm{~B}\right|$

$\left|0_{1} C\right|+\mid \underline{\left|O_{2} C\right|}-\underline{\left|O_{1} A\right|}=\underline{\left|O_{1} A\right|}+\underline{|D F|}+\underline{|F E|}+\underline{|F|} \underline{\left|O_{1} A\right|}-\underline{\left|0_{1} A\right|}=$

$2 d \cos p_{1}(i n c m)=\frac{2 d_{1} n_{1} \cos \rho_{1}}{\lambda_{0}}\left(i n\right.$ wavelength) $=\frac{4 m d_{1} n_{1} \cos \rho_{1}}{\lambda_{0}}$ (indegrees) 
So the total phase difference is $\frac{4 \pi d n_{1}}{n_{0}} \cos p_{1}=x$

$x$ is real if the thin layer $d_{1}$ does not absorb for only then the optical constant is real.

2.2 Multiple reflection (Drude equation)

Thus far we calculated the effect of passing one boundary of two media. In reality the lightwave has multiple reflections and refractions in the thin layer. For this situation we sum up all effects and calculate the total peflection coefficient.

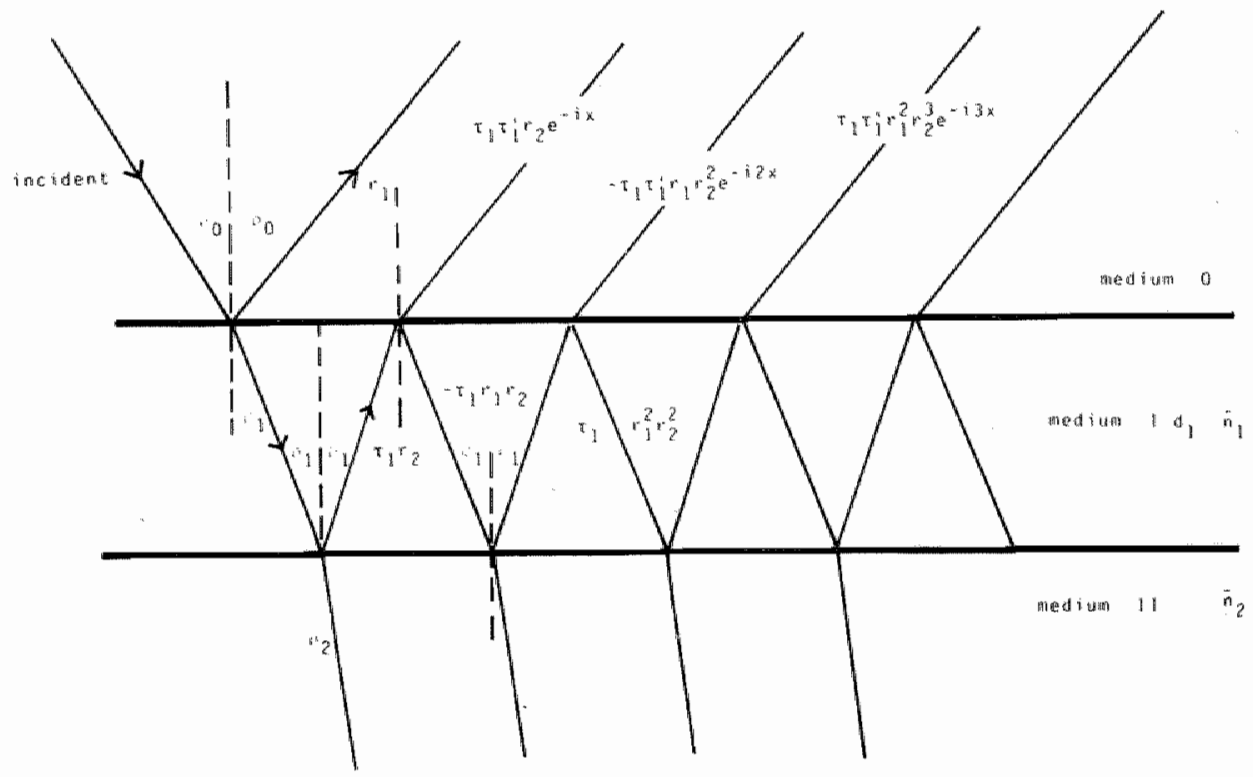

Fig. III.5 Multiple reflection and refraction on an absorbing substrate covered by a thin absorbing layer. Light waves that enter the substrate are supposed not to come out of the substrate. The p component is parallel the plare of incidence, the $s$ component is perpendicular on the plane of incidence. 
From the figure we see:

$\left.\begin{array}{l}r_{1}^{+r_{1}}=1 \\ -r_{1}+\tau_{1}=1\end{array}\right\} \rightarrow-T_{1}{ }^{\prime}=1-r_{1}^{2}$

$r_{1 p}=\frac{\mathbb{E}_{1 p}^{(r)}}{\mathbb{E}_{1 p}(i)}=\frac{n_{1} \cos p_{0} n_{0} \cos p_{1}}{n_{1} \cos p_{0}+n_{0} \cos \theta_{1}}$

$r_{1}=\frac{E_{15}(r)}{E_{1 s}(i)}=\frac{n_{0} \cos p_{0} n_{1} \cos p_{1}}{n_{0} \cos p_{0}+n_{1} \cos p_{1}}$

Fresnel's reflection caefficients

Now we define the total amplitade weflection coefficient where the behaviour of the light waves inside the thin layer is also included:

$$
\begin{aligned}
& k_{p}=\frac{{ }_{p}(r)}{\vec{E}_{p}(i)}=r_{1 p}+\left(r-r_{1 p}{ }^{2}\right) r_{2 p} e^{-i x}-\left(1-r_{1 p}{ }^{2}\right) r_{1 p} r^{2} 2 p^{e^{-i 2 x}}+\ldots \ldots \\
& k_{s}=\frac{\tilde{E}_{s}(r)}{E_{s}(i)}=r_{15}+\left(1-r_{1 s^{2}}\right) r_{2 s} e^{-i x}-\left(1-r_{1 s}{ }^{2}\right) r_{1 s^{2}} r^{2} s^{-i 2 *}+\ldots \ldots
\end{aligned}
$$

Except for the first term this is a converging geometric progression with a common ratio: $-r_{1 p}{ }^{r} 2 p^{e^{-i x}}$, so

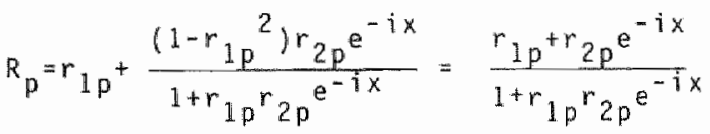

similarly

$R_{s}=\frac{r_{1 s}+r_{2 s} e^{-1 x}}{1+r_{1 s} r_{2 s} e^{-1 x}}$

We write $\vec{E}_{p}=A_{p} e^{i f_{p}}$ and $\bar{E}_{s}=A_{s} e^{i s_{s}}$ 


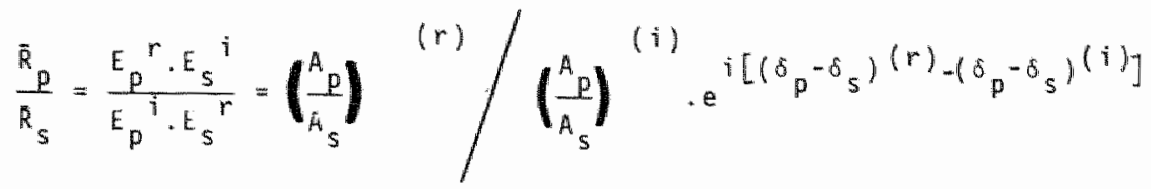

This may be expressed in terms of the relative attenuation and phase shift of the parallel component with respect to the perpendicular component that occurs, represented by the azimuthal angle $\psi$ and relative phase shift $\Delta$ by:

$\Delta \equiv\left(\delta_{p}^{-\delta_{s}}\right)^{(r)_{-}\left(\delta_{p}-\delta_{s}\right)^{(i)}} \operatorname{tg} \psi=\left(\frac{A_{p}}{A_{s}}\right)^{(r)} /\left(\frac{A_{A}}{s}\right)^{(i)}$

$\operatorname{tg} \sin ^{i \Delta}=\frac{r_{1} p^{+r_{2}} 2 e^{e^{-i x}}}{1+r_{1 p} r_{2 p} e^{-i x}} \cdot \frac{1+r_{1 s} r_{1} e^{-j x}}{r_{1 s}+r_{2 s} e^{-i x}}$

where $x=\frac{4 \pi d_{1}{ }^{n} 1}{\lambda_{0}} \cos \rho_{1}$

This equation was derived for the first time by Drude in $1889(3 \cdot 5)$.

2.3 system of several layers

For a system of several layers the orude equation can be gleneralized according to several methods $(6-8)$.

The generalizations are based on the conception that the reflection of light from one film (i.e. at two optical boundaries) can be replaced by the reflection of light at ane hypothetical boundary. which gives the same amplitude and phase, i.e. the sane complex amplitude. The mathematical basis for the conception was given by Murmann (9). The conception is clear from fig. III.6 which schematically shows the reflection of light both from clean glass and from glass with ane film. 
8)

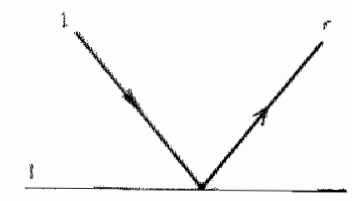

(5)
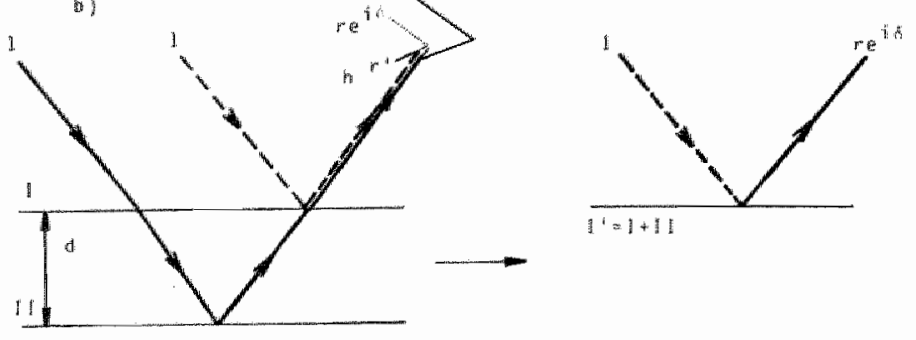

Fig. III.6 Schematic representation of reflection of light a) from cleam glass, b) from glass with one thin film and the equivalent reflection from a hypothetical medium.

In the theory of reflection of light from two films, the resultant anplitude $r_{2} e^{i \delta_{2}}$ can be calculated in two ways:

1. we first consider reflection from the upper film 1 . e. at the first two boundaries with basic amplitudes $r^{\prime}$ and $r^{\prime \prime} e^{-i x_{1}}$ ) and obtain the equivalent a boundary having basic amplitude $r * e^{-i\left(x_{1}+i x_{2}\right)}$.

This procedure can be schematically represented as follows:

$r^{\prime \prime} \longrightarrow r_{1} \mathrm{e}^{i \delta_{1}}$

$r^{\prime \prime \prime}$

$r_{2} e^{i \delta_{2}}$

It is shown graphically in fig. III.7a. 

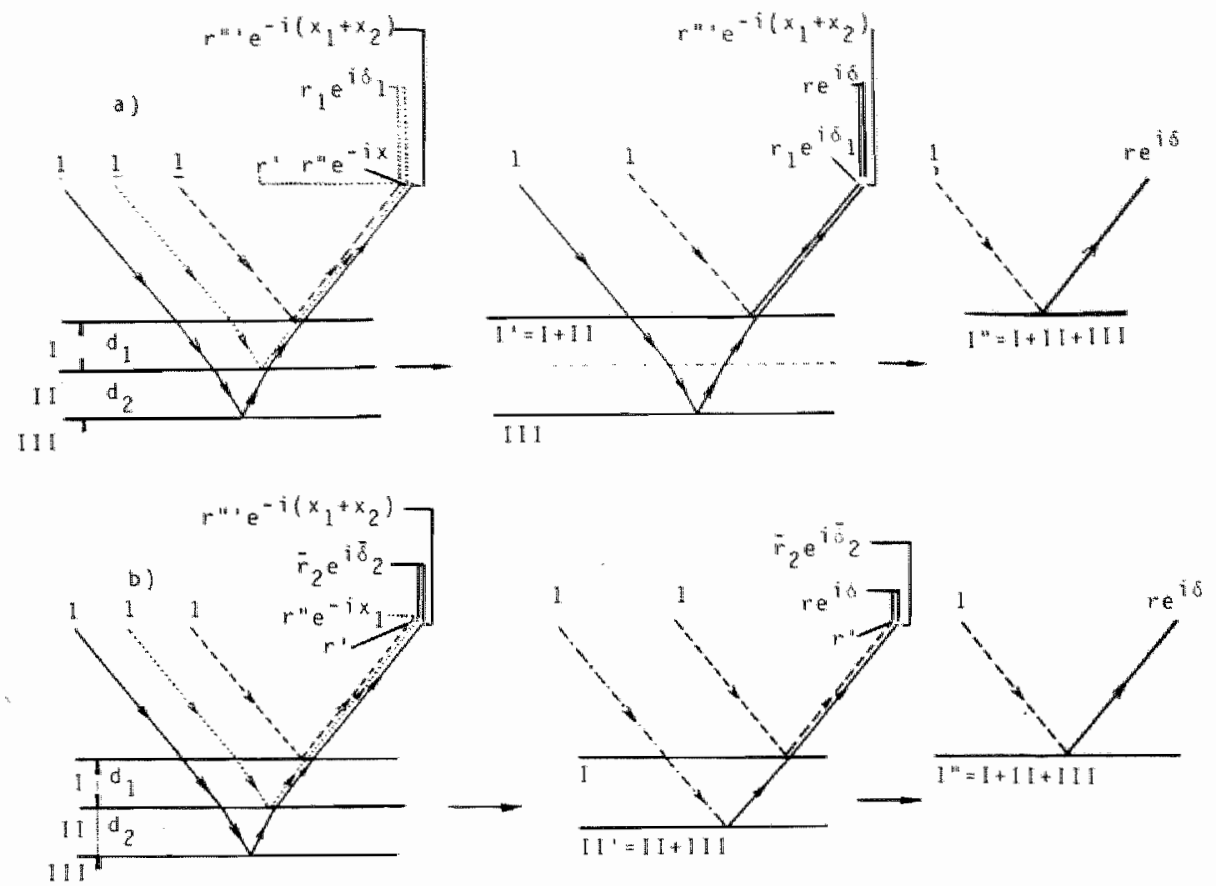

Fig. III.7 Schematic representation of reflection of 1 ight from two thin films on glass, the equivalent reflection from one thin film and the equivalent reflection from a hypothetical medium.

2. The second possible way of calculating the reflection of light from two thin films is by first calculating for the lower film (i.e. for the second and third boundaries with the basic amplitudes $r^{\prime e^{-i x_{1}}}$ and $r$ ' $e^{-\left(x_{1}+x_{2}\right)}$ ) and getting the equivalent amplitude $\dot{r}_{2} e^{1 \delta_{2}}$ to which we add the upper boundary with basic amplitude $r^{\prime}$. This procedure can be schematically written as follows

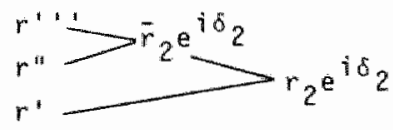

and is graphically represented in $f i g .7 \mathrm{~b}$.

For a system with an arbitrary number of parallel isotropic films the total reflection coefficients $R_{p}$ and $R_{s}$ are found by an iterative summation process (8). For the case of a surface covered with two layers the result is for both $p$ and $s$ components: 


$$
\begin{aligned}
& R=\frac{r_{1}+R^{\prime} \exp \left(-i x_{1}\right)}{1+r_{1} R^{\prime} \exp \left(-i x_{1}\right)} \\
& R^{\prime}=\frac{r_{11^{+r}} 111^{\exp \left(-i x_{2}\right)}}{1+r_{11^{r}} 111^{\exp \left(-i x_{2}\right)}}
\end{aligned}
$$

\subsection{Influence of very thin transitional films (approximated Drude theory)}

For Wery thin fllms ( $d_{1}<x$ ) Drude derived equations which numertcally represent the influence of thin transitional films which are spontaneously formed on the surface of metal for example by oxydation, on the measured optical quantities in reflected 1 ight, $i$.e. the azimuth $\psi$ and the phase difference $B$. If the quantities measured on the clean surface of metal (without a superficial film) are denoted and $t^{\text {" for }}$ an angle of incidence a $_{0}$ and the same quantities measured on the same metal hawing a thin superficial film and $\Delta$ and the layer thickness. is $L$, then Drudes formulae have the form:

$$
\begin{aligned}
& 2 \psi=2 \psi^{\prime}+\sin 2 \psi^{\prime \prime} \frac{4 \pi \cos \phi_{0} \sin ^{2} \phi^{a}}{x\left(\cos ^{2} \phi_{0}-a\right)^{2}+a^{2}} \int^{L}\left(1-n_{1}^{2} \cos ^{2} \phi_{0}\right)\left(1-\frac{1}{n_{i}^{2}}\right) d L \\
& \Delta=\Delta-\frac{4 \pi \cos \phi_{0} \sin ^{2} \phi_{0}\left(\cos ^{2} \phi_{0}-a\right)}{\lambda\left(\cos ^{2} \phi_{0}-a\right)^{2}+a^{2}} \int_{0}^{0}\left(1-\frac{d}{n_{1}^{2}}\right) d L \\
& \text { where } a=\frac{1-k^{2} / n^{2}}{n^{2}\left(1+k^{2} / n^{2}\right)^{2}} \quad a^{\prime}=\frac{2(k / n)}{n^{2}\left(1+k^{2} / n^{2}\right)^{2}}
\end{aligned}
$$

If a transitional file of thickness $d_{1}$ and refractive index $n_{1}$ is regarded as homogeneous, then the above equations can be written in the form

$\frac{2 \psi-2 \psi^{\prime}}{\sin 2 \psi^{\prime}}=\frac{4 \pi d_{1} \cos \phi_{0} \sin ^{2} \phi_{0} a^{\prime}}{\lambda\left(\cos ^{2} \phi_{0}-\pi\right)^{2}+a^{2}}\left(1-n_{1}{ }^{2} \cos ^{2} \phi_{0}\right)\left(1-\frac{1}{n^{2}}\right)$

$\Delta=\Delta=\frac{4 \pi a_{1} \cos \phi_{0} \sin ^{2} \phi_{0}\left(\cos ^{2} \phi_{0}-a\right)}{x\left(\cos ^{2} \phi_{0}-a\right)^{2}+a^{2}}\left(1-\frac{1}{n^{2}}\right)$ 
Tronstad generalized Drudes formulae for the case when the first medium is not air with refractive index 1, but has generally the refractive index $n_{0}$. The Tronstad-Drude formulae have the form (10, 10a)

$$
\begin{aligned}
& \Delta-\Delta^{\prime \prime}=-\frac{4 \pi d_{1} \cos \phi_{0} \sin ^{2} \omega_{0}\left(n_{1}^{2}-n_{0}^{2}\right)}{x\left(\cos ^{2} \phi_{0}-n_{0}^{2} a\right)^{2}+n_{0}^{4} a^{2}} \times \\
& x\left[\left(\cos ^{2} \phi_{0}-n^{2} a\right)\left(1 / n^{2}-a\right)+n_{0}^{2} a+2\right] \text {, } \\
& 2 \psi-2 \psi^{n}=\sin 2 \psi^{2} \frac{4 \pi d_{1} \cos \phi_{0} \sin ^{2} \phi_{0}\left(n_{1}^{2}-n_{0}^{2}\right)}{\lambda\left(\cos ^{2} \phi_{0}-n^{2} 0^{2}+n_{0}^{4} a^{2}\right.} x \\
& x\left[n_{1}^{2} a n\left(1 / n^{2}-a\right)-\left(\cos ^{2} \phi_{0}-n^{2} 0^{a}\right) a\right]
\end{aligned}
$$

The Tronstad-orude formulae are only valid for very thin films (d $<x$ ). These formulae can also be derived from the exact Drude equations by expanding the formulae according to the Taylor series.

3 Determimations of $\psi$ and $A$ from ellipsometer scale readings

\subsection{Introduction}

By equation 33) the reflection of 1 ight from a surface is characterized by the complex reflection coefficient tanwe ${ }^{i \Delta}$, and hemce by the two quamtities $\psi$ and $\Delta$. However, the determination of and $\Delta$ from polarizer and analyzer readings merits same discussion, for this is not always a perfectly direct matter.

For any given surface there is a multiplicity of polamizer, analyzer an compensator scale settings that produce extinction by the analyzer of the reflected light from the surface, and the problem rises of how to exactiy determine the values of and $_{\Delta}$ from these various readings. In order to explain how these numeraus readings arise and how be computed from them it is well to keep two facts in mind:

a. all azimuthal angles are measured positiwe counter-clockwise from the plane of incidence when looking into the ight beam, and

b. the compensator which may be set at any azimuth is generally set so that its fast axis is in an azimuth of $\# \pi / 4$. 
The presert discussion is for an instrumert with the compensator before reflection. If the compensator is placed after reflection, the reasoning has to be changed accordingly. The various readings fall into four sets called zones. two ith the fast axis of the compensator set at H/4, numbered 2 and 4 and two with it set at $-\pi / 4$, numbered 1 and 3 . In each sone there is one independent set of polarizer and analyzer readings, naking four independent sets of p and A readings in all. However, since both analyzer and polarizer may be rotated by $\pi$ without affecting the result, there are 16 polarizer and analyzer settings falling into four independent zones. Since the compensator may 150 be rotated by $\pi$ without affecting the results, there are 32 possible sets of readings on the ellipsometer. Rather than calculating a and if drectly from the $P^{\prime}$ and $A$ values, it is useful to calculate three other quantities, $p_{\text {, }} a_{p}$ and $a_{s}$ from the $P$ and $A$ values, $p$ befing related to the $P$ readings, a rellated to the $A$ readings in zones 1 and 4 , and a related to the $A$ readings in zones 2 and 3 .

3.2 The relationship of $p, a_{p}$, and $a_{s}$ to the $p$ and $A$ readingsobserved an the elipsometer

The relationship of $p$, $a_{p}$, and $a_{s}$ to the $P$ and $A$ readings observed on the ellipsometer is derived below.

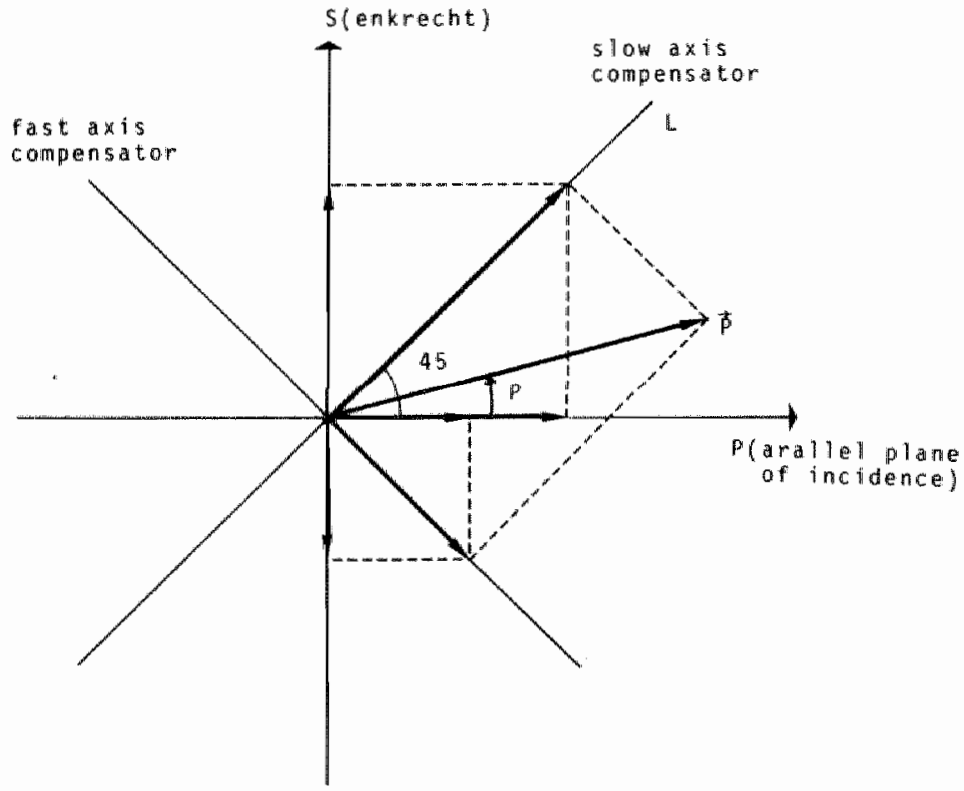

Fig. III.8 Schematic representation of the light beam, when standing between the sample and the compensator. 
In fig. III.3 we are standing between the compensator and the reflecting surface and we are looking into the beam. The slow axis of the compensator is fixed at $+45^{\circ}$. The components of the unit light vector $\vec{p}$ along the axis of the compensator are

F component: $-\sin \left(45^{\circ}-p\right)$

L component: $\cos \left(45^{\circ}-P\right)$.

After passing the compensator, the phase of the $L$ component is $\delta$ degrees behind the phase of the $F$ component.

$e^{-i b}=\cos \delta-i \sin \delta$

The compoments alang the $p$ and $s$ axis are now (fig. III.8):

$\bar{E}_{S} \dot{y}=-\sin \left(45^{\circ}-P\right) \cos 45^{\circ}+\cos \left(45^{\circ}-P\right) \sin 45^{\circ}(\cos \theta-i \sin \delta)$

( $F$ component) ( $L$ component)

$\overline{\mathrm{E}}_{\mathrm{p}}^{i}=\sin \left(45^{\circ}-p\right) \sin 45^{\circ}+\cos \left(45^{\circ}-P\right) \cos 45^{\circ}(\cos \delta-1 \sin \delta)$

$\left(\frac{E_{p}}{E_{S}}\right)^{(i)}=\frac{1+\cos \left(45^{\circ}-P\right) \cos \delta-i \cot \left(45^{\circ}-P\right) \sin \delta}{-1+\cot \left(45^{\circ}-P\right) \cos \delta-i \cot \left(45^{\circ}-P\right) \sin \delta}=$

$=\frac{\cot ^{2}\left(45^{\circ}-P\right)-1+2 i \cot \left(45^{\circ}-P\right) \sin \delta}{\cot ^{2}\left(45^{\circ}-P\right)+1-2 \cot \left(45^{\circ}-P\right) \cot \delta}$

We already defined eq. 32a)

$\Delta=\left(\delta_{p}-\delta_{s}\right)^{(r)}-\left(\delta_{p}-\delta_{s}\right)^{(i)}$

To have complete extinction, the light reaching the analyzer has to be planely polarized, so

$\left(\delta_{p}-\delta_{s}\right)^{(r)}=0 \rightarrow \Delta=-\left(\delta_{p}-\delta_{s}\right)^{(i)}$

We can say $\frac{\overline{\mathrm{E}}_{\mathrm{p}}}{\overline{\mathrm{E}}_{\mathrm{s}}}=\operatorname{tanLe} \mathrm{e}^{-i \Delta}$

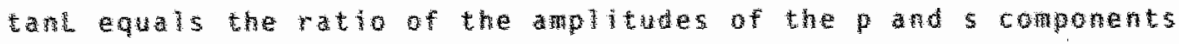
of the neident beam.

50 wheg. 42

$\frac{\cot ^{2}\left(45^{\circ}-p\right)-1+2+\cot \left(45^{\circ}-p\right) \sin }{\cot ^{2}\left(45^{0}-p\right)+1-2 \cot \left(45^{0}-p\right) \cos \theta}=\operatorname{con}\left(e^{-i \theta}\right.$ 
$\frac{\cot ^{2}\left(45^{\circ}-P\right)-1}{\cot ^{2}\left(45^{\circ}-P\right)+1-2 \cot \left(45^{\circ}-P\right) \cos \theta}=\tan \cos \theta=\frac{\cos \left(90^{\circ}-2 P\right)}{1-\sin \left(90^{\circ}-2 P\right) \cos 0^{\circ}}$
$\frac{2 \cot \left(45^{\circ}-P\right) \sin \delta}{\cot ^{2}\left(45^{\circ}-P\right)+1-2 \cot \left(45^{\circ}-P\right) \cos \theta}=-\tan \sin \Delta=\frac{\sin \left(90^{\circ}-2 P\right) \sin \delta}{1-\sin \left(90^{\circ}-2 P\right) \cos \theta}$

From eq. 44) en eq. 45) we get by division

$-\tan A=\sin \delta \tan \left(90^{\circ}-2 p\right)$

$50 \tan A=\sin 0 \tan \left(90^{\circ}+2 P\right)$

first zone

Squaring and adding eq. 44) and eq. 45) gives

$\tan ^{2} L=\frac{\cos ^{2}\left(90^{\circ}-2 P\right)+\sin ^{2}\left(90^{\circ}-2 P\right) \sin ^{2} \delta}{1+\sin ^{2}\left(90^{\circ}-2 P\right) \cos ^{2} \delta-2 \sin \left(90^{\circ}-2 P\right) \cos \delta}=$

$=\frac{1+\sin \left(90^{\circ}-2 P\right) \cos \theta}{1-\sin \left(90^{\circ}-2 P\right) \cos 6}$

$\rightarrow \sin \left(90^{\circ}-2 P\right) \cos \delta=\frac{\tan ^{2} L-1}{\tan ^{2} L+1}-\cos 2 L$

so $\cos 2 L=-\cos 1 \cos 2 P$

first zone

In the third zone the formulas are

$\tan \Delta=\operatorname{sind} \tan \left(90^{\circ}+2\left(90^{\circ}+P\right)\right)=\sin \delta \tan \left(90^{\circ}+2 \mathrm{P}\right)$ third zone

$\cos 2 L^{\prime}=-\cos \delta \cos 2\left(90^{\circ}+P\right)=\cos 6 \cos 2 P$

third zone

From formulas eq. 47 ) and eq. 49) it follows $\cos 2 L^{\prime}-\cos 2 \mathrm{~L}=\cos (180+2 \mathrm{~L}) * \mathrm{~L}^{\prime}=90+\mathrm{L}$

so $\operatorname{tanL} "=-\cot L$. 


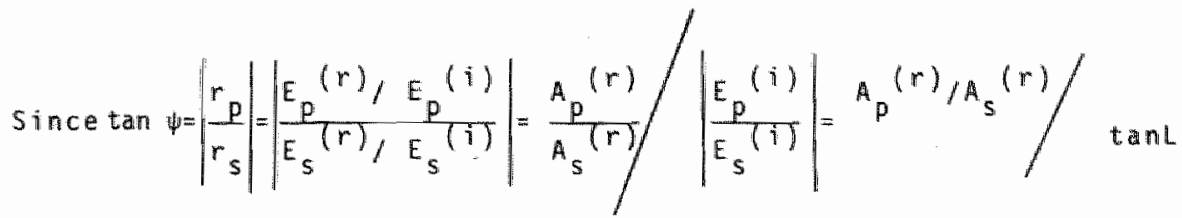

where $A_{p}$ and $A_{s}$ are the amplitudes of the reflected components (here we use the amplitudes because after reflection the light has to be plane polarized to have complete extinction.)

To obtain complete extinction, the analyzer setting has to be perpendicular to the plane of polarization. It is easy to see that

$\frac{A_{p}^{r}}{A_{s}}=\cot \left(90^{\circ}+A\right)$

that is why

$\tan \psi=\frac{\cot \left(90^{\circ}+A\right)}{\tan L}$

first zone $\tan \psi=\frac{\cot \left(90^{\circ}+A_{1}\right)}{\tan L}$

third zone $\left.\tan \psi=\frac{\cot \left(90^{\circ}+A_{3}\right)}{\operatorname{tanL} "}\right\}$ $\tan ^{2} \psi=-\tan A_{1} \tan A_{3}$

set $A_{3}=180^{\circ}-a s$ $A_{1}=a_{p}$

this gives $\tan ^{2} \psi=$ tana $\operatorname{tana}$

Second and fourth zones are obtained by changing the places of the fast and slow axis

$$
\begin{aligned}
& \left(\frac{E_{p}}{E_{s}}\right)^{(i)}=\frac{1+\cot \left(45^{\circ}-P\right) \cos \delta+i \cot \left(45^{\circ}-P\right) \sin \delta}{-1+\cot \left(45^{\circ}-P\right) \cos \delta+i \cot \left(45^{\circ}-P\right) \sin \delta}= \\
& =\frac{\cos \left(90^{\circ}-2 P\right)-i \sin \left(90^{\circ}-2 P\right) \sin \delta}{1-\sin \left(90^{\circ}-2 P\right) \cos \delta}=\operatorname{tanLe} e^{-i s}
\end{aligned}
$$


$\tan \Delta=\sin \tan \left(90^{\circ}-28\right)$

$$
=\sin \theta \tan \left(90^{\circ}-2\left(90^{\circ}+\mathrm{P}\right)\right)
$$

$\tan ^{2} L=\frac{\cos ^{2}\left(90^{\circ}-2 P\right)+\sin ^{2}\left(90^{\circ}-2 p\right) \sin ^{2} \sin }{\left(1-\sin \left(90^{\circ}-2 P\right) \cos \right)^{2}}$

$\cos 2 L=\cos t \cos 2 \theta$

$\cos 2 L=\cos 8 \cos 2 P$ second zone

fourth zone

These calculations can also be done for the second, third, and fourth quadrant. In this way we get 16 possible combinations for extinction.

The relations for the different quadrants are sumarized in the next table; with this table we determine $p$, $a_{5}$, and a from the polarizer and andlyzer settings $P$ and $A$. The introduction of the small "p" in the table is for the simplification of the relation. The formulas eq. 52) and eq. 53) give the relations between $\psi, \Delta$, and $p$, a ${ }_{s}$, and $a_{p}$. If the compensator is exactly quarterwavelength then we have $s=90^{\circ}$, this gives:

$\Delta=\frac{1}{2} \pi+2 \mathrm{p}$

$\psi=a_{p}=a_{s}$

\begin{tabular}{|c|c|c|c|}
\hline zone & compensator & $\mathrm{P}$ & A \\
\hline \multirow[t]{4}{*}{1} & $-\pi / 4$ & $\mathrm{p}$ & $a_{p}$ \\
\hline & & $p+\pi$ & $a_{p}$ \\
\hline & & $\mathrm{p}$ & $a_{p}+\pi$ \\
\hline & & $p+\pi$ & $a_{p}+\pi$ \\
\hline \multirow[t]{4}{*}{3} & $-\pi / 4$ & $p+\pi / 2$ & $\pi-a_{5}$ \\
\hline & & $p+3 \pi / 2$ & $\pi-a_{s}$ \\
\hline & & $p+\pi / 2$ & $2 \pi-a_{5}$ \\
\hline & & $p+3 \pi / 2$ & $\pi-a x_{S}$ \\
\hline \multirow[t]{4}{*}{2} & $+\pi / 4$ & $\pi / 2-p$ & $a_{s}$ \\
\hline & & $3 \pi / 2-p$ & $a_{5}$ \\
\hline & & $\pi / 2-p$ & $a_{s}+\pi$ \\
\hline & & $\pi / 2-p$ & $a_{5}+\pi$ \\
\hline \multirow[t]{4}{*}{4} & $+\pi / 4$ & $\pi-p$ & $\pi-a_{p}$ \\
\hline & & $2 \pi-p$ & $\pi-a p$ \\
\hline & & $\pi-p$ & $2 \pi-a_{p}$ \\
\hline & & $2 \pi-p$ & $2 \pi-a_{p}$ \\
\hline
\end{tabular}


Exact compensator

Non-exact compensator
1) $4=1 \pi+2 \mathrm{p}$

2) $w=a_{p}=a_{s}$

1) $\tan \Delta=\operatorname{sind} \tan \left(90^{\circ}+2 \mathrm{P}\right)$

2) $\cos 2 L=-\cos 6 \cos 2 P$

3) $\tan ^{2} \psi=+\tan a_{p} \operatorname{tana}_{s}$

4) $\tan ^{2} L=\operatorname{tana} \operatorname{cota}_{s}$

The meanings of $p_{,} a_{p}$, and $a_{s}$ in the four zones are as follows:

Zone 1: The fast axis of the compensator is set at $-\pi / 4$. The polarizer plame of transmissiom makes an angle of tp with the plane of incidence. The analyzer plane of transmission makes of angle of $+a_{p}$ with the plane of incidence.

Lone 2: The fast axis of the compensator is set at +m/4. The polarizer plane of transmission makes an angle of $-p$ with the surface (an angle of $\pi / 2-p$ with the plane of incidence). The analyzer plane of transmission makes an angle of tas with the plane of incidence.

Zone 3: The fast axis of the compensator is set at - I/4. The polarizer plane of transmission makes an angle of tp with the surface (an angle of $p+w / 2$ with the plane of incidence). The analyzer plane of transmission makes an angle of $-a_{s}$ with the plane of incidence.

zone 4: The fast axis of the compensator is set at +7/4. The polarizer plane of transmission makes an angle of $-p$ with the plane of incidence. The amalyzer plane of transmission makes an angle of - $a_{p}$ with the plane of incidence.

The meanings of $p$, a and $a_{s}$ are now clear. The first is the angle between the polarizer plane of tramsmission and either the plane of incidence or the plane of the surface, while ap and a represent the angle between the analyzer plane of transmission and the plane of incidence, being labeled either $a_{p}$ or $a_{s}$ according to whether $p$ is the angle between the polarizer plane of transmission and the plane of incidence or the plane of the surface, respectively.

In practice, the values of $p, a_{p}$, and $a_{s}$ found from the $p$ and $A$ readings in the various zones are not identical. Mc. Crackin et a 1. (11) pointed out the discrepancy and suggested a simple avering technique to adjust experimental data. They show that the average of the observed vallue of $p$ in zones 1 and 3 is the same as the average of the value obtained in zones 2 and 4 . The source of this discrepancy is explained by Archer et al. (12) who show that the deviation is due to a difference of trams- 
mitance for components of the polarized light with electric wectors caincldent with the fast and slow axes of the quarter wave plates.

Influaces of non-ideal polarizer, compensator and analyzer on the measurements are treated thoroughiy by W.R.Hunter et al. (13) and many others $(14-21)$.

4 Determination of $n$ and $k$ on a clean surface

If the surface is not covered with a thin film we can simplify the Drude equations. In this case $d_{1}=0, n_{2}$ and $k_{2}$ are unknown.

$\operatorname{tg} \psi \mathrm{e}^{\Delta 1}=\frac{\bar{R}_{p}}{\tilde{R}_{s}} \rightarrow \frac{1-t g \psi e^{i \Delta}}{1+t g \psi e^{i \Delta}}=\frac{R_{s}-R_{p}}{R_{s}+R_{p}}=$

according to eq. 24) and eq. 25)

$\frac{\left(n_{0} \cos \phi_{0}-\bar{n}_{1} \cos \phi_{1}\right)\left(\bar{n}_{1} \cos \phi_{0}-n_{0} \cos \phi_{1}\right)-\left(n_{0} \cos \phi_{0}+\bar{n}_{1} \cos \phi_{1}\right)\left(n_{1} \cos \phi_{1}-n_{0} \cos \phi_{1}\right)}{\left(n_{0} \cos \phi_{0}-\bar{n}_{1} \cos \phi_{1}\right)\left(\bar{n}_{1} \cos \phi_{0}+n_{0} \cos \phi_{1}\right)+\left(n_{0} \cos \phi_{0}+n_{1} \cos \phi_{1}\right)\left(\bar{n}_{1} \cos \phi_{0}-n_{0} \cos \phi_{1}\right)}=$

$=\frac{n_{0}{ }^{2} \cos \phi_{0} \cos \phi_{1}-\bar{n}_{1}{ }^{2} \cos \phi_{0} \cos \phi_{1}}{n_{0} \bar{n}_{1} \cos ^{2} \phi_{0}-n_{0} \bar{n}_{1} \cos ^{2} \phi_{1}}$

Snellius $\rightarrow \cos \phi_{1}=\frac{1}{\bar{n}_{1}} \sqrt{\bar{n}_{1}^{2}-n_{0}{ }^{2} \sin ^{2} \phi_{0}}$

$\left.\begin{array}{l}=\frac{\cos \phi_{0} \sqrt{n_{1}^{2}-n_{0}^{2} \sin ^{2} \phi_{0}}}{n_{0} \sin ^{2} \phi_{0}} \\ \vec{n}_{1}=n_{1}-i k_{1}\end{array}\right\} \rightarrow=\frac{\sqrt{n_{1}^{2}-k_{1}{ }^{2}-n_{0}^{2} \sin ^{2} \phi_{0}-2 i n_{1} k_{1}}}{n_{0}{ }^{2} g^{2} \phi_{0} \sin ^{2} \phi_{0}}$

$=\sqrt{\frac{h_{1}^{2}-k_{1}^{2}-n_{0}^{2} \sin ^{2} \phi_{0}-\sin k_{1}}{n_{0}^{2} \operatorname{tg}^{2} \phi_{0} \sin ^{2} \phi_{0}}}=\frac{1-\operatorname{tg} \psi \cos \Delta-i \operatorname{tg} \psi \sin \Delta}{1+\operatorname{tg} \psi \cos \Delta+i \operatorname{tg} \psi \sin \Delta}=$

$\frac{1-\operatorname{tg}^{2} \psi-2 i \operatorname{tg} \psi \sin \Delta}{1+\operatorname{tg}^{2} \psi+2 \operatorname{tg} \psi \cos \Delta}=\frac{\cos 2 \psi-i \sin ^{2} \psi \sin \Delta}{1+\sin ^{2} \psi \cos \omega}$ 
Separation of the real and imaginary part gives

$n_{1}^{2}-k_{1}^{2}-n_{0}^{2} \sin ^{2} \psi_{0}=n_{0}^{2} t g^{2} \phi_{0} \sin ^{2} \frac{\cos ^{2} 2 \psi-\sin ^{2} 2 \psi \sin ^{2} \Delta}{(1+\sin 2 \psi \cos \Delta)^{2}}$

$2 n_{1} k_{1}=m_{0}^{2} \operatorname{tg}^{2} \phi_{0} \sin ^{2} \frac{2 \cos 2 \phi \sin 2 \psi \sin A}{\left(1+\sin ^{2} \psi \cos \Delta\right)^{2}}$

If we measure in air $n_{a}=1$

we get

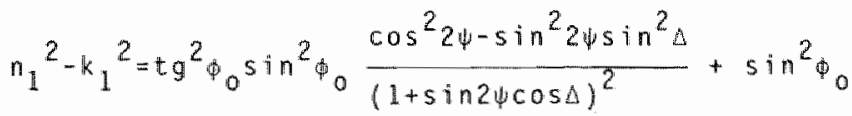

$2 n_{1} k_{1}=\operatorname{tg}^{2} \sin _{0}^{2} \frac{2 \cos 2 \psi \sin 2 \psi \sin \Delta}{(1+\sin 2 \psi \cos \Delta)^{2}}$

For the calculation of the numerical values see the computer fortinan program Virgin (Chapter IV).

5. Ellipsometric theories in the submonolayer range

\section{Introduction}

Apart from considering the thin layer as homogeneous the optical behaviour of thin films may be considered from another viewpoint. From studies an the structure of the films formed by mast avaliable methods it is found that films generally consist of aggregates of crystallites of variabie size and orientation and with different extent of accupation. Description of the optical behaviour of such a system is essentially a scattering problem. One can ask the question of how much of optical theory is applicable to this situation.

A number of measurements in the manolayer range has been reported. The adsarption of relatively long polar organic molecules, tagged with ${ }^{14} \mathrm{C}(22,23)$ or tritiun (24) on metal substrates was studied simultaneously using ellipsometry and radiotracer methods. The measurements showed at least qualitatively a linear mellationship between optical and radiochemical readings, suggesting that the ellipsometric signal is proportional to the amount adsorbed even for films with an incomplete cover. Hayfield and white (25) used controlled vacuum evaporations of calcium fluoride on aluminum and metal oxide surfaces to obtain non-uniform (partly) covered surfaces. They found that the 
change in ellipticity followed the average thickmess of the film. Clasem and Archer determined ellipsometric adsarption isothems (ellipsometric effect versus pressure) at room temperature for water and a nuber of small arganic molecules on variousily treated siticon surfaces $(26,27)$.

In their interpretation of the data both authors assume that the values of the "index of refraction" of the adsorbed layers are constant and equal to those of the corresponding bulk liquid phases. They found that in most cases the ellipsometric thickness of the monolayer was smaller than the molecular diameter of the adsorbed malecules. Archer ascribed this partly to duferences in reactivity of the surfaces and partly to surface irregularities on an atcomic scale whereas clausen preferred the first explamation, implying a non-complete cower of the surface and thus a lower walue of the "index of refraction".

The interpretation of the ellipsometric measurements in the (sub) monolayer range is not yet clear. Within the scope of a three-dimensional madel in which the layer is characterized by the macroscopic parameters. of an index of refraction (n) and a thickness (d) one usually assumes that an incomplete monolayer in which only the fraction of the possible sites is occupied behaves like a continuous filn ( $n$ constant) of effective thickmess $d_{m}\left(d_{m}\right.$ idiameter of the molecules). The proportionality between ellipsometric effect and then follows inmediately from the appraximate Drude equations. Another possibility is that the thickness (d $d_{m}$ ) is constant and that the index of refraction varies with $\theta$. In general, this no longer implites a linear rellationship between ellipsometrïc effect and $\theta$.

According to Hall (28) one would expect the ellipticity to wary as the square root of the fractional cover.

5.2 Short review of the ellipsometer thearies $(29,30,35)$

In this section I shall give a short review of the ellipsometer theories, especially with regard to the subnonolayer range. The following subjects will be treated:

1. General equations (macroscopic theory).

2. Approximation used in the macroscopic theory.

3. Some theories in the submonolayer range.

4. Some theories of inhomogemeous films. 
5.2 .1 General equations

We already found that upon reflection there is generally a change both in the amplitudes A and the phases of the twa components $E_{p}=A_{p} \exp \left(i s_{p}\right)$ and $E_{s}=A_{s} \exp \left(i \delta_{s}\right)$.

This change was described by the two angles 4 and $\Delta$ defimed as eq. $32 a)$.

$$
\Delta=\left(\delta_{p}(s)_{-\delta_{s}}(s)\right)-\left(\delta_{p}(i)_{-\delta_{s}}(i)\right.
$$

$\tan \psi=\frac{A_{p}(r) / A_{s}(r)}{A_{p}(i) / A_{s}(i)}$

The total effect upon refiection summarized in equation 32):

$\frac{\overline{\mathrm{R}}_{\mathrm{P}}}{\overline{\mathrm{R}}_{\mathrm{S}}}=\frac{\overline{\mathrm{E}}_{\mathrm{p}}(r) / \overline{\mathrm{E}}_{\mathrm{p}}(\mathrm{i})}{\overline{\mathrm{E}}_{\mathrm{S}}(r) / \overline{\mathrm{E}}(\mathrm{T})}=\tan \psi \mathrm{e}^{i \Delta}$

Here $R_{p}$ and $R_{s}$ are the amplitude reflection coefficients wich we wil use for a reflecting system in general and $r_{p}$ and $r_{s}$ for one interphase. Three speciall cases of the exact Drude theory will be given now.

5.2.1a clean surface (Fig.111.9a)

For the clean surface the amplitude reflection coefficients take the form of the Fresnel coefficients:

$r_{p}=\frac{\bar{n}_{1} \cos \phi_{0}-n_{0} \cos \bar{\phi}_{1}}{\bar{n}_{1} \cos \phi_{0}+n_{0} \cos \bar{\phi}_{1}} \quad$ and $\quad r_{s}=\frac{n_{0} \cos \phi_{0}-\tilde{n}_{1} \cos \bar{\phi}_{1}}{n_{0} \cos \phi_{0}+\bar{n}_{1} \cos \bar{\phi}_{1}}$

with $n_{0} \sin \phi_{0}=\bar{n}_{1} \sin \bar{x}_{1}$

and $\bar{n}_{1}=n_{1}-1 k_{1}$

In this case the measurement of $\psi$ and $\triangle$ yields the real and imaginary parts, $n_{1}$ and $k_{1}$ of the index of refraction of the substrate (eq. 56 ) and 57)).

5.2. Ib Surface covered with one layer (fig. III.9b)

If a film is present on the surface, multiple reflections will occur within the fllm which for both components lead to extra phase differences. For ane passage these are equal to 
$\left.x_{1}=\frac{4 \pi}{\lambda} m_{1} d_{1} \cos \phi_{1} \quad(e q .27)\right)$

The total reflection coefficients are derived directly and they are $(e q .30), 31)$

$R_{p} \frac{r_{1}+r_{2} \exp \left(-i x_{1}\right)}{1+r_{1} r_{2} \exp \left(-i x_{1}\right)} \quad$ and $\quad R_{s}=\frac{r_{1}+r_{2} \exp \left(-i x_{1}\right)}{1+r_{1} r_{2} \exp \left(-i x_{1}\right)}$

where ${ }_{1}$ denotes the Fresnel coefficient for boundary 1 etc.

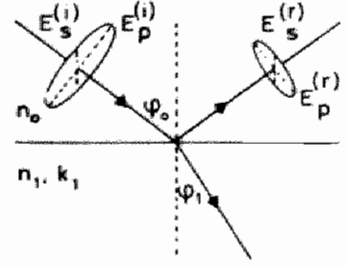

0.

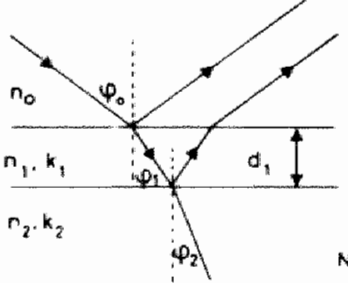

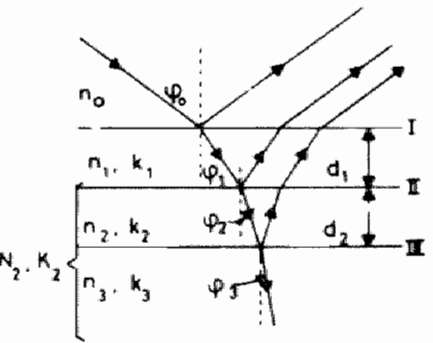

$\epsilon$

Fig. III.9 Schematic representation af the reflection of polarized $1 \mathrm{ight}$
a: clean surface
b: surface cavered with one layer
c: surface cavered with two layers.

5.2.1c Surface covered with several layers (fig.III.9c)

Far a system with an arbitrary number of parallel isotropic films the totall reflection coefficlents $R_{p}$ and $R_{s}$ are found by an iterative summation process as described by croak (8). For the case of fig. III. $9 \mathrm{c}$ the result is, for both $p$ and $s$ components: 


$$
\begin{aligned}
& R=\frac{r_{1}+R^{\prime} \exp \left(-i x_{1}\right)}{1+r_{1} R^{\prime} \exp \left(-i x_{1}\right)} \\
& R^{\prime}=\frac{r_{2}+r_{3} \exp \left(-i x_{2}\right)}{1+r_{2} r_{3} \exp \left(-i x_{2}\right)}
\end{aligned}
$$

For the computation we make use of a fortran program called Elli2, kC, $C A$, written far a PDP-8 computer. With this program we can calculate values of $\Delta$ and $\psi$ for every desired combination of $\lambda_{\text {. }}{ }_{0}$, and the optical parameters of the reflecting system.

It is also passible to give an explicite expression of the orude equation in d. The procedure ta invert the Orude equation is given in $5.2 .1 d$. 5.2.1d Inversion of Drudes exact ellipsometric equation (43)

The formula of 5.2 . Ic can be written as follows:

$$
p \equiv \tan \psi e^{i}=\left[\frac{r_{p}+r_{2} e^{-2 i \delta}}{1+r_{1} r_{2} e^{-2 i \delta}}\right]\left[\frac{1+r_{1} r_{2}-2 i \delta}{r_{1}+r_{2} e^{-2 i \delta}}\right] \text {, }
$$

where the Fresnel reflection coefficients are given by:

$$
\begin{gathered}
r_{j p}=\frac{n_{j+1} \cos \phi_{j}-n_{j} \cos \phi_{j+1}}{n_{j+1} \cos \phi_{j}+n_{j} \cos \phi_{j+1}} \\
r_{j s}=\frac{n_{j} \cos \phi_{j}-n_{j+1} \cos \phi_{j+1}}{n_{j} \cos \phi_{j}+n_{j+1} \cos \phi_{j+1}}
\end{gathered}
$$

where $j$ denotes interphases 1 or 2 between media $n_{0}$ ard $n_{1}$ or media $m_{1}$ and $n_{2}$, respectively.

Let us rewrite the fundamental equation of ellipsometry into a form suitable far the present numerical method. Let $n=e^{-21}$ 
then the fundamental equation can be expressed as:

$$
\left.\rho\left[r_{1}+r_{1} r_{1} r_{2}+r_{2}\right) r+r_{1} r_{2} r_{2} r_{s}{ }^{2}\right]=r_{1}+\left(r_{1} r_{1} r_{2}+r_{2}\right) r+r_{1} r_{2} r_{2} n^{2}
$$

or inore simpily as

$$
A n^{2}+B n+C=0
$$

where:

$$
\begin{aligned}
& A=\left(\rho r_{1}-r_{1}\right) r_{2} r_{p} 2_{s} \\
& B=r_{1} r_{1}\left(\rho r_{2}-r_{2}\right)+\left(\rho_{r_{2}}-r_{2_{p}}\right) \\
& C=\rho r_{1}+r_{1}
\end{aligned}
$$

The solutions of the quadratic equation are simply:

$$
n=\left[-B+\left(B^{2}-4 A C\right)\right] / 2 A
$$

Substitution of the Fresnel coefficients give

$$
d=(\lambda / 4 \pi)\left[i \ln n /\left(n_{1}^{2}-n_{0}^{2} \sin ^{2} \phi_{0}\right)^{\frac{1}{2}}\right]
$$

Because the left-hand side of the above equation is real and that of the right hand side is complex, the above complex equation can be written as

$$
\begin{gathered}
d=\left[\lambda / 4 \pi\left(n_{1}^{2}-n_{0}^{2} \sin ^{2} \phi_{0}\right)^{\frac{1}{2}}\right] \text { Re }(11 n n) \\
\operatorname{Im}\left(11 n r_{i}\right\}=0
\end{gathered}
$$

where Re and Im denote real and imaginary parts respectively of the quantity in the \{\} brackets. $n$ is a function of $\phi, \Delta, 4, n_{0}, n_{1}, n_{2}$. Because $\lambda, \phi, n_{0}, \Delta$, and $\psi$ are known from the experimental measurements the filn thickness is a function of three unknown optical parameters $n_{1}$. $n_{2}$, and $k_{2}$ only. This function can numerically be calculated by standard procedures. 


\subsubsection{Appraximations (macroscopic theory)}

Although the computer permits the use of exact equations, approximations are sometimes preferred for reasons of clarity and comparison.

b.2.2a Approximated Drude equations for thin fillms $(50-100 R)$

(Fig. III.9b) $(4,5,10,31,33)$

When a very thin film $d_{1}<\alpha$ is present an a clean substrate (characterized by $\bar{A}$ and $\bar{\psi}$ : one gets from equation 33 ) wsing the approximations $e^{i x}=1-i x \quad 1 / 1-i x=1+i x$ for $n_{0}=1$ and $k_{1}=0$

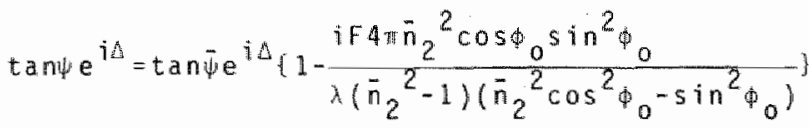

The parameter $F$ cantains the information about the layer $\left(d_{1}, n_{1}\right)$ and is given in table 1 (first column).

\begin{tabular}{|c|c|c|c|}
\hline & Drude & Stracham & Siv vukh in \\
\hline$F$ & $d_{1}\left(n_{1}^{2}-1\right)\left(\frac{1}{n_{1}}-\frac{1}{\bar{n}_{2}{ }^{2}}\right)$ & $4 \pi\left(x_{z}-\frac{\pi x}{\pi_{2}^{2}}\right)$ & $\left(\gamma_{2}-\gamma_{x}\right)\left(1-\frac{1}{\bar{n}_{2}}\right)$ \\
\hline L & $d_{1}\left(n_{1}^{2}-1\right)\left(\frac{1}{n_{1}^{2}}-a_{2}\right)$ & $4 \pi\left(T z^{-T} x^{a} z_{2}\right)$ & $\left(\gamma_{2}-\gamma_{x}\right)\left(1-a_{2}\right)$ \\
\hline M & $d_{1}\left(n_{1}^{2}-1\right)$ & $4 \pi T^{\top} Z$ & $\left(\gamma_{2}-y_{x}\right)$ \\
\hline
\end{tabular}

Table III.I Expressions for the parameters $F, L$, and $M$ in equations 58). 59), and 60) for the Drude, Strachan and sivukhin madels.

Separating the real and imaginary parts at both sites of equation (58) gives with intraduction of: 
$B \Delta=\ddot{\Delta}-\Delta$

$$
\delta \psi \bar{\psi} \bar{\psi}-\psi
$$

The expressions for $\delta \Delta$ and sit read:

$$
\begin{aligned}
& \delta \Delta=4 \pi \cos \phi_{0} \sin ^{2} \phi_{0} \quad x \\
& \times \frac{L\left\{\cos ^{2} \phi_{0}-a_{2}+\sin ^{2} \phi_{0}\left(a_{2}{ }^{2}-a_{2}{ }^{2}\right)\right\}+m_{a}{ }^{2}\left(1-2 a_{2} \sin ^{2} \phi_{0}\right)}{\lambda\left[\left[\cos ^{2} \phi_{0} a_{2}+\sin ^{2} \phi_{0}\left(a_{2}{ }^{2}-a^{\prime}{ }^{2}\right)\right)^{2}+a_{2}{ }^{2}\left(1-2 a_{2} \sin ^{2} \phi_{0}\right)^{2}\right]}
\end{aligned}
$$

and

$$
\begin{aligned}
& B \psi=-2 \pi \cos \phi_{0} \sin ^{2} \phi_{0} \sin 2 \bar{\psi} a_{2} \quad x \\
& \times \frac{L\left(1-2 a_{2} \sin ^{2} \phi_{0}\right)-i n\left(\cos ^{2} \phi_{0}-a_{2}+\sin ^{2} \phi_{0}\left(a_{2}^{2}-a_{2}^{2}\right)\right)}{\left(\left[\left(\cos ^{2} \phi_{0}-a_{2}+\sin ^{2} \phi_{0}\left(a_{2}^{2}-a^{2} 2^{2}\right)\right)^{2}+a_{2}^{2}\left(1-2 a_{2} \sin ^{2} \phi_{0}\right)^{2}\right)\right.}
\end{aligned}
$$

where $a_{2}=\frac{1-k_{2}{ }^{2} / n_{2}{ }^{2}}{n_{2}{ }^{2}\left(1+k_{2}{ }^{2} / n_{2}{ }^{2}\right)^{2}}$

and $a_{2}=\frac{2 k_{2} / n_{2}}{n_{2}{ }^{2}\left(1+k_{2}{ }^{2} / n_{2}{ }^{2}\right)^{2}}$

The expressians for the parameters $L$ and $M$ are given in the first column of table III.1. It should be noted that values of $\delta 4$ calculated with (59) and (60) can deviate already considerably from the exact vallues for thickmesses of less than $10 \AA(32,33)$.

\section{2 .2 b Multiple film systems (Fig. III.9c)}

For very thin fillms (total thickness $\leqslant 50-100 \&$ ) the change due to any $f 11 \mathrm{~m}$ is the same as that which wowld occur if the film were present as a single layer (27).

Mertens et al. (34) proposed a method of accounting for the presence of the first layer on the substirate by calculating the apparent optical 
constants ( $\mathrm{N}_{2}$ and $\mathrm{K}_{2}$ ) of substrate and layer from the measured $\Delta$ and * values (at $d_{1}=0$ ). The effect of the following layer is them calculated with these optical parameters.

This method was checked by C.A. Bootsma and F. Heyer (35) who used the method of crook (B). The differences between their wallues and those obtained with the Mertens methad were never more than 3 .

\subsubsection{Theories for the submonolayer range}

5.2.3a Extrapolated macroscopic theory (Drude model).

The optical properties of a system consisting of a large number of spherical metal particles of a diameter that is small compared to the wavelength of the light used and embedded in a dielectric medium were investigated in 1904-1906 by J.C.Maxwell Garmet (36). In the light of the results of structure examinations of thin films it is clear. that the thin film appraximates better the system considered by Maxwe $\mathbb{1}$ Garnet than to a parallel-sided homogeneous $s 1$ ab of bulk metal. The proposed model envisaging spherical partictes possessing properties identical to those of the bulk metal is a considerable simplification of the real thing; the agreement between the predictions af the simplie theory and the experimental results, although in same instances not quantitatively impressive, is sufficient to demonstrate the essential correctness of this approach to the problem (37). When an electromagnetic wave traverses such a system, the spherical crystallites will be polarized by the electric field $E$ of the wave and will thus produce an additional field $E_{S}$. This field may be callculated in precisely the way in which the polarization field in a dielectric is calculated. In this model we can use the Lorentz relation:

$$
E=E+\frac{4 \pi P}{3}
$$

for the effective local field $E^{e}$ at an atom. In this case one can obtain the wellknown Clausius Mosotti relation (Born) (2)

$$
\frac{E-1}{E+2}=\frac{4 \pi a}{3 a^{3}}
$$

where $e$ is the dielectric constant, a is the atomic polarizability and $a^{3}$ is the atomic volume. If the Maxwell relation $n=\sqrt{\varepsilon}$ it is used, 
and sume $\mu=1$, we get $\varepsilon=n^{2}$, so

$$
\frac{n^{2}-1}{n^{2}+2}=\frac{4 \pi a}{3 a^{3}}
$$

known as the Lorenz-Lorentz equation (Barn). This relation is seen to be bijge which connects atomic theory of matter. Extrapolation of this equation to a monolayer with formal index of refraction $n_{\text {m }}$ occupied by molecules with diameter $d_{m}$ and cross-section $c_{m}$ gives

$$
\frac{n^{2}-1}{n^{2}+2}=\frac{4 \pi}{3} \quad \frac{a}{d m^{c} m}
$$

The subscript $m$ is used for parameters characteristic for the complete monolayer. For a further extrapolation into the submonolayer range, in which only the fraction $0<1$ of the possible sites is occupied, we consider the following possibilities:

1. constant index of refraction $\left(m_{m}\right)$ varying average thickness (d $\left.{ }_{m}^{\theta}\right)$. Here eq. 62) is no longer valid for $\theta<1$.

2. Varying index of refraction $(n \theta)$, constant thickness $\left(d_{m}\right)$.

In both cases the dependence of $\delta \Delta$ and $\$ \psi$ on $a$ is again described by the equations eq. 59) and eq. 60). In case 1. one has to replace d, by $d_{m} \theta$ and $n_{1}$ by $n_{m}$ in $L$ and $M$ of Table III.1. In case 2 . on the assumption of the validity of eq. 61) for the sub-monolayer range too, one gets upon replacing $c_{\text {m }}$ by $c_{m} r^{\theta}$ in eq. 63 ).

$$
\frac{m_{\theta}^{2}-1}{n_{\theta}^{2}+2}=\frac{n_{m}^{2}-1}{n_{m}^{2}+2}
$$

In $L$ and $M$ thickness $d_{1}$ has to be replaced by $d_{\text {m }}$ and $n_{1}$ by $n_{\theta}$. The relationship between $\delta A$ and $\theta$ can be derived from equations 59 ) and 64):

Schopper (37) modifled this Maxwe11 Garnet theory by the assumption of ellipsoidal particles instead of spherical particles. This theory gives in the case of goldfilms even better agreement with the experimental results.

Another suggestion for the dependence of $\delta \Delta$ on $\theta$ in the submonolayer 
range was given by $H a 11$ (28) by assuming that an incomplete monolayer scatters incoherently, we propases that the ellipsometric signals vary as the square root of coverage.

5.2.3b Quasi microscopic theary (strachan's model) (38)

In treating the optical effect of submonolayers a physically more appropriate model is that of a two-dimensional distribution of Hertzian oscillators. In Strachan's model the film is characterized by the scattering indices ${ }^{x} x$, $\tau y$ and $z$ in the three directions $x, y$ lboth parallel to the surface) and $z$ (normal to the surface). These indices are defined as proportionality factors between the $x, y$, and $z$ components of the oscillator strength per unit surface area and the camponents of the total electric field. According to strachan an element dS of the surface becomes a Hertzian oscilllator of strengths $d 5\left(\tau_{x} A_{x}\right.$ " $\left.{ }^{\top} y^{A}{ }_{y},{ }^{\prime} z_{z}{ }^{A}\right)(65)$. By correcting for the field produced by the oscillatiors on both sides af the surface, new boundary conditions are found, from which by keeping anly first order terms strachan derives the Fresnel coefficients $R_{p}$ and $\mathbb{R}_{s}$. From these expressions we get for $R_{p} / R_{s}, 8 d$ and swequations. 32 ), 59), and 60) withi $F, L$, and $M$ as given in the second colum of table III.I for $\pi_{x}{ }^{=\tau} y$. Strachan's theory is of a quasi-microscopic nature. strachan does not give a microscopic interpretation of the $T^{\prime} s$ in tems of structure and malecular polarizabilities. In cases of low oscillatom strengths per unit area, where the influence of the dipole fields of the ather adsorbed molecules can be neglected, one can identify the $t$ with polarizability per surface area

$$
\tau_{i}=a_{i} / c \quad i=x, y, z
$$

This is equiwalent to a linear dependence of $\pi$ on cowerage $\theta$, and therefore implies also a linear relationship between $\delta \Delta$ and $\theta$. For migher oscillator strengths relation eq. 66) may no longer be used. $5.2 .3 c$ Microscopic theory (Sivukhin's model) $(39,40$ )

Using the results of earlier calculations by Ewald, Sivukhin allso derived expressions for $R_{p}$ and $\mathbb{R}_{s}$. In his theory the transtion layer at the surface is characterized by the parameters $\gamma_{x}$. $y$ (parallel to the surface) and $\gamma_{2}$ (normal to the surface). These parameters are defined a 5

$$
Y_{i}=\frac{T_{i}}{P_{i}} \quad i=x, y, z
$$


Here $\tau$ is the dipole moment induced in the transition layer per unit surface area and the polarization vector of the homogeneous substrate. The resulting expressions for $\mathbb{R}_{\mathrm{p}} / \mathbb{R}_{\mathrm{s}}$ and also for bu and $\mathrm{d}_{\mathrm{H}}$ are again given by eq. 32), eq. 59) and eq. 60) with $F, L$, and 4 as given in the third collum of table 1 (for $\left.\gamma_{x}=y\right)$.

By electrostatic calculations sivukhin related the $\mathrm{r}^{\mathrm{s}}$ to the structure and molecular polarizabllities of substrate and layer. His considerations for the case of a monolayer on a homogeneous isotropic substrate (a simple cubic latice) will be sumarized here. The layer consists of atoms with polarizability $\alpha_{0}$ and mutual distance a for the substrate these parameters and denoted by $\alpha$ and $a$. The effective field $E^{e}$ working at an atom in the origin of the layer is written as the sum of three terms

$E_{0}^{e}=E^{h o m}+E^{s}+E^{i n h}$

The first term $E^{\text {hom }}$ is the homogeneous field produced by the incident wave and the dipoles of the substrate lattice. This field is equal to the average field in the macroscopic Maxwell theory

$E_{x, y}$ hom $=E_{x, y} \quad E_{z}^{\text {ham }}=E_{z}+4 \pi P_{z}$

The second term in eq. 67) $E^{5}$ represents the field of the dipoles in the adsorbed layer and is calculated by two-dimemsional summation, resulting in

$E_{x, y}{ }^{S}=\frac{A_{0}}{2 a^{3}} P_{0} x, y \quad E_{z}{ }^{S}=-\frac{A_{0}}{a_{0}^{3}} P_{0, z}$

Here $A_{0}$ is the lattice sum depending only on the symmetry of the layer. $A_{0}=9,035$ for a simple cubic lattice and 11,034 for a hexagonal lattice (41) and $P_{o}$ is the atoric dipole moment $\left(P_{o_{i}}=\tau_{i}\right)$. The third term in eq. 67) E $^{\text {inh }}$ the inhomogeneous field of indicent wave and substrate lattice is zero at a great distance from the surface siwukhin derives for $\mathrm{E}^{\text {inth }}$ the following expression

$E_{x, y}=-\frac{1}{2} \mathrm{BP}_{x, y} \quad \mathrm{E}_{z}{ }^{\text {inh }}=\mathrm{BP}_{z}$

For a simple cubic lattice where eq. 61) is valid

$B=\left(\frac{A}{2}-\frac{4 \pi}{3}\right) \exp \left(2 \pi\left(a-a_{1}\right) / a\right)$ 
Here is the lattice sum for alane in the substrate lattice parallel to the surface and $a_{1}$ is the distance between the plane of the layer and the first plane in the substrate lattice. Insertion of eq. 68), eq. 69), and eq. 70) in eq. 67) yields with

$P_{i}=a_{i} E_{i}^{e} \quad P_{D_{i}}=a_{o_{i}} E_{0 i}$

The following expressions for $\gamma_{x_{y}}$ and $\gamma_{Z}$ :

$Y_{x, y}=\frac{a, a x, y}{c}\left(\frac{a^{3}}{\alpha}-\frac{4 \pi}{3}-\frac{B}{2}\right) /\left(1-\frac{A_{a}}{2 a_{0}^{3}} a_{0 x, y}\right)$

$r_{z}=\frac{\alpha_{0} z}{c}\left(\frac{a^{3}}{\alpha}+\frac{8 \pi}{3}+B\right) /\left(1+\frac{A_{0}}{a_{0}^{3}} \alpha_{0, z}\right)$

The dependence of $\gamma_{z}-\gamma_{x}$ and therefore of $s \Delta$ on the degree of coverage is rather complicated as both the cross-section and the distance between the atoms in the layer a change with $\theta$.

6 Computation methods for some inhomogeneous films (42)

only now-adsorbing films are considered which are such that their refractive index is a function of the coordinate $z$ only, the direction $0_{2}$ being the normal to the planes which limit the film.

Two different methods of computatiom are discussed below:

a. the use of the Maxwell differential equation:

b. the replacement of the inhomogeneous layer by a number of nomogeneous layers.

These two methods are general which means that they are not restricted to special experimental circumstances but can be employed in any circumstiance.

\section{1 Maxuell differential equation}

The thin film is bound by the planes $z=0$ and $z=d$. It is comprised between two seri-infinite media, the refractive indices of which are $n_{0}($ for $z<0)$ and $n_{5}$ (for $\left.z>d\right)$. Light is incident an the plane $z=0$ and we shall generally have $n_{0}=1$. The refractive index under study $h(z)$ is a complex function of $z$ which means that it can be absorbing. It is. convenient to use the dielectric constant of the film $\varepsilon(z)=n^{2}(z)$. The refractive index of the substrate, $n_{s}$, may be camplex which occurs when the medium is adsorbing.

The law of refraction will be written: 
$n_{0} \sin \phi_{0}=n_{s} \sin \phi_{s}=s$

In the layer the fields verify a wave equation which is a direct consequence of Hawell's equations. First the s vibration is discussed. We shall chose the xoy coordinates in such a way as to have $E=\left(E_{x, 0,0}\right)$ which means that the plane yoz is the plane of incldence. We are laoking for solutions of Maxwell's equations which are: $k_{x}=u(z) \exp (i(u t-k s y))$

$H_{y}=\mathbb{V}(z) \exp (i(\omega t-k s y))$

Here the notation $k=2$ is $/ \lambda$ is used, $\lambda$ being the wavelength of the incident ifight in vacto.

It can be shown that

$V(z)=\frac{i}{k \mu} \frac{d U}{d z}$

W being the magnetic permittivity.

IJ verifies the second order differential equation (wave equation).

$\frac{d^{2} u}{d z^{2}}-\frac{d l o g \mu}{d z} \frac{d u}{d z}+k^{2}\left(c \mu-s^{2}\right) u=0$

for the p vibration

$\frac{d^{2} u}{d z^{2}}-\frac{d \log \varepsilon}{d z} \quad \frac{d U}{d z}+k^{2}\left(\varepsilon \mu-s^{2}\right) u=0$

Tet $U_{1}(z)$ and $U_{2}(z)$ be two arbitrary solutions of the wave equation. The general integrals of eq. 75) and eq. 76) are

$$
\begin{aligned}
& u=a U_{1}(z)+b U_{2}(z) \\
& u=\frac{i}{k_{n}(z)}\left(a u^{\prime \prime}(z)+u^{\prime}{ }_{2}(z)\right)
\end{aligned}
$$

a and b being the arbitrary constants which must be chosen in order to satisfy the boundary conditions. On the plane $z=0$ we must have

$U_{0}=a U_{1}(0)+b U_{2}(0)$

$H_{0}=\frac{1}{k i(0)}\left(a U{ }_{1}(0)+b U{ }_{2}(0)\right)$

E. and $H_{0}$ being the tangential components of the fields in the first medium on the plane $z=0$. The equations 80 ) and 81 ) may be written: 


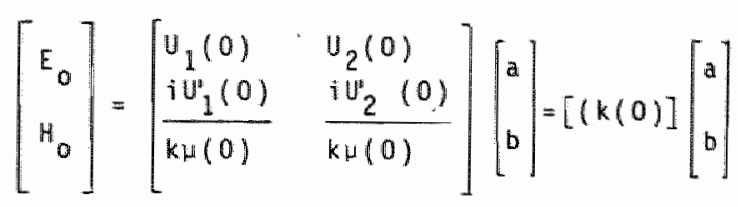

In the same way the boundary conditions on the plane $z=d$ are

$$
\left[\begin{array}{l}
E_{t} \\
H_{t}
\end{array}\right]=[k(d)]\left[\begin{array}{l}
a \\
b
\end{array}\right]
$$

$E_{t}$ and $H_{t}$ being the tangential components of the fields in the substrate on the plane $z=d$. Combining we may write:

$$
\left[\begin{array}{l}
E_{0} \\
H_{0}
\end{array}\right]=[k(0)][k(d)]-1\left[\begin{array}{l}
E_{t} \\
H_{t}
\end{array}\right]=[M]\left[\begin{array}{l}
E_{t} \\
H_{t}
\end{array}\right]
$$

This shows that an inhomogeneous film may be characterized by a twoby-two matrix like a homogeneous one. The advantage of this representation is that the complex reflected and transmitted (if it exists) amplitudes will have the same expression as for homogeneous films, name ly:

$$
r_{s}=\rho_{5} \exp \left(i \delta_{r s}\right) \frac{y_{0}\left(m_{11}+y_{5} m_{12}\right)-\left(m_{21}+y_{5} m_{22}\right)}{y_{0}\left(m_{11}+y_{s} m_{12}\right)+\left(m_{21}+y_{s} m_{22}\right)}
$$

where $[M]\left[m_{i j}\right](i, j=1,2) \quad y_{0}=n_{0} \cos \phi_{0} \quad y_{s}=n_{s} \cos \phi_{s}$ In the same way the expression for $r_{p}$ is found.

6.2 An inhomogeneous filtin replaced by a pile of homagenecus ones It is possible to replace an inhomogeneous film by a superposition of homogeneous films of different refractive indices. In that case the problem pertaining to the solution of the differential field equations is eliminated. The amly difficulty is the estimation of the number of homogeneous layers which is necessary for the replacewent of the inhomogeneous one. In practice this is done by successive 
trials. The imhomogeneous film is replaced first by a unique layer hasing an average refractive index

$\bar{n}=\frac{1}{d} f_{0}^{d} n(z) d z$

and the computation is dome.

Then the film is replaced by two, three etc. homogeneous films and the values of $\psi$ and $\Delta$ are computed. The refractive index of each layer is an ayerage of the refractive indices of the inhomogeneous layer it replaces. The satisfactory result w111 be obtained when $\psi_{j}, \Delta_{j}$, and $\psi_{j+1}$ $\Delta_{j+1}$ do not differ from each other to the desired accuracy (the index indicates the number of layers which replace the inhomogemeous film).

There are no practicall difficulties when using a large and rapid computer. The computation may take some time when the variation of the refractive index is rapid. 
Literature references

1. Born,M. (1933) Optik (Berlin) 19

2. Born, M. and Wolf, E. (1965) Principles of optics, 39 Pergaman Press

3. Alkemade V.Rijn, A.C. (1883) Thes is Wied.Ann, 20,22

4. Drude, P. (1889) Wied. Ann. Physic, 36, 532

5. Drude, P. (1889) Wied. Ann. Physic. 36, 865

6. Rouard, P. (1937) Wied. Ann. Physic. 7, 291

7. Vasicek, A. (1947) J.Opt..Soc. Amer. 37,623

8. Crook, A.W. (1949) J.opt.Sac. Amer. 38, 954

9. Murmann, 0. (1933) Zeitschr. f. Phys. 80, 161

10. Tronstad, L. and Höverstad, T. (1934) Trans.Farad.Soc.30, 362

11. MC.Crackin, F.L., Passaglia, E. (1963) J.Res. Nat.Bur.St.A.Physics. Chen. 67,363

12. Archer,R.J. and Shank, C.V. (1967) J.0pt.Soc.Amer. 57,191

13. Hunter,W.R. (1973) J.0pt.Soc.Amer. 63, 951

14. Smith, P.H. (1969) Surface Science 16, 34

15. So,S.S., Knausenberger, H. H. and Vedam, K.(1971) J.Opt.Soc. Amer. 61, 124

16. Azzam, R.M.A. and Bashara, M.M. (1971) J.Opt.Soc.Amer. 61, 1380

17. Azzam, R.M.A. and Bashara.M.M. (1971) J.0pt.Soc.Amer. 61, 1236

18. Azzam, R.M.A. and Bashara, M.M. (1971) J.0pt.Soc.Amer. 61, 773

19. Azzam, K.M.M. and Bashara, M.M. (1971) J.0pt.Soc.Amer.61, 600

20. Hunter, W.R. and Eaton, D.H. (1970) Surface science 20, 355

21. Jerrard, H.G. (1969) Surface Science 16, 67

22. Barte11, L.S. and Betts, J.F. (1964) J.Phys.Chen. 64,1075

23. Miller,J.R. and Berger, J.E. (1966) J.Phys.Chem. 70,3070

24. Stromberg, R.R.and Grant, W.H. (1964) J.Res.Nat.Bur.St. 68 A, 391

25. Hayfield,P.C.S. and White, G.W.T. In "Ellipsometry im the measurement of surfaces and thin films" (1963) Proc. Washington. Nat.Bur. St. Misc.

PubT. (1964) 256

26. Clausen,B.H. (1964) J.ETectrachem. Soc. 111, 646

27. Archer, K..J. Int" Ellipsometry in the measurement of surfaces and thin films" (1963) Proc.Washington Nat.Bur.St.Misc.Publ. (1964) 255

28. Hal1, A.C. (1966) J.Phys.Chem. 70, 1702

29. Mayer, H. (1950) Physik düner Schichten. Wiss. Verlag Ges.Stuttgart

30. Vasicek (1960) Optics of thin films. North Holland Publ. Comp. Ansterdam

31. Archer, R.J. and Gobeli, G.M. (1965) J.Phys.Chem.50lids 26, 343

32. Burge, D.K. and Benmett. H.E. (1964) J.Opt.Soc. Amer. 54,1428

33. Saxena, A.M. (1964) J.0pt.Soc.Amer. 55, 1061 
34. Mertens, F.P., Theroux, P. and Plumb, R.C. (1963) J.0pt.Soc.Amer. 53,788

35. Bootsma, G.A. and Heyer, F. (1969) surface science 14, 52

36. Maxwell Garnet, J.C. (1904) Phil. Trans. 203,385

37. Schopper, H. (1951) Z. Phys. 130, 565

38. Strachan, C.S. (1933) Proc.Cambridge Phi1.Soc. 29, 116

39. Sivukhim, D. Y. (1948) Zh.Eksperim.Teor.Fiz. SSSR. 18, 976

40. Sivukhin, D.V. (1956) Soviet Phys. JETP 3, 269

41. Hoff, B.M.E.V.d.and Benson, G.C. (1953) Can.u.Phys. 31, 1087

42. Abelès, F. In "Elipsometry in the measurement of surface films" Symp. Proc.itat. Bur. Stand. (1964) Publ.256, 41

43. So, S.S. and Vedam, K. (1972) J.0pt.Soc.Amer. 62, 596

44. Winterbottom, A.B. (1946) Trans.Far.Soc. 42, 487. 


\section{CHAPTER IV}

Calculations of thickness and refractive index from analyzer and polarizer data

\section{Introduction}

The use of the exact Drude equations involves calculations which can not be solved without the aid of the computer. We, therefore, made computer programs which could convert amalyzer- and polarizer data into thickness and refractive index. The following pragrams were developed:

1. Virgin: this program calculates the effective refractive index of the reflecting surface on which the adsorption experiments are to be carried out.

2. Elits: the program Ellis simulates the theoretical behaviour of any set of layers an any surface. Because the Drude equations are difficult to solve in a closed form we calculated analyzer and polarizer settings to a large series of thicknesses and refractive indices. In this way a map was created from which the thickness and refractive index cauld be read from any amalyzer and polarizer setting to be expected.

3. ElTip: the progran Ellip gives the graphical representation of values calculated by Ellis.

\section{Computer programs}

These three computer programs will now be discussed in detail.

\subsection{Virgin}

The computer program Virgin was developed to calculate the optical canstants $n$ and $k$ af the reflecting surface, on which the processes we wanted to study, took place. These walues of m and k are essential for the input of the computer program Ellis. The calculations of the Virgin program are based on the formulae for a clean surface derived in chapter III. As the reflecting surface is immersed in a dielectric medium a correction has to be applied to formulas $(56,57)$ as they are derived from a reflecting surface in ailm.

Input: Read delta, psi, angle of incidence, refractive index of the medium. 
DELTA,PSI, F10(3F7.2): $108.20 \quad 23.02 \quad 68.00$

REFRACTIVE INDEX OF THE MEDIUM(FG.4):1.3335

Program

5 READ(1,10)DELTA,PSI, FIO

10 FORMAT('DELTA,PSE,FIO(3F7.2):'3F7.2)

$R E A D(1,15) R N O$

15 FDRMAT( INDEX OF REFRACTION OF THE MEDIUM(F6.4): "F6.4)

$P I=3.14159$

$\mathrm{RAD}=2 . * \mathrm{PL} / 360$

DELTA $=D E L T A * R A D$

$P S I=P S I R A D$

$F I O=F I O N R A D$

$U=(\operatorname{TAN}(F I 0) * \operatorname{SIN}(F I O)) * 2$

$V=(1 .+S I N(2 . * P S I) * \operatorname{COS}(D E L T A)) * 2$

$W=\cos (2 . * P S I) * 2-(S I N(2 . * P S I) * S I N(D E L T A)) * 2$

$X=\operatorname{SIN}(4 . * P S 1) * \operatorname{SIN}(D E L T A)$

$Y=U / V$

$Z=W * Y+S I N(F 10) * 2$

$H I=0.5 * S Q R T(Z * Z *(X * Y) * 2)$

$\operatorname{REN}=\operatorname{SQRT}(0.5 * Z+H \mathbb{I})$

$C O N=X \times Y / 2 . / R E N$

$R E N=R N O * R E N$

CON $\triangle R N O * C O N$

WRITE $(1,20) R E N$, CON

20 FORMAT(" iN $={ }^{\circ} F 7.4, " K=" F 7.4$ )

GOTO 5

END

Output: $n=2,8852 \quad k=-2,5639$

\section{2 EIIIS}

The ellipticity of light reflected on a surface can be changed by a number of parameters. Thickness and refractive index of a dielectric layer are of interest as they are the wariablies we want to follow in a given experiment. Others as $m$ and $k$ of the bare surfaces (see above), angle of incidence, wallength of the light and refractive index of the medium can be kept constant in one experiment. Ellis calculates the dependency of azimuth and ellipticity on thickness and refractive index in a given experimental setup" over a range in which the experimental changes are to be expected. It thus maps out the $(m, d)$ pairs on a $(4, \Delta) p l a n e$. 
These maps are used to convert experimental data $(\psi, \Delta)$ into the variables of biochenical interest $(n, d)$. These mas wil be called conversion Maps. The use of Ellis is not restricted to one variable dielectric layer on a bare surface. Any number of dielectric llayers can be taken into accoumt, and anyone of these layers can be treated as the variable one, once the optical constants of the others are given.

vescription of the program.

Hs an example we give the input of a system, consisting of three layers: air, barium stearate and chromium. On this chromium layer we simulate the growth or a layer of barium stearate in steps of $25 \mathrm{~A}$ till a thickness of $500 \AA$ is reached. Angle of incidence $\phi=68^{\circ}$ degrees. Wavelength of the laser 1 ight is $632,8 \mathrm{~nm}$.

The input is given in the following form

$N=3$

$\begin{array}{lll}V(1,1)=1.0000 & V(2,1)=0.0000 & D(1)=0.0 \\ V(1,2)=1.4800 & V(2,2)=0.0000 & D(2)=0.0 \\ V(1,3)=2.1092 & V(2,3)=-2.3685 & \\ D R=0.0000 & D C=0.0000 & D D=25.0 \\ F=68.0000 & D F=0.0000 & W=6328.0\end{array}$

$L R=2, \angle C=1, \quad L D=2, \quad N R=1, \quad H C=1, \quad N D=20, \quad N F=1$

Explanation is given in table IV.1.

READ DATA

$N=$ TOTAL NUMBER OF LAYERS

$W(1, J)=R E A L$ PART REFRACTION INDEX LAYER U

W $(2, J)=$ COMPLEX PART REFRACTION INDEX LAYER J

$D(J)=$ THICKNESS LAYER J IN ANGSTROM

$L R, L C, L D=N U M B E R$ OF LAYER TO BE INCREMENTED

$D R, D C, D D=I N C R E M E N T$ OF $V(1, L R), V(2, L C), D(L D)$

$M R, N C, N D=N U M B E R$ OF INCREMENTS DR,DC, DD

$C I=C O S$ INCIDENT ANGLE LAYER I

RP, RN=FRESNEL COEFF.

TRP, TRN =TOTAL REFLECTION COEFF. (MC. CRACKIN)

PSI $(J)=$ CALCULATED VALUE OF PSI

DEL $(Y)=C A L C U L A T E D$ VALUE OF DELTA

T1, T2=STORAGE VARTABLES

W= WAYELENGTH IN ANGSTROPH

$F=$ ANGLE OF INCIDENCE

DF $=I M C R E M E N T$ OF $F$

NF $=$ WUMBER OF INCREMENT DF

Table IV.1. Explanation of the input variables of E1 is.

Because of the complexity of this program which has several subroutines like "Complex Arithmetic" (CA) and "Reflection Coefficient" (RC) we only give here the flowchart of the program in fig. IV.2. 


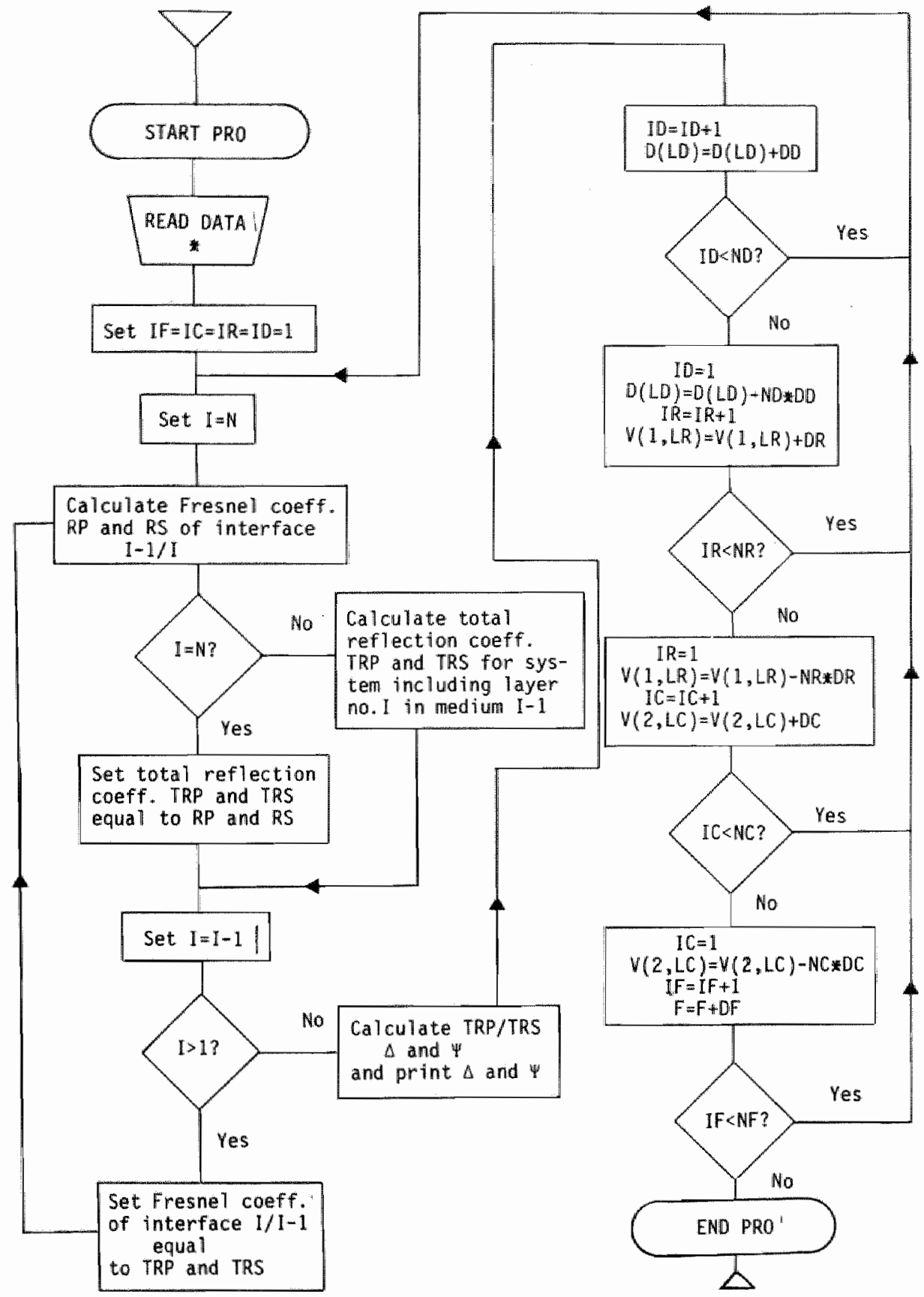

Fig. IV.2. Fowchart of Ellis. 
Dutput

The output is given in the following form: the first five rows are the psi values, the last five ones the delta values. With the given input the following output ab obtained:

$\begin{array}{rrrrrrrrrr}26.56 & 27.03 & 27.51 & 27.99 & 28.47 & 113.48 & 110.80 & 108.25 & 105.81 & 103.48 \\ 28.95 & 29.44 & 29.92 & 30.41 & 30.89 & 101.26 & 99.15 & 97.15 & 95.25 & 93.46 \\ 31.38 & 31.87 & 32.36 & 32.86 & 33.36 & 91.77 & 90.18 & 88.69 & 87.30 & 86.01 \\ 33.87 & 34.39 & 34.92 & 35.46 & 36.02 & 84.32 & 83.74 & 82.76 & 81.89 & 81.13\end{array}$

This output is alsa given in the form of a paper tape. This paper tape gives the values of psi and delta with a higher accuracy and can be used as input for the program Ellip.

L.3 ETI ip

The data obtained by the program Ellis can be plotted by the program Ellip. This prograll requires as accessory input a specification of the graphical output format of the conversion map.

3. Applications

We will now illustrate the type of variation of $\psi$ and $\Delta$ with $n$ and $d$ under various simulations of experimental circumstances.

3.1 The growth of layers of different real parts of refractive index onto a silicon surface

In fig: IV.3. a system consisting of a silicon reflecting surface with layers of waying refractive index and various thicknesses is represented. The refractive indices vary between 1.2 and 3.5 as is indicated in the giraphs. The lines show the effect of changing thickmess at constant refractive index. The marks on each line represent a change in thickness of $25 \AA$. This figure shows the differences in sensitivity of both analyzer and polarizer in different regions of the plane.

In region $A$ e.g. $\Delta$ vapies with d and $\psi$ with $n$; in region $B$ the apposite is true. In region $C$ w varies with d and 3 is hardiy sensitive to $n$. In region $B$ a change in $d 25 \AA$ castes a change in $A$ of $70^{\circ}$, whereas in region the sensitivity is more than ten times less.

From this type of graph it is clear that

a. a simulation of the situation to be expected experimentally should be carried out in order to see if indeed the experimental setting is adequate c.q. how it can be changed to become adequate;

b. any method, using a fixed palarizer setting and estimating analyzer changes by measuring the intensity of the transmitted light is applicable only under very restricted circumstances. 


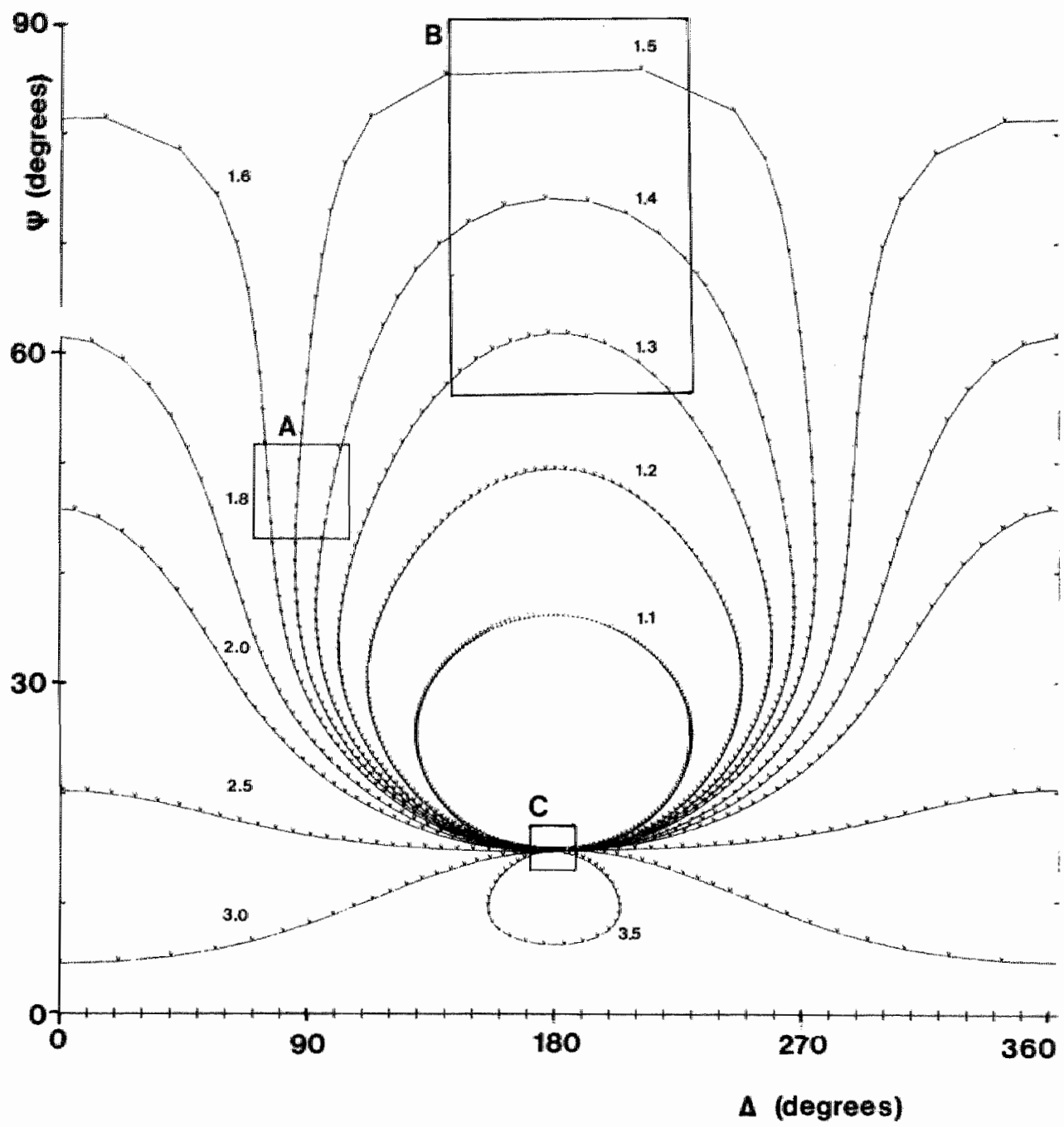

Fig. IV.3. Map of $\Delta, \psi$ on $n, d$ for a silicon surface $(n=4,05 \quad k=0,028)$. Angle of incidence: $68^{\circ}$; refractive index of the medium $n=1$ (air); wavelength 6328 \& (see text). 
With the different refractive indexes the periodicity of the function is reached at a thickness which is shown in the next table.

\begin{tabular}{|c|c|c|}
\hline$n=1,1$ & $d_{p}= \pm$ & 5500 \\
\hline 1,2 & & 4400 \\
\hline 1,3 & & 3750 \\
\hline 1,4 & & 3250 \\
\hline 1,5 & & 2750 \\
\hline 1,6 & & 2500 \\
\hline 1,8 & & 2250 \\
\hline 2,0 & & 2000 \\
\hline 2,5 & & 1500 \\
\hline 3,0 & & 1250 \\
\hline 3,5 & & 1000 \\
\hline
\end{tabular}

These periodicities set a practical limit to the thickness of the layers that can be measured.

3.2 The influence of the optical properties of the reflecting surface In fig. IV.4. The variation of $\psi$ and $\Delta$ with $n$ and $d$ of a Ba-stearate layer $(n=1,47)$ is shown with silicon or with chromium, as the underlying reflective surface.

These graphs show clearly the difference in behaviour of both systems. The change in $A$ caused by a step of $0-50 \AA$ in the silicon system is 10.28 degrees, the change in $\psi$ in this case is anly 0. is degrees. In the chromium system these changes are respectively 6.06 degrees and 0.89 degrees.

Consequently in the silicon system we have a higher sensitivity to changes in thickness but in the chromium system we cam differentiate better between several refractive indices. The curves obtained on chromium at different refractive indices diverge at a smaller thickness than in the case of silicon.

The influence of varying the complex part of the refractive index of the reflecting surface on the conversion map of bariun stearate (fig. IV.5.) shows that there is hardly any difference in sensitivity unless the complex walte is very smal1. A difference is observed between $n=2,8-0,05 i$ and $n=2,8-0,55$ i on $y$.. 


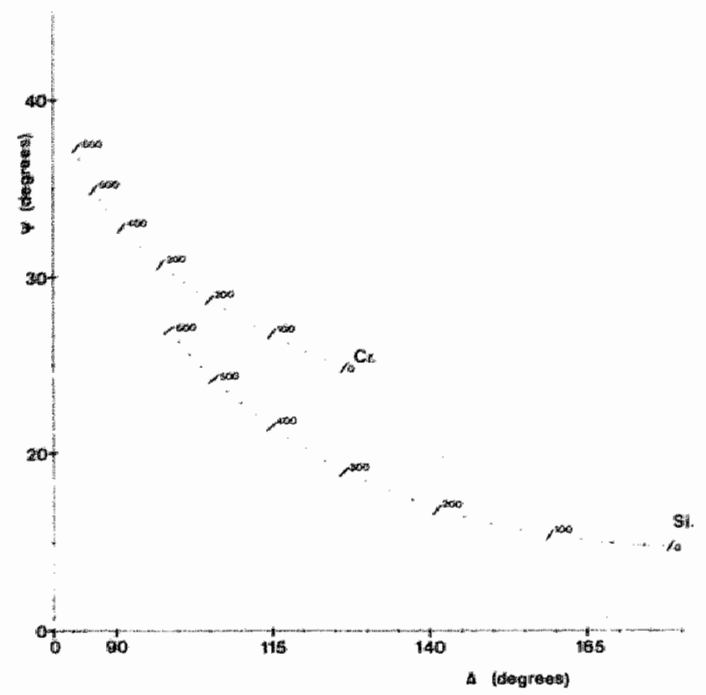

Fig. IV. 4. Conwersion map for Ba-stearate $(n=1,47)$ onto silicon $(n=4,05$ $k=0,028)$, and on chromium $(n=2,8 \quad k=2,5) \quad \phi=68^{\circ} \quad \lambda=6328 \AA$. The figure undicates d in Angström.

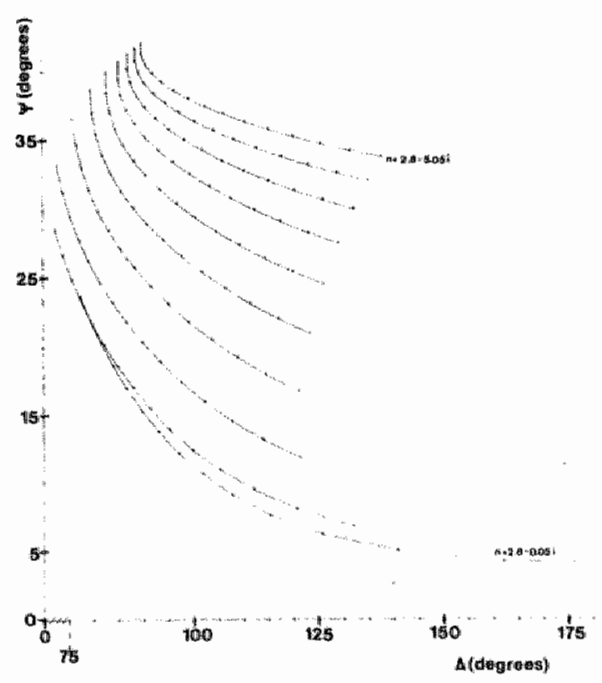

Fig. IV.5. The influence of varying the complex part of the refractive index of the reflecting surface on the conversion map of barium stearate. Optical constants: chromium $n=2,8 \quad k=0,05-5,05$ in 10 steps of 0,5 ; barium stearate $n=1,47$, thickness $0-750 \AA$ in 15 steps of 50 R. Angle of incidence $\phi=68^{\circ}$. 
3.3 The influence of the angle of incidence (fig. 1W.6.)

The graph shows a growth of a barium stearate layer $(n=1,47)$ in steps of $125 \&$ until a thilckness of $600 \&$ is reached on a chromium surface $\left(n=2,8-2,3\right.$ i) at 10 different angles of incidence $\left(55-82^{\circ}\right)$.

In the graph the difference is indicated in $\Delta$ value caused by one step of 125. . An optimal sensituwity is found between 73-67 degrees.

3.4 The influence of wavellength on the sensitivity of $n=1,47$ layers on chromium:

In fig. IV.7. Five graphs of d versus $4, \Delta$ at $n=1,47$ (d $10 \times 50 R$ ) are ploted for wavelengths of $2328,4328,6328,8328$, and 10,000 . The reflecting surface is chromium $(n=2,8-2,3 i)$. In this figure one notices that the five curves completely overlap. the only difference lifes in the sensitiwity of the thickness, $500 \AA$ at $2328 R$ wavelength gives about the same effect at $1200 \AA$ at $6328 \AA$. The differences caused by a change of $50 \&$ of $n=1,47$ are plotted in fig. IV. 8 .

3.5 The influence of varying real parts of refractive index of the immersion medium on the chromium barium stearate system (fig.iv.9.)

The reflecting surface is chromium $(n=2,8-2,3 i) ; n=1,50 ; d=10 \times 40$. The refractive index of the immersion medium varies between 1.0 and 1.9 . obviousily the sensitivity is $n i 1$ for $m=1,5$, $i$.e. When no difference between the refractive indexes of the medium and the substrate exist. The sensitivity increases with the difference between the refractive ind ices. 


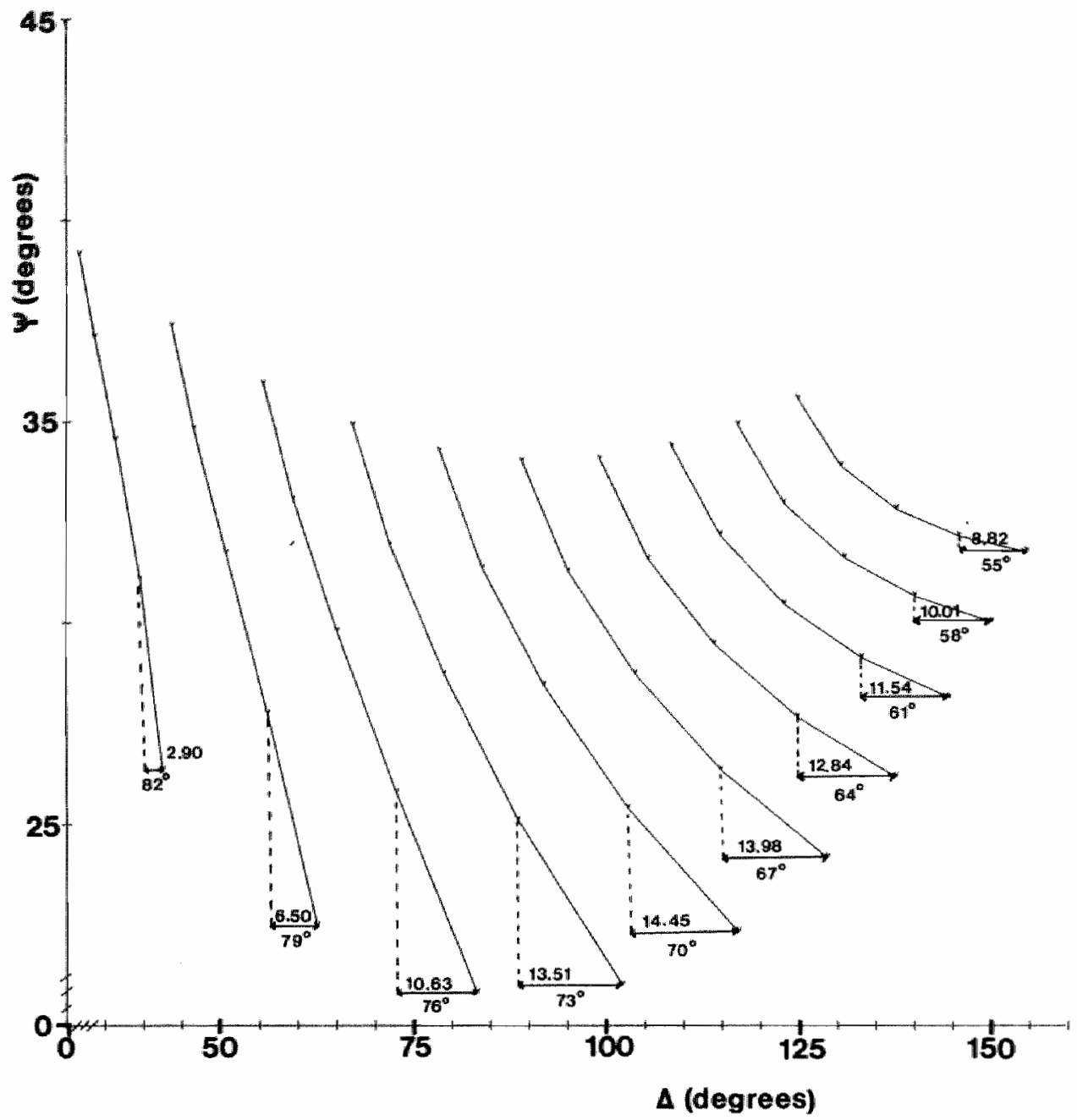

Fig. IV.o. Influence of angle of incidence on the sensitivity at a change in thickness of $125 \&$ at $n=1,47$ on chromium $(n=2,8-2,3 i)$. The different angles $\left(55^{\circ}-82^{\circ}\right)$ are indicated in the graph. Each marl indicates a $125 \&$ step in thickness. 


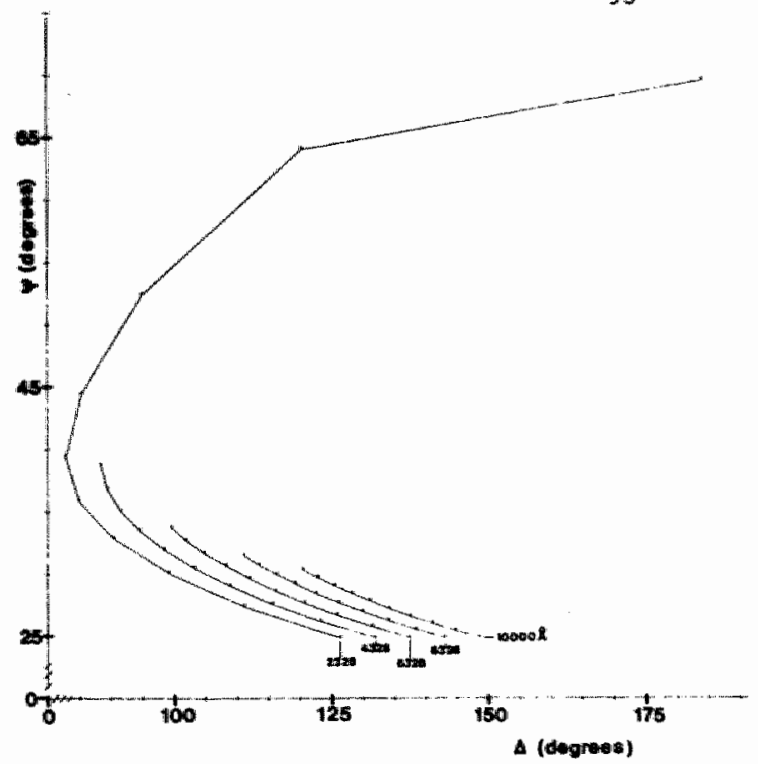

Fig. IV.7. Influence of wavelength on the sensitivity of the growth of barium stearate layers upon chromium (see text). The abscissa gives the correct value for $\lambda=2328 \&$ only. The other graphs are shifted to the right 10 mm per graph. Plotted normally, they fall within less than $0.5 \mathrm{~mm}$ of the $\lambda=2328$ graph.

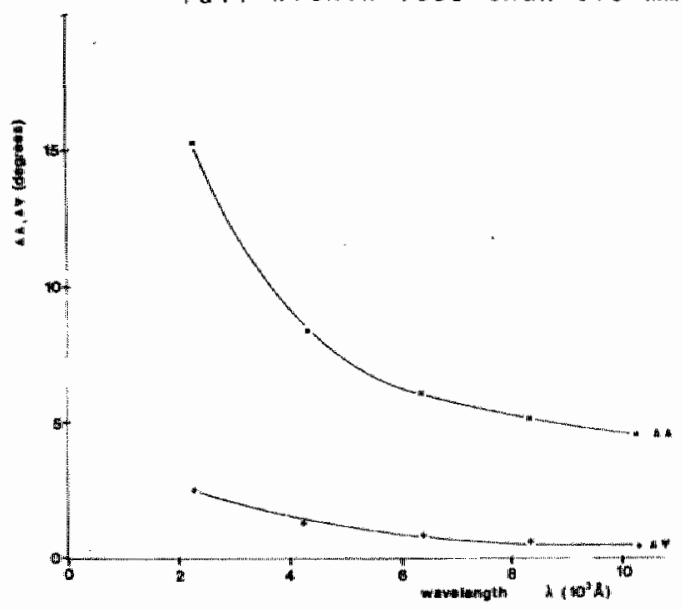

Fig. IV.8. The changes caused by 50 R barium stearate on chromium measured at different wavelengths. 


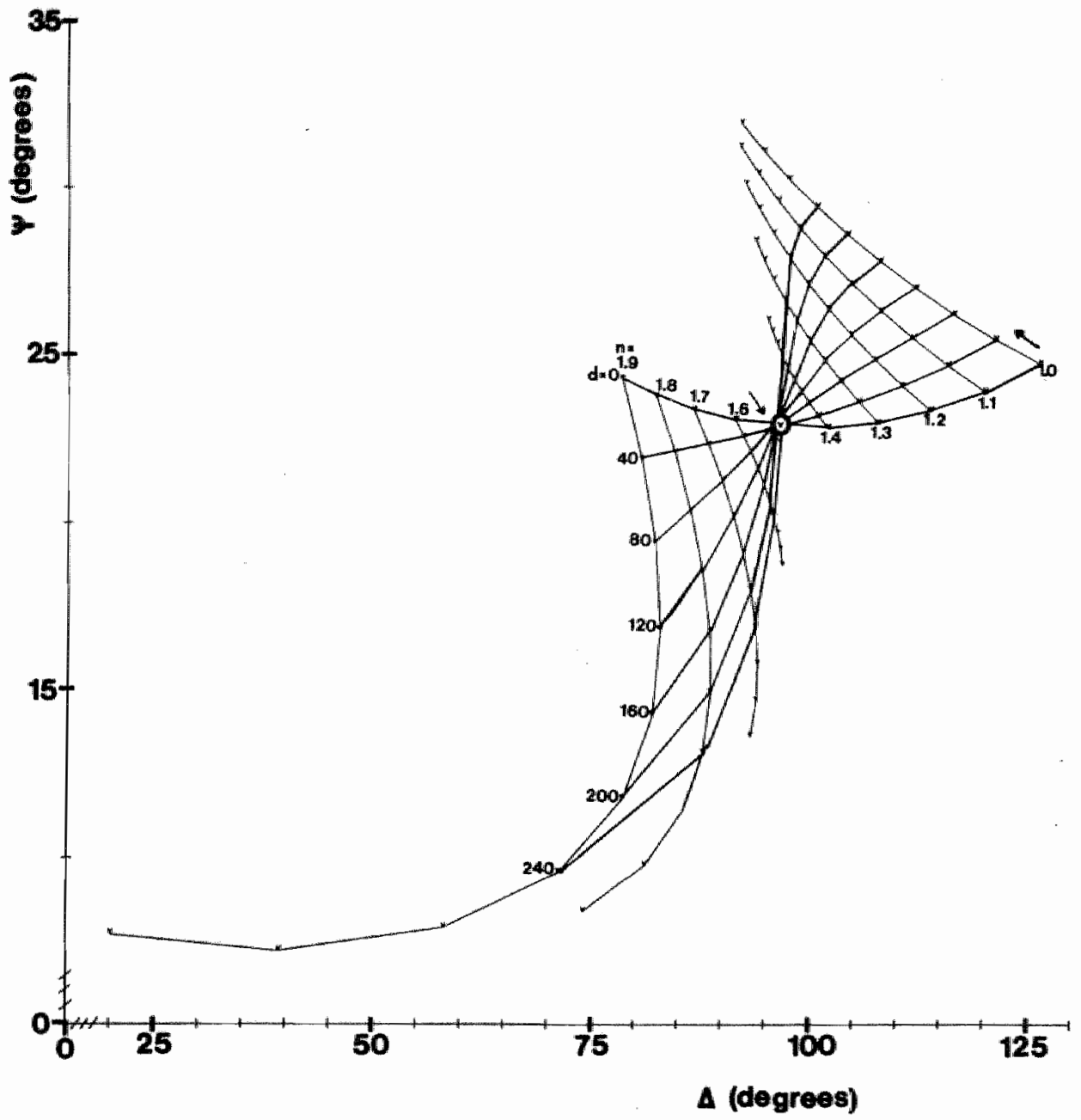

Fig. IV.9. The influence of varying the real parts of the refractive index of the fimersion medium on the chromium barium stearate system (see text). 


\section{CHAPTER V}

\section{Experimemtal calibrations}

\section{Introduction}

In order to be able to check the functioning of the instrument and the precise characteristics of the optical components it is necessary to calibrate these components. If necessary corrections can be introduced in the equations, from which $n$ and $d$ are calculated to accommodate the non ideal behaviour of the optical components. Consequently they have to be checked against predictable observations $(\mathbb{1}-6)$, i. e. the instrument has to be calibrated using known standards.

Three different sets of experiments were carried out:

1. Exact determination of the angle of incidence from the reflection on a dielectric of a known refractive index.

2. Variation of the angle of incidence to obta in an optimal response from the reflexion of five bariam stearate monolayers on a chromium surface.

3. Calibration of the instrument with 1-101 layers of barium stearate transferred to a chromium surface.

In the last two systems the calibration was done by means of multilayers of barium stearate on a chromium covered glass slide. For this reason we will first describe this technique of preparation of multilayers on solid surfaces.

\section{1 Preparation of momolayers}

A monomolecular barium stearate film is formed on water by putting a small amaunt of stearic acid, dissolved in benzene, on a clean surface of buffer containing bariunsalts $\left(3 \times 10^{-5} \mathrm{M} \mathrm{BaCl}_{2}, 4 \times 10^{-4} \mathrm{M} \mathrm{KHCO}_{3}\right.$ " pH $7.0-7.2$, temperature $22^{\circ} \mathrm{C}$. The stearic acid spreads rapidly in a monomolecular film. In this $\mathrm{pH}$ range the Ba $\mathrm{a}^{+}$ions in the water combine with the carbaxylgroups of the spread molecules, converting the film to barium stearate.

Langmuir,Blodgett and many other investigators have demonstrated $(7-15,20)$ that the fatty acids tend to orient themselves on a water surface with the -COOH "head" of each molecule in contact with the water and the chain tilted upwards in a more or less steep angle to the plane of the water surface. 


\subsection{Transfer of the monolayers to solid surfaces}

In our experiments ve used thoroughly cleaned chromium coated glass slides as the solid support. The cleaning was done with Rogipal and twice distilled water. A good quality of distilled water is compulsory. The clean chromilum surface is hydrophobic. Chroming surfaces treated with chromic acid $-\mathrm{H}_{2} \mathrm{SO}_{4}$ give hydrophilic chromium axide fitms.

The film is transferred from water to chromium by lowering a clean slide slowly into the water on which the film is spread by means of a motor driven device. By lowering the hydrophobic surface into the water, the fatty acid chain bound to the surface and the layer is transferred to chramium with the hydrocarbon tails attached to the surface. The exposed upper surface of the film is composed of closely packed $-(c 00)_{2}$ Ba groups. By rasing this slide 5lowly out of the water. a second layer attaches with the polar head groups bound to the polar head groups of the already adsorbed fatty acid molecules. The slide emerges from the water completely dry. Now the exposed upper surface of the film is composed of closely packed hydrocarbon growps. So, when starting with a hydrophobic surface one gets even numbers of layers. While starting with a hydrophilic surface one gets odd numbers of layers.

A film in which the molecules are orientated with the hydrocarbon groups outwards will be unwettable. The property of sheding water is an important factor in these experiments. As the chromium slide is raised out of the water on which the film its spread, the water recedes from the glass wherever the film attaches to the solid surface. If the slide is withdrawn from the water rather slowly $(1-3$ cm per minute) it will emerge completely dry. This emables us to select a lifting speed at which the film is deposited uniformy over the entire surface.

In this methad it is important that the film is kept under constant pressure while the chromina is being raised. This pressure can be kept constant in two ways, described under 1.2 .1 and 1.2 .2 .

1.2.1 Piston oil method

This method was first described by langmuir (1,6-19) who pointed out that pressure could be most convenientiy applied by placing a tiny drop of castor oll, or oleyc acid, or any kind of hydrophilic oil, at one end of the trough. A hydrophilic oil has the property that the mollecules of the oil spread on water until they have covered all the avallable area with a monomolecular layer and crowd into this layer until they have established an equitibrium surface pressure.

Rogier Bosman 3.V. Rotterdam, Holland. 
The equilibrium pressure exerted by an oil is characteristic for each Individual pure oil, e.g. Oleic acid exerts approximately twice the pressure of castor oil. After the surface is covered ith a momomolecular layer, the surplus ail remains gathered in many droplets. If, however, new space becones avaliable on the water surface, the ofl spreads instantaneousiy from these lenses, and covers the new area with a monomolecular layer too. Thus a drop of oil placed at one end of a trough on which a barium stearate film has been spread. acts as a surface piston to hold the stearate film under constant pressure at any instant. oil for this purpose is called piston ail. The barium stearate molecules are separated from the piston ail molecules by means of a waxed thread.

1.2.2 Automatic recording Langmuir trough (Fig. V.1.)

The Langmuir trough is a device to measure film pressure as a function of a surface area ailable to the film. It consists of am inert thermoregulated container for the subphase (water, c. a. buffer solution) shaped in such a way that a large surface is available. This surface is devided into twa compartments by a floating barrier. The pressure exerted by a film present on one side of the barrier is electronically recorded. At the side of the barrier where the film is applied, a motor driven second barrier can change the surface available to the film.

The difference of the surface tension:

$$
F=\tau-\tau_{0}
$$

$T_{0}=$ surface tension of the clean subphase

$\tau=$ surface tension of the film covered subphase

is measured with an electranic tension measuring system (C) multiplied

(D) and recarded on the $r$ channel of an $X / Y$ recorder (E). The spread mollecules are in the area ( $\dot{A}$ ) between the measuring barrier (F) and the moving barrier (G). The latter is propelled by a motor and changes the area $A$. In a smaller area (filmcompression) the surface tension $F$ increases in a characteristic way. A potentioneter connected to the moving barrier transduces the area to a proportional current that is connected to the $X$-channel of an $X / Y$ recorder.

The Langmuir trough we used was a modified analytical trough. The modification consisted of the lowering of a part of the teflon coated trough in order to allow the dipping of the chromium slide. The trough was of the type: Lauda filmage, Messgerate Werk Lauda.P.0.Box 350697 Lauda/ Taber. Our first experiments were carried out with the piston 011 method. The remaining experiments were performed with the Langmur $\operatorname{trough}$. 


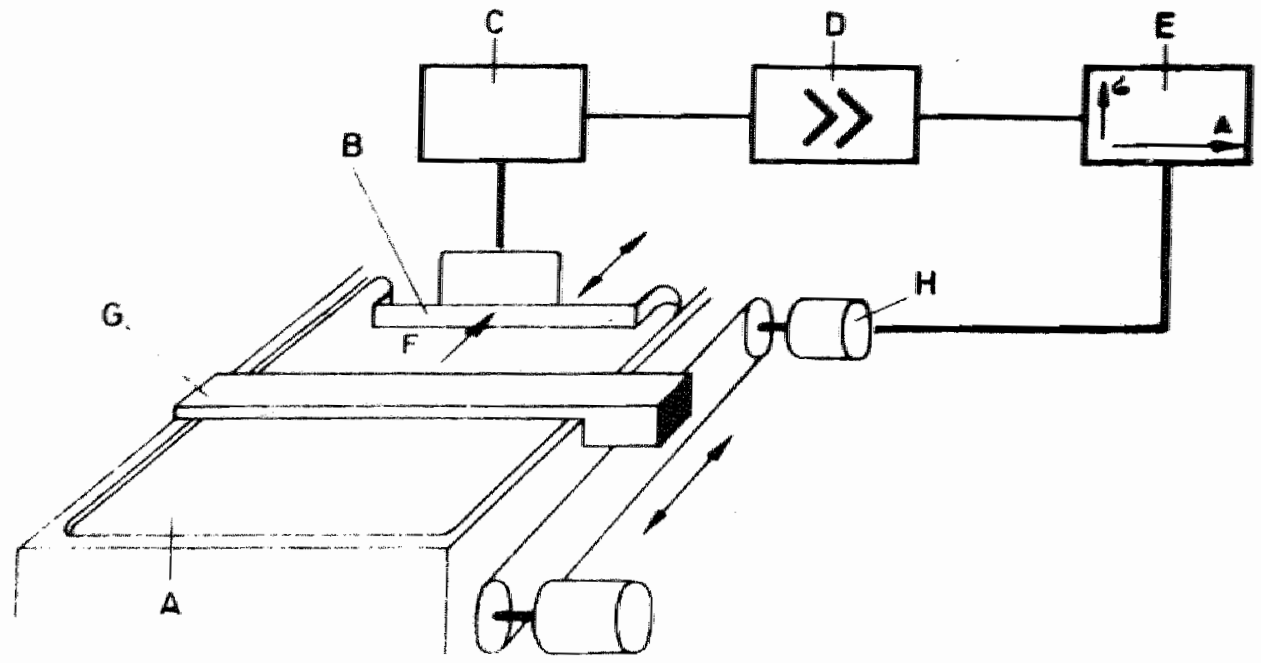

Fig. V.1. Schematic representation of the automatic Langmuir trough. 2 Experimental calibrations

2.1 Determination of the angle of incidence

The instrument was set at an angle of $68^{\circ}$ and the exact angle of incidence was determined by means of reflection on a giass slide of a known refractive index. In order to be sure to measure anly reflection on the front side of the glass slide the back side was made matte with carborundum powder. Measuring in two zones resulted in: $\Delta=0.84 ; \psi=17.74$.

The refractive index was measured by the Abbe refractometer and gave $n=1.5125$. From these values the angle of incidence was calculated to be $68.12^{\circ}$ which was quite correct in comparison with the setting of $\psi=68^{\circ}$. The graded circle on which the angle of incidence was set was checked from $45-75^{\circ}$ and we never found a difference more than about 0.1 of a degree between the angle set and the angle calculated.

2.2 Variation of the angle of incidence

We determined experimentally the angle of incidence which showed an optimal change in the polarizer, caused by five monolayers of barium stearate. We measured the difference of the polarizer readings ( $D P$ ) between a clean chromium slide $P_{C}$ and a chromium slide covered with barium stearate layers $\left(P_{b}\right)$ as a function of $\phi$.

$\Delta^{P}=P_{c}-P_{b}=f(\phi)$. 
We measured at 14 different angles, starting at $55^{\circ}$ in steps of two degrees. The results are shown in fig. W.2. The curve of $\Delta P$ versus shows a maxinum of about $68^{\circ}$ which compared well to the optimum calculated theoretical1y.

2.3 Calibration of the ellipsometer with monolayers of barium stearate on chromium in air.

By transferring monolayers of barium stearate to a solid surface, one obtains a very useful system to compare theory and experiment in a range between zero and several thowsands of angströns of a layer of known refractive index. The transfer of the monollayers was done with the Langmuir trough as described above. Up to 101 layers of barium stearate were used.

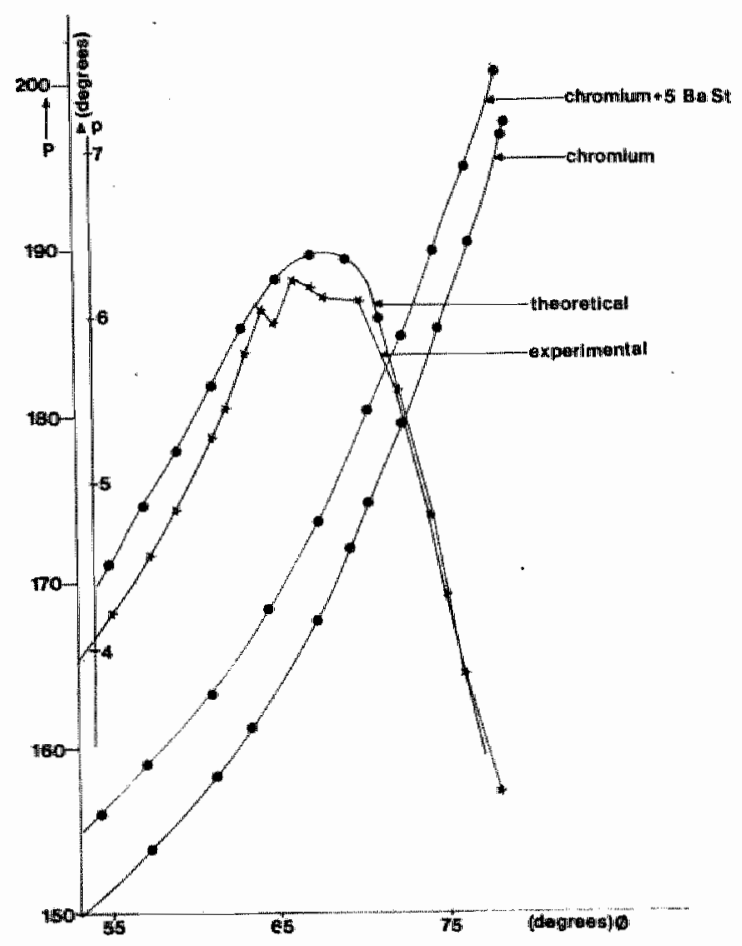

Fig. V.2. The differences of polarizer readings 4 , between a chromium slide covered with five monolayers bariumstearate and a bare chromium slide, as a function of the angle of incidence $\$$. 


\subsection{1 procedure and results}

A11 measurements were performed in two zones. The optical constants of a bare chromium slide were determined from the and 1 readings wa the program Virgin (page 85 ). Starting from these values we calculated and plotted conversion graphs in the relevant ranges of $n$ and d via the programs Ellis and Ellip. The chromium slide was covered then w th wrying layers of barium stearate and $\psi$ and $\Delta$ were measured. The values of $w$ and $\Delta$ thus found experimentally were platted in the conversion graph. Measured in this way $n$ and d can be compared to the mand of wich a multilayer of Ba stearate should theoretically have.

The result is given in Fig. V.3. The black curves are the theoretical curves. Each curve gives the changes in $\Delta$ and when a layer of given refractive index grows on the chromium surface until a thickness of $3000 \AA$ in steps of $25 \mathrm{~A}$ each is reached. The four different curves have refractive indices of $n=1,47 ; n=1,49 ; n=1,51$; and $n=1,53$. The red curve is the experimental curve. This one shows the values of 101 monolayers of barium stearate.

The experimental curve fits the theoretical ones reasonably well, however. there are still some differences.

1. The first part of the curve does not exactly fit in with the theoretical curves.

2. The refractive index is a function of the thickness. These changes are summarized in Fig. W. 3 . 


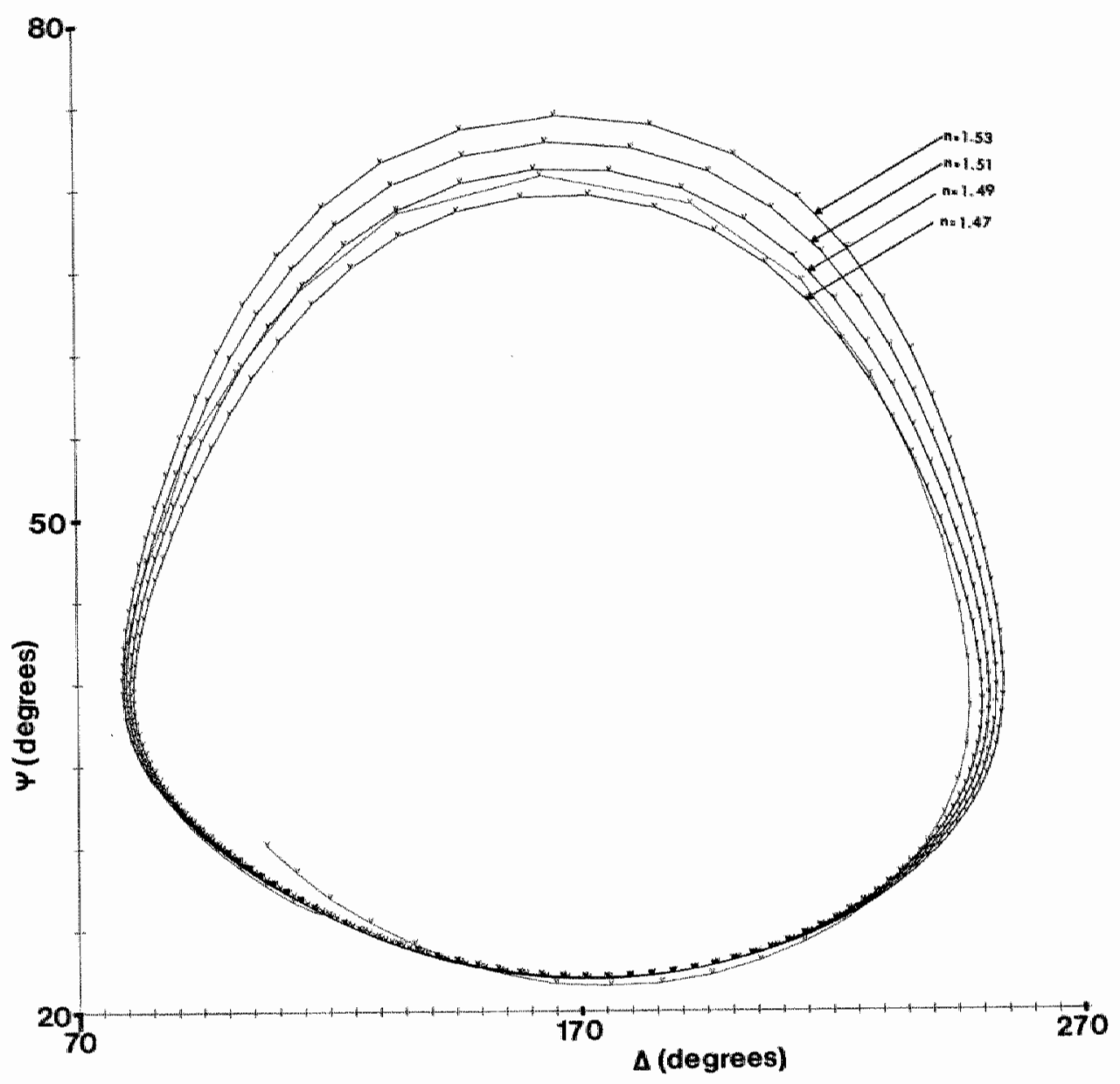

Fig. V.3. The effect of 101 layers of barium stearate on a chromium surface. $n=2,4152-2,4737$ (red curve). Black curwes are the theoretical curves of layers of $n=1,47 ; n=1,49 ; n=1,51 ; n=1,53$. Angle of incidence $4=68^{\circ}$ (see text). 
3 Discussion

If the non ideal behaviour of the opticall components would contribute slgnificantly to the readings obtained it could also be expected that systematic differences would be found between the angle of incidence set, and the angle of incidence calculated from the reflexion at a glass surface. The angle of optimal sensitiwity would be shifted too. This appeared not to be the case. We came to the conclusion that the $\Delta$ and walues as read by the instrument were sufficiently close to the real values. The similarity between the experimental and the theoretical curves obtalned with Ba-stearate layers of increasing thickness cowld not be improved either by assuming a different angle of incidence as will be shown in fig. W.6.

Yet there is a deviation of the readings obtained with multilayers of Ba stearate and the readings to be expected from the known thickness of these layers and the known refractive index. The thickness of one monolayer is cited in the literature to be $24.48(7,12)$. A 1-fold multi layer will therefore be $1 \times 24.4 \&$. The refractive index of Bastearate is givem as $1.46(7,12)$.

If the differences found in $\Delta$ and $\psi$ cannot be blamed on imperfections of the instrument, they must necessarily be explained in terms of non-ideal behaviour of the layers.

In fig. V,4. it is shown that the experimental findings can be accommodated when the first three layers hawe a refractive index that is much higher than that of bulk Ba-stearate. This assumption appeared to be rather fruitful, as can be seen from fig. V.5. An almost perfect similarity is found fmom 3 - 50 layers when it is assumed that the first three layers mave a refractive index that is higher tham 1. 48. For the first layer e.g. we find a thickness of 8 and a refractive index of 2.3. The physical basis of this phenomenon is unclear; mabe that after all the molecular configuration of $\mathrm{Ba}-\mathrm{stearate}$ layers deposited on chromium is very different from the cype of monolayers at an air-water interphase. It might also be possible that the effect is caused by uniaxial anisotropy in the adsarbate (Den Engelsen, 21).

Starting with an effective refractive index of the chromiun and the first three layers (Virgin) we find: (fig. V.5.) 
After the first three layers we find:

0 - 200 R refr.ind. $n=1,47$ thickness of a monolayer 27.0 200 - 500 \& refr.ind. $n=1,46$ thickness of a monolayer 26.6 500 - $800 \AA$ refr.ind. $n=1,47$ thickness of a monolayer 26.6 $800-1400 \AA$ refr. ind. $n=1,48$ thickness of a monolayer 26.5 .

Ba-steancte layers of more than w $1400 \&$ i.e. of more than about 50 monolayers. start to deviate from the theoretical values again.

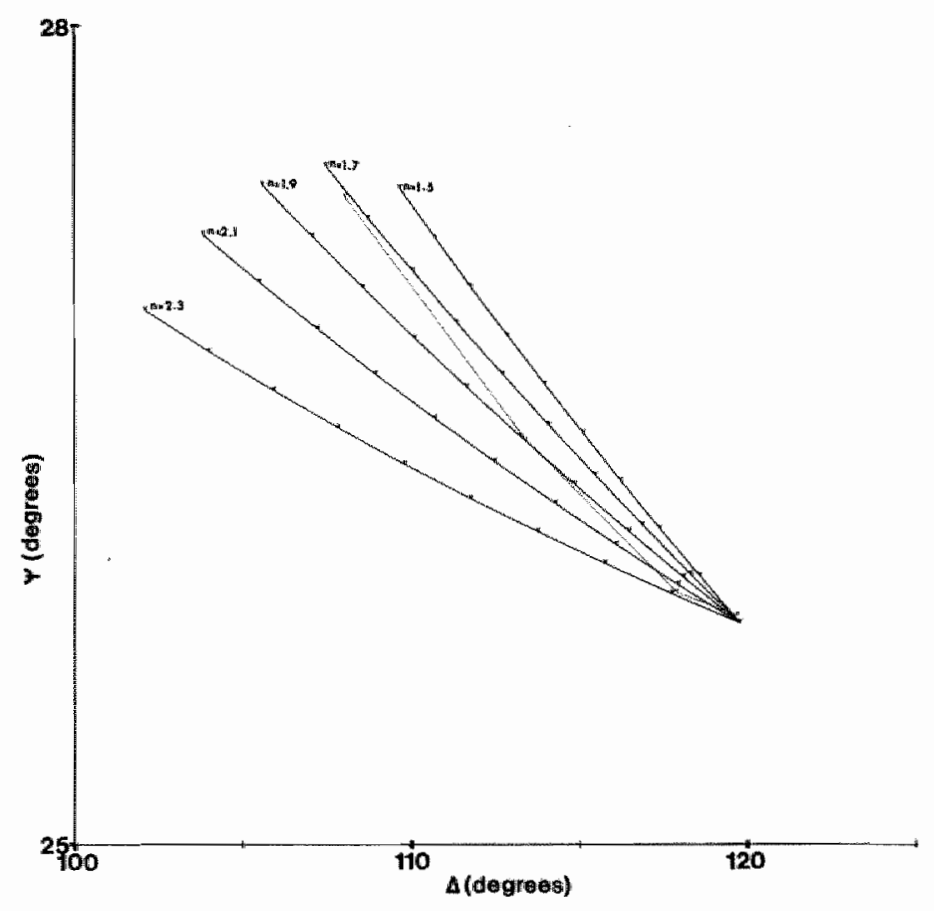

Fig. V.4. The behaviour of the first monolayers of bariumstearate on chromium. Each mark indicates tem angström. Refractive index $n=1,5-n=2,3$. See text. 


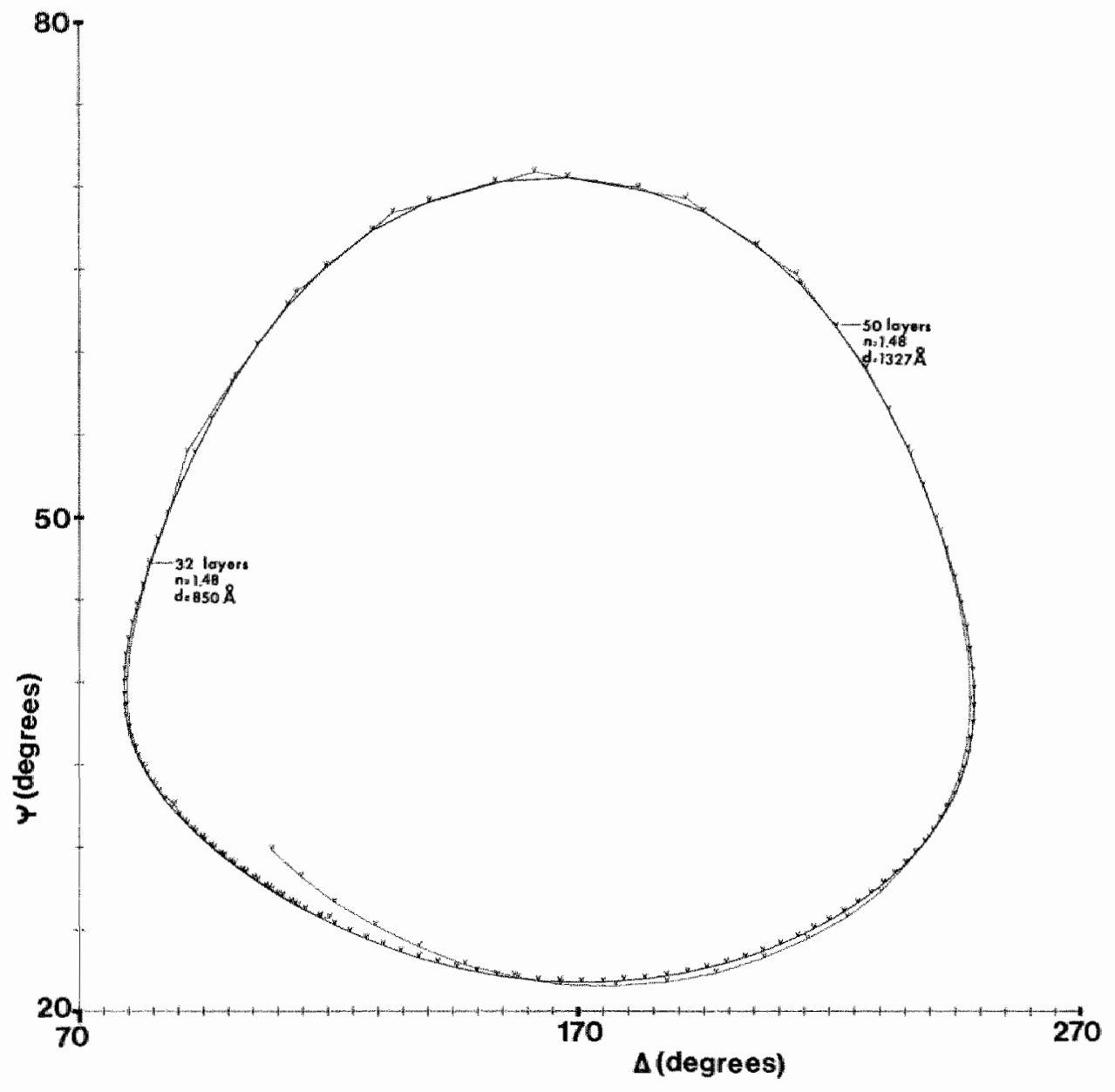

Fig. V.5. Banimstearate layers on the effective sumface of chromium and the first three layers. Refractiwe index n $\mathrm{n}_{\mathrm{f}}=2,1092-2,36851$ (Virgin). 
To obtain a better fit the effect of small changes in the angle of incidence was simulated. Three angles: $\phi=67.5 ; 68.0 ; 68.5$ are simulated in this system as is shown in fig. W.6. These changes, however, did not cause a better fit.

The experimental curve is not a closed one so we tried the effect of assuming a small complex part of the refractive index of Ba-stearate as 11 . The result is shown in fig. W.7.

This figure shows that this assumption would not improve the similarity between the theoretical curve and the observed curve. In our experiment these thick layers, howewer, were several hours old on account of the long procedure necessary to deposit the monolayers. Perceptible disturbances of the layers can be abserwed ("blisters and patches"). We therefore think that the cause of the non-ideal behawiour is very trivial at least in our case.

4. Calibration in the cuwet

In our ellipsometer we want to abserve biological processes. These processes take piace in a liquid surrounding so we have to carry out thes measurement in a cuvet. To minimize the influence of the curet on the measurement we had trapezoid cuvets made, which allowed a perpendicular angle of incidence on the windows of the cuvet. The angles of the cuvet were 68 degrees. Special care had to be taken to prevent birefringence in the windows because of stress.

To measure possible influences of the cuvet we first compared the measurements of bare chromium in air with and without cuvet. Second, we measured the optical constants of bare chromium in the cuvet filled with media of different refractive indices. Although the refractive indices differed a little, no systematic influences of the cuvet weme measured. The differences of the refractive indices in air and in the media were already described by Mc. Crackin et a 1. (22). We a 150 measur. ed the barium stearate calibration in the cuvet filled with water. In this case we only checked a limited number of experimental points in the cuve because the momolayers of barium stearate were not completely stable when transferred through the air-water interphase of the cuvet. The experimental points are shown in fig. W.8. In this experiment too, we find a predictable behaviour of the barium stearate layers. The refractive index of the layer, however, is about $n=1,51$ and the thickness after 35 layers is about $890 \AA$, which gives a thickness of about 25.4 Rer monolayer. The thickness in this case is lower than 
the one we found in air. A possible explanation may be that some material from the monolayer is lost by going through the air-water interphase of the cuvet severall times.

The higher refractive index is in accordance with the experiments of Mc.Crackin et a 1. (22) who found differences in the refractive index of several surfaces when measured in air or in water. A good explanation cannot be given, although as will be seen in the next chapter. we allays find an increase in refractive index mhen we have a decrease in thickness. Consequently, it may be a mateer of packing of the layers.

From these experiments, we conclude that the cuvet does not substantially influence the experimental results, at least when care is taken that the incident and reflected beams are normal to the cuvet windows. 


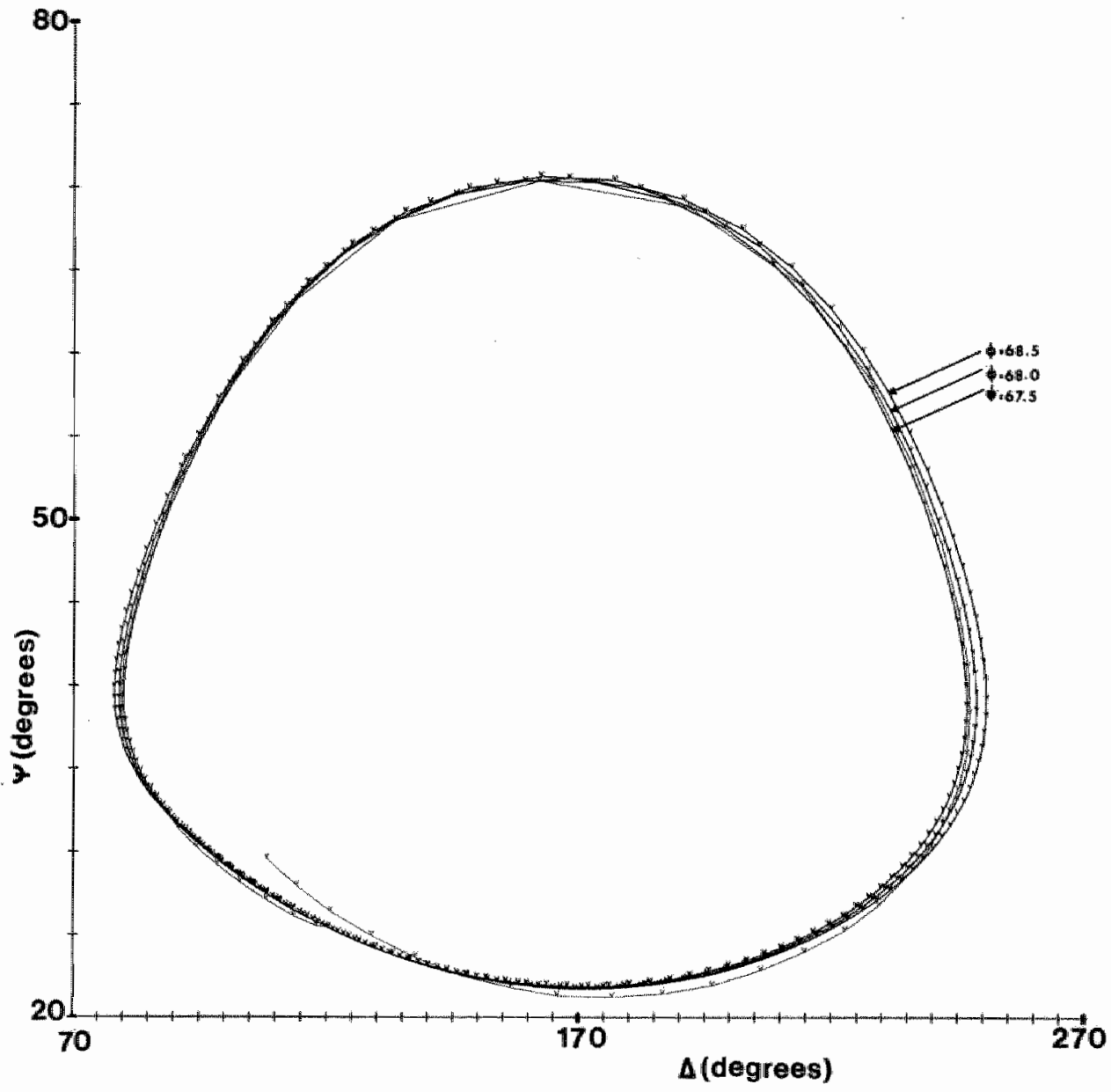

Fig. V.5. The effect of different angles of incidence on the barium stearate calibrations (see text and V.5). 


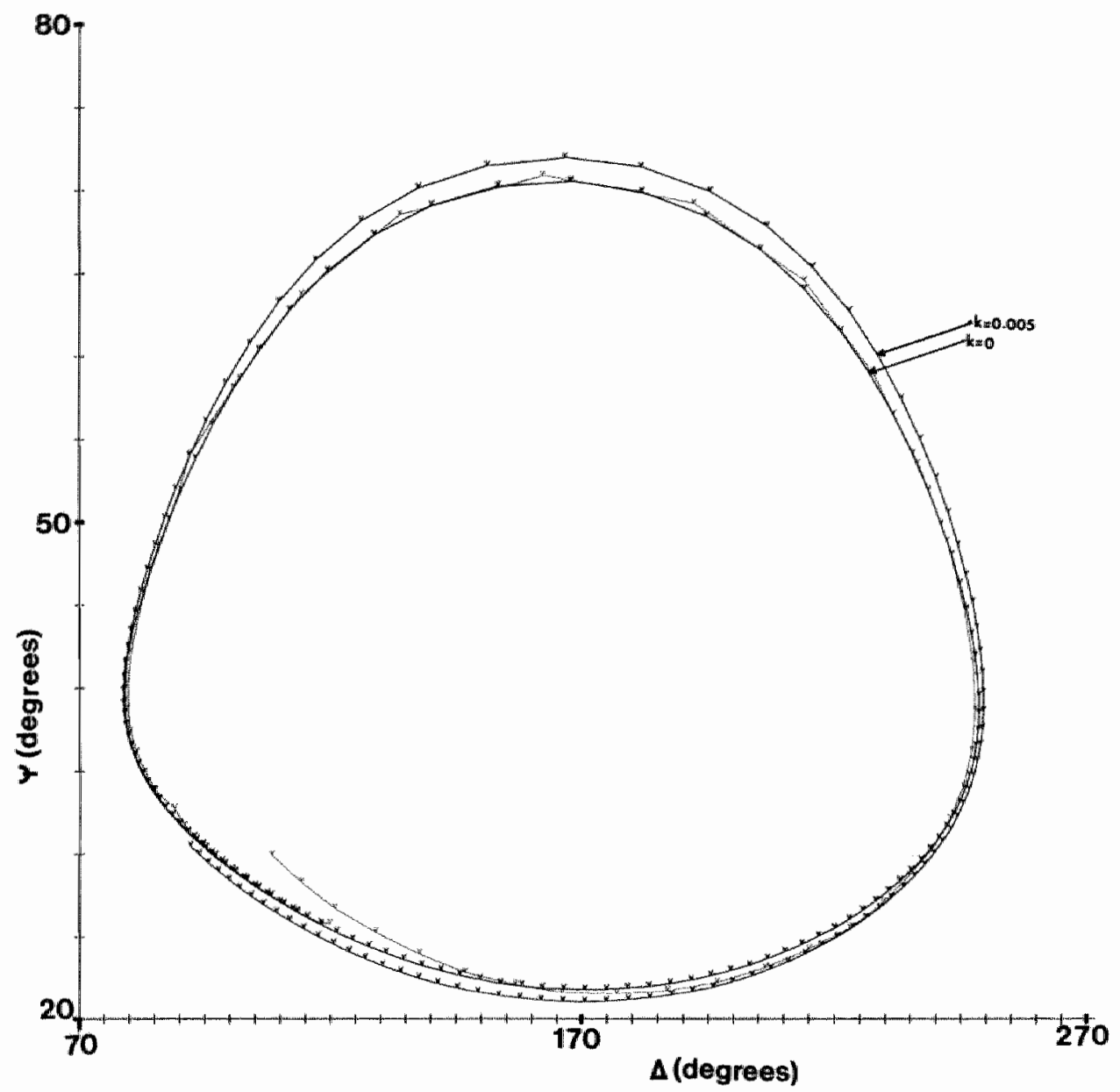

Fig. W.7. The effect of a sila 11 complex part of the refiractive index of bariumstearate (see text and V.5). 


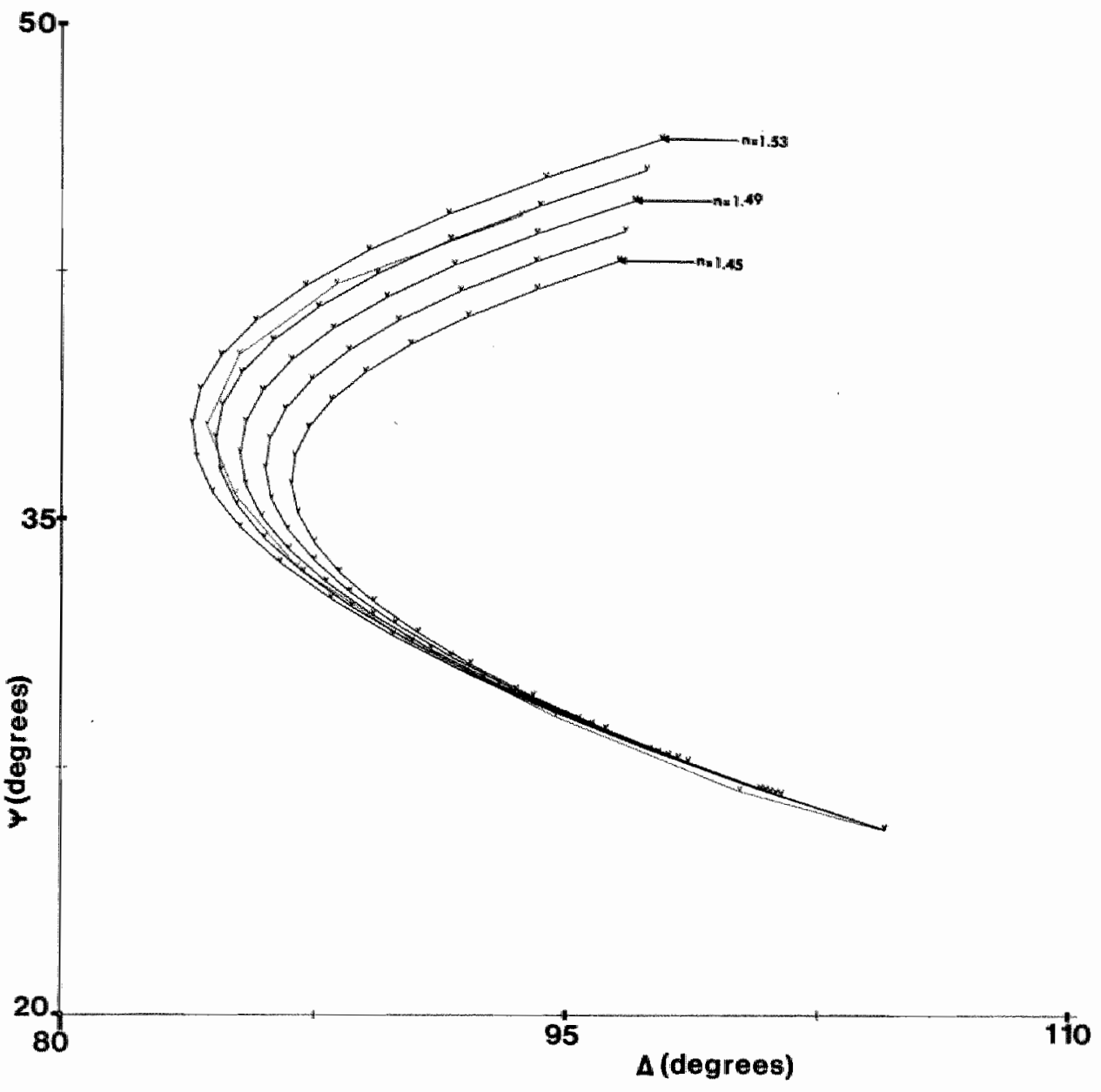

Fig. Y. 8. Barium stearate calibration in the cuvet. Refractive index chromium $n=2,5680-2,4371 \mathrm{i}$. Refractive index medium $n=1,3335$. Each mark indicates 50 angström: 
Literature references

1. Jerrard, H.G. (1969) Surface Science 16, 67

2. Hunter, W. R. (1973) J.0pt.50c.Amer. 63, 951

3. Aspnes, D.E. (1974) J.0pt. Soc.Amer. 6, 64

4. Aspnes, D.E. (1971) J.opt. Soc.Amer. 5, 64

5. Azzam, R.M.A. and Bashara, N.M. (1971) J.0pt.Soc.Amer. 10, ol

6. Azzam, R.M.A. and Bashara, M.M. (1971) J.0pt.50c.Amer. 5, 1236

7. Blodgett, k. B. (1935) J.Am.Chem. Soc. 57, 1007

8. Langmuir, I. (1937) Science 85,76

9." Langmuir, 1. (1938) Science 87,493

10. Pope1, W.J.(1970) Sci.Progr.0xt. 58, 237

11. Bladgett, K.B. (1937) Physical Rev. 51, 964

12. Bateman, J.B. and Covington, E.J. (1961) J.Co11.Science 16, 531

13. Bagg, J., Morris, B., Abramson,M.B. (1964) J.A.n.Chem. Soc. 86, 2759

14. Bikerman, J.J. (1939) Proc.Roy.Soc. London 170 A, 130

15. Kuthn, H. and Möbius, D. (1971) Angew. Chemie Int. Edit. 10,620

16. Langmuîr, 1. (1917) đ.Am.Chem.Soc. 39, 1848

17. Blodgett, K. (1934) U.Am.Chem.Soc. 56,495

18. Blodgett, K. (1937) J.Phys.Chem. 41, 975

19. Bladgett, K. (1940) Phys. Rew. 57,921

20. Gaines,G.L. (1965) Insaluble Monolayers at Liquid-Gas Interfaces Intersci.Pub1. Wiley, Loman

21. Den Engelsen, D. (1971) J.0pt.Soc. Amer.61*1460

22. MC.Crackin, F.L., Passaglia, E., stromberg, R.R. and Steinberg, H.L. J.Res. Nat.Bur.Stand. 67 A (1963) 363 . 
CHAPTER VI

Applications

6. I Introduction

As an application of dynamic ellipsometry in studying protein adsorption and protein-protein interaction, the following experiments are presented:

1. Adsorption of human fibrinogen onto different surfaces like chromium-chromium oxide and silicon-silicon oxide.

2. Adsorption of human albumin on a hydrophitic chromium surface.

3. Interaction of these proteins with their antibodies.

4. Replacement af prateins by fibrinogen.

5. The relation between refractive index and thickness of a monolayer of protein on a chromium-chromium oxide surface with varying hydrofobicity.

These experiments will be interpreted according to the methods given in chapters IV and $V$.

6.2 Materials

As a reflecting surface we used: chromium sputtered glass slides manufactured by stabilix. The Hague, Holland. Silican slides were a gift of Philips Natuurkundig Laboratorium, Eindhoven, Holland.

Human fibrinogen (Tyophilized,grade L) was obtained from Kabi A.B., Stocknolm, Sweden. Human serum albumin was obtained from calbiochem. Anti-albumin (agglutinating antiserum Batch mo. KHO $2^{-15-A O L)}$ and antiFibrinogen (precipitating antiserum Batch KH 18-05-p0 $0_{2}$ ) were obtained from Central Laboratarium Bloedtransfusiedienst van het Mederlamdse Rode Kruis, Amsterdam, Holland. Serum was obtained from momal human blood by clotting during 2 hours, and centrifugation during 30 min $12,000 \mathrm{~g}$.

6.3 Adsorption of fibrinogen

6.3.1 Hydrophilic chromium surface

The chromium sputtered glass slides which are hydrophobic can be made hydrophilic by treating them with hot chromic acid. In this way a poliar chromic oxide layer is formed which binds water. The cuvet was filled with buffer (Tris-HCl, 0.01 $\mathrm{M} \mathrm{pH} 7.4$ ) and the sides were measured in two different zones to determine their initial optical properties. After about 800 seconds, $0.1 \mathrm{mg}$ of fibrinogen was added (100 ul of a $1 \mathrm{mg} / \mathrm{ml}$ solution). After this addition 
the polarizer (A) and analyzer (W) changes are recorded in time (fig. VI.1). After the moment of addition, the polarizer and analyzer change rather fast and an end level is reached after about 600 seconds for both analyzer and polarizer. Further addition of fibrinogen does not cause any further changes. Interpretation of the curves in terms of thickness (d) and refractive index (n) is done via the conversion graphs of the $\Delta$ and $\psi$ valuescorresponding to the $n$ and $d$ values (fig. 1,2 ). The black lines give the theoretical curves of refractive indices 1.4-1.8 in steps of 0.1 . The marks on each graph represent a chamge in thickness of $10 \AA$. The calculated behaviour of $n$ and d as a function of time is given in pig. W1.3. This figure shows that the refractive index does not change much during the adsorption. The thickmess follows the saturation behaviour of a monolayer adsorption (type 1 af Winterbatton (1)). After about 4000 seconds the thickness stabilizes around $130 \%$. The refractive index is then 1.38 .

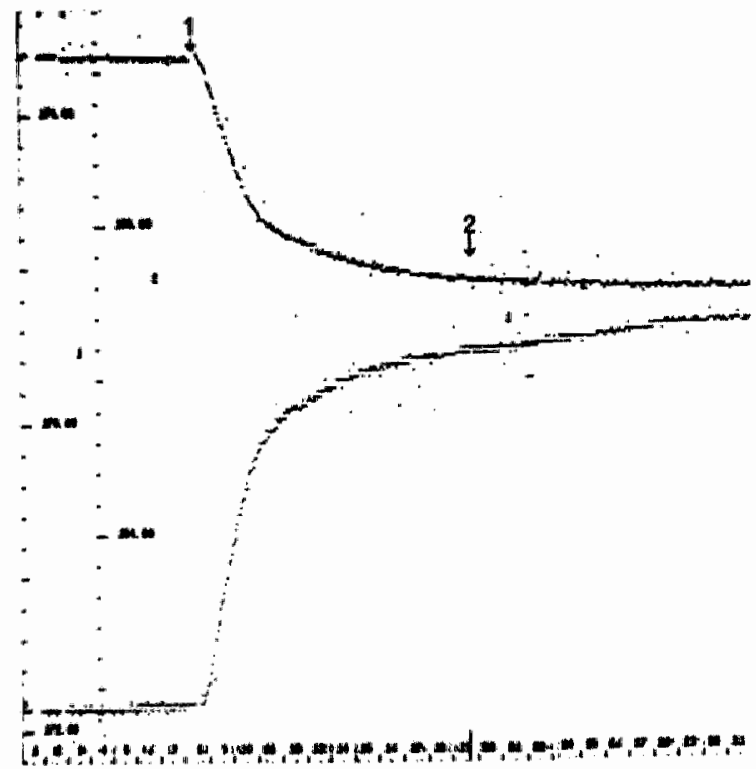

Fig. VI.1. Fibrinogen adsorption.

Hard copy of the memory scope recording of the change in analyzer and polarizer after two additions $(1,2)$ of 100,1 of fibrimogen i mg/ml.

Surface: chromium oxide: $n=2,7525-2,6544 \mathrm{i}$.

Buffer: Tris-HCl $0.01 \mathrm{M} \mathrm{pH} 7.0$. 


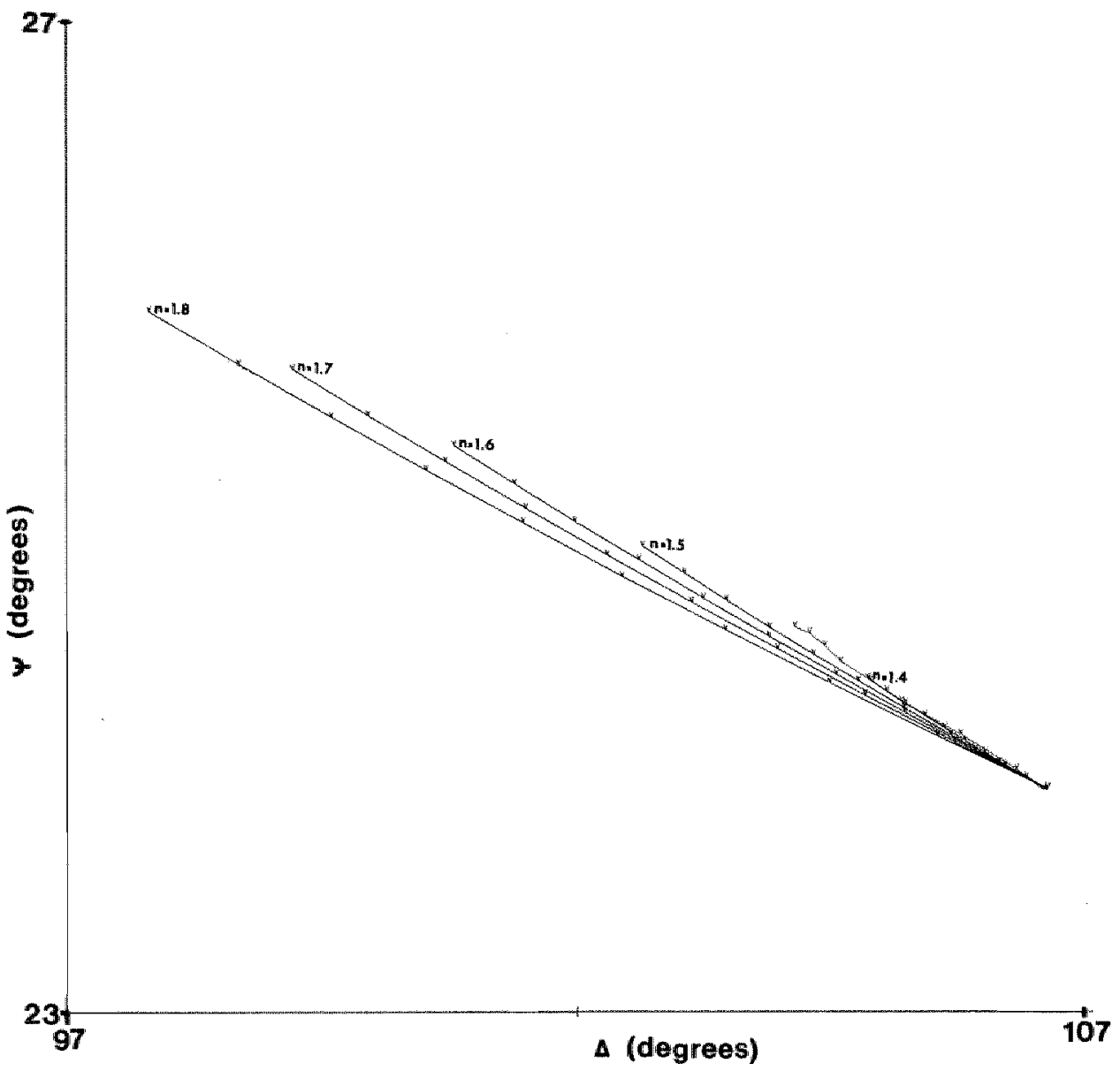

Fig. W1.2. Conversion graph of fibrinogen adsorption. ked Tine gives the experimental points. Black lines are the theoretical points. Further details: see text. 


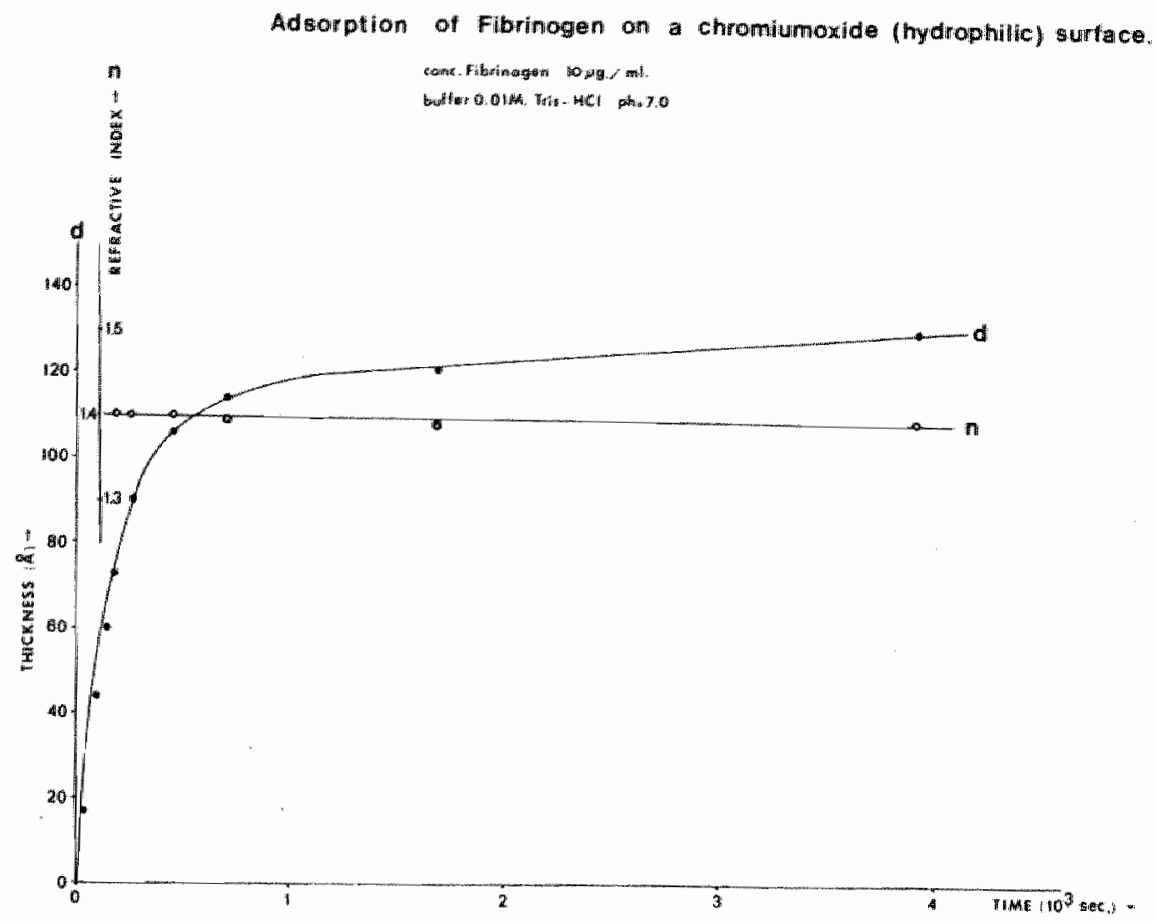

Fig. VI.3. Behaviour of thickness and refractive index as a function of time during the adsorption of fibrinogen $(10 \mathrm{~kg} / \mathrm{ml})$ in 0.01 M Tris-HCl buffer pH 7.0 onto a chromium oxide (hydrophilic) surface (see text).

\subsubsection{Hydrophobic chromium surface}

The adsarption of fibrinogen on chromium which is hydrophobic is done under the same experimental conditions as in the foregoing paragraph. The adsorption behaviour of analyzer and polarizer are shown in fig. VI. A. In this graph one observes immediately that at 1.600 seconds the analyzer does not change anymore, whereas the polarizer is not yet stable. This indicates that other processes than adsorption of a layer of constant refractive index must be going on. Fig. W 1.5 shows the relevant $\psi \Delta \rightarrow n$. d map with the experimental findings.

The black curves represent the theoretical curves of the refractive indices $n=1.4-1.8$ in steps of 0,1 . The marks indicate changes of thickness of $10 \AA$. The refractive index of the chromium was $n=2,6645$ $k=2,4782$. 


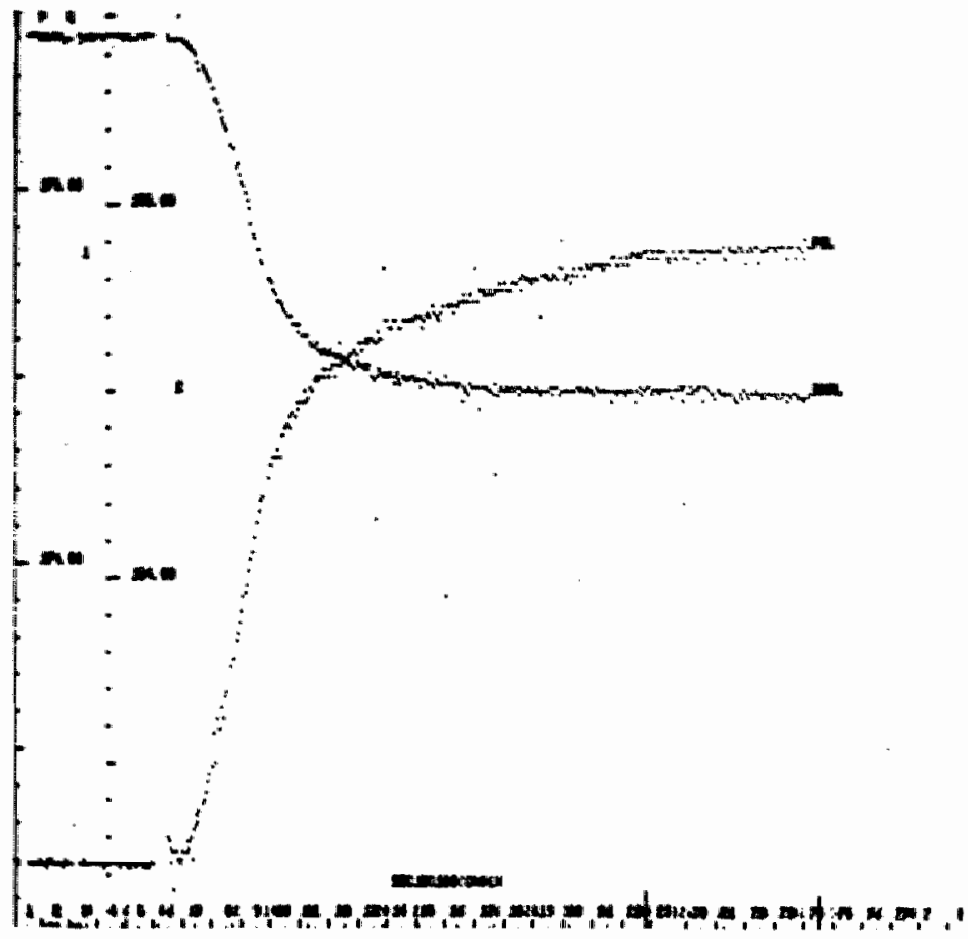

Fig. Vi.4. Fibrimogen adsarption on hydrophobic chromium. (see text).

The experimental curve apparently does not follow one of the theoretical black curves of constant refractive index. In fig. VI, 6 n and d are plotted as a function of time. During the first 150 seconds the thickness grows at constant refractive index $n=1,8$. Then the refractive index lowers and the thickness 5 till increases. The thickness grows till about 68 \& whille the refractive index lawers till about 1.5. From this point on the layer gets thinner and optically denser. The layer stabllizes at $d=35$ and $n=1,8$. 


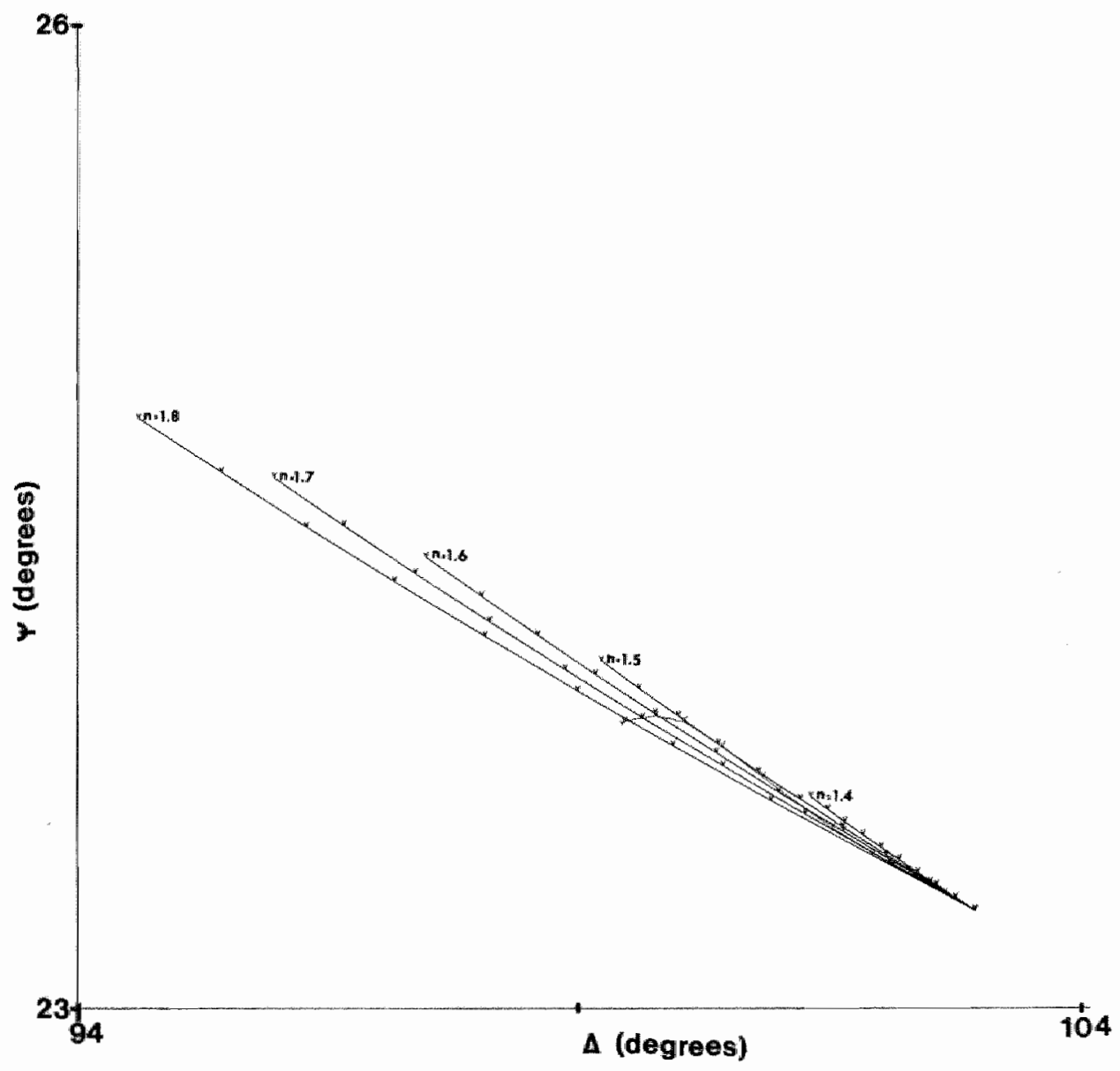

Fig. VI.5. Conversion graph of fibrinogen adsorption anto hydrophobic chromic surfaces (see text). 


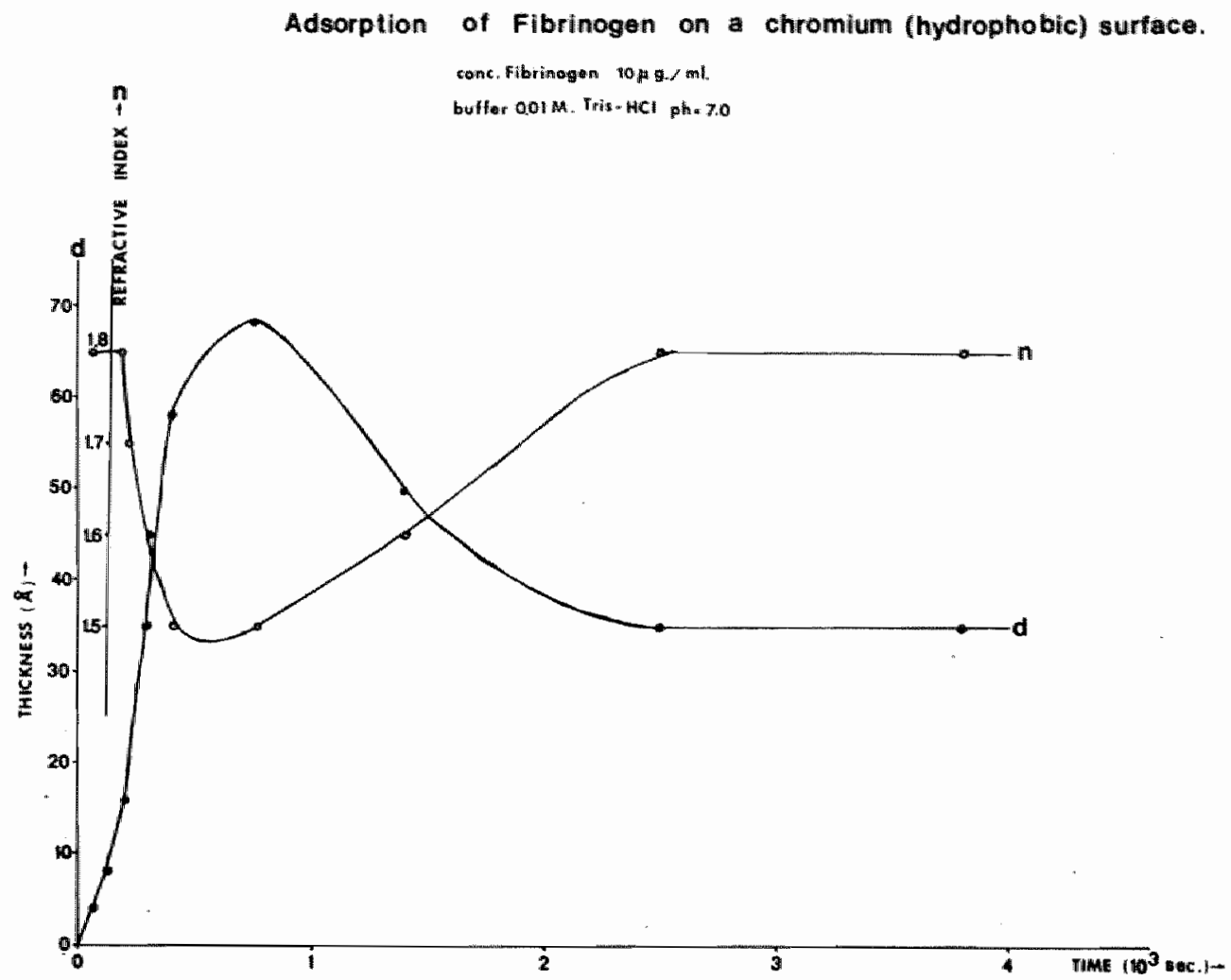

Fig. VI.6. Behaviour of thickness and refractive index as a function of time during adsorption of fibrinogen $(10 \mu \mathrm{g} / \mathrm{mill})$ in $0.01 \mathrm{M} \mathrm{Tris-HCl}$ buffer $\mathrm{pH} 7.0$ anta chromium (hydrophobic) surfaces. 


\subsubsection{Adsorption on silicon-silicon oxide surfaces}

Sillicon sidies had to be treated during ane hour with chromic acid to become hydrophilic, for hydrophobic surfaces it took several hours to stabilize in buffer. By treating the silicon with chromic acid the silanon structures of the surface are hydrolized to slanol structures which are hydrophilic. The same process takes place in buffer but in this case the process takes much more time. stable hydraphoblc surfaces cannat be abtained with silicon.

In fig. VI.7 the experimental conditions were the same as in fig. VI.4 but for the surface which was silicon-silicon axide. In this figure one sees that the changes in analyzer and polarizer markedly differ from those obtained with the chromium surfaces because of the different refractive index of the reflecting surface (see chapter IW). In this experiment adsorption of fibrinogen causes the polarizer to change about 6 degrees whereas the analyzer changes only about 0.4 degrees. This illustrates the sensitivity of the technique. About 120 A thickness causes a change in polarizer of about 6 degrees while the accuracy of the instrument is about 0.01 of a thegree, so changes in thickness of about 0.2 of an Angström can be seen. Interpretation of the analyzer and polarizer curves by the method used before shows identical adsorption behaviaur of the protein as on hydrophilic chromium. 


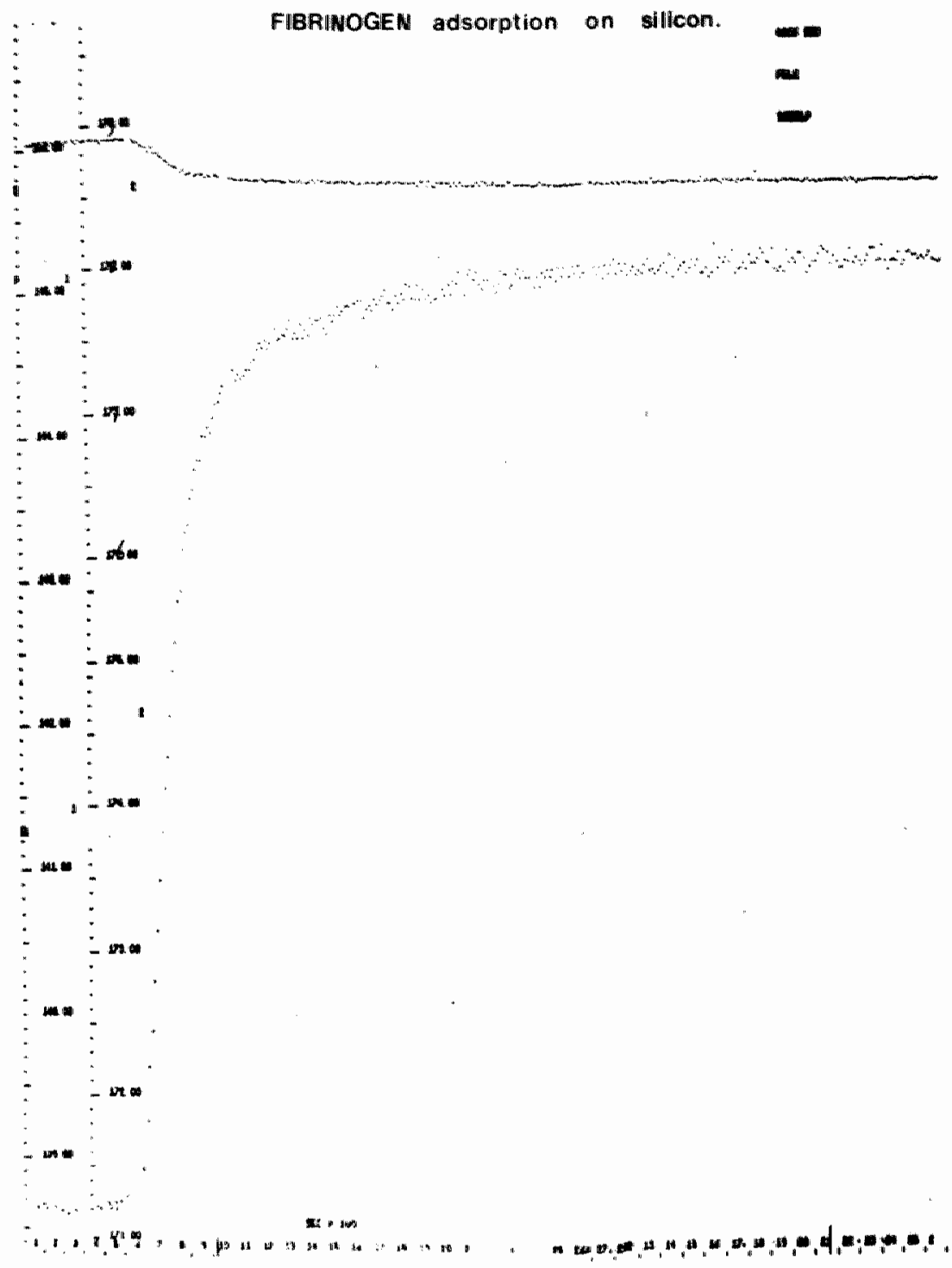

Fig. VI.7 Adsorption of fibrinogen onto silicon. 


\subsubsection{Conclusions from the fibrinogen adsorption experiments}

The difference in character of adsorption an hydrophobic and hydraphilic surfaces depends upon the interaction of the protein and the surface. The interaction with hydrophobic surfaces is much stronger than with hydrophilic ones. This is to be expected as a hydrophilic surface to a certain extert resembles the natural surroundings of a protein in solution. our explanation of the adsorption behaviour is as follows:

The first fibrinogen molecules adsorb onto the surface with the whole length of the molecules fixed to the surface. This gives a thin layer which is optically very thick so we have a high refractive index. wter some time the surface is partly covered and it is not possible anymore for the molecule ta attach to the surface directly over its whole length. So we get a layer of random orientated fibrinogen molecules partly attached to the surface. This results in a thick layer which is loosely packed i.e. a layer with a high water content and a low refractive index. These random orientated molecules rearientate giving a layer which is closely packed with a high refractive index and a thickness of about $40 \%$. This thickness indicates a layer of one molecule thick if we accept the dimension af the molecule being length 375-450 R; mean transverse diameter $60-90(2,3,12,13,14)$.

\subsection{Adsarption of human albumin}

The adsorption of human albumin on hydrophilic chromium surfaces was studied. The experimental conditions were the same as described in 6.3.1. The result is shown in fig. W1.8. The figure shows that in the beginning of the adsorption there is a very thick layer of very loosely packed albumin molecules. The "thickness" is about $400 R$ with a refractive index which is only slightly higher than the refractive index of water.

Then rearrangement takes place and a layer which has an average thickness of about $15 \AA$ is formed. The refractive index is about $n=1,55$. This thickness correlates. well with the reported dimensions of albumin $21,5 \times 50 \times 106 \mathbb{A}(4,5)$. As will be shown im 6.7 it is very difficult, however, to compare our results with those in literature.

6.3 Protein antibody interactions

6.5. I Fibrinogen-antifibrinagem interaction

In the study of these interactions we used the same experimental conditions and surfaces as described in 6.3.1. We first adsorbed the fibrinagen as sub 6.3.1. When the analyzer and polarizer did 
not change anymore, the content of the cuvet was washed twice with new buffer. During this washing the polarizer and analyzer did not change so the fibrinogen layer remained unchanged on the chromium. After this washing the antifibrinogen was added and the polarizer and analyzer started to change (fig.VI. $y$ ). The results calculated as shown before are given in fig. V1.10. In this figure we see a thickness of the fibrinogen of $100 \AA$ at a refractive index of 1.40 . Addition of antifibrinogen gives a change in thickness of about $400 \&$ with refractive index of 1.366 .

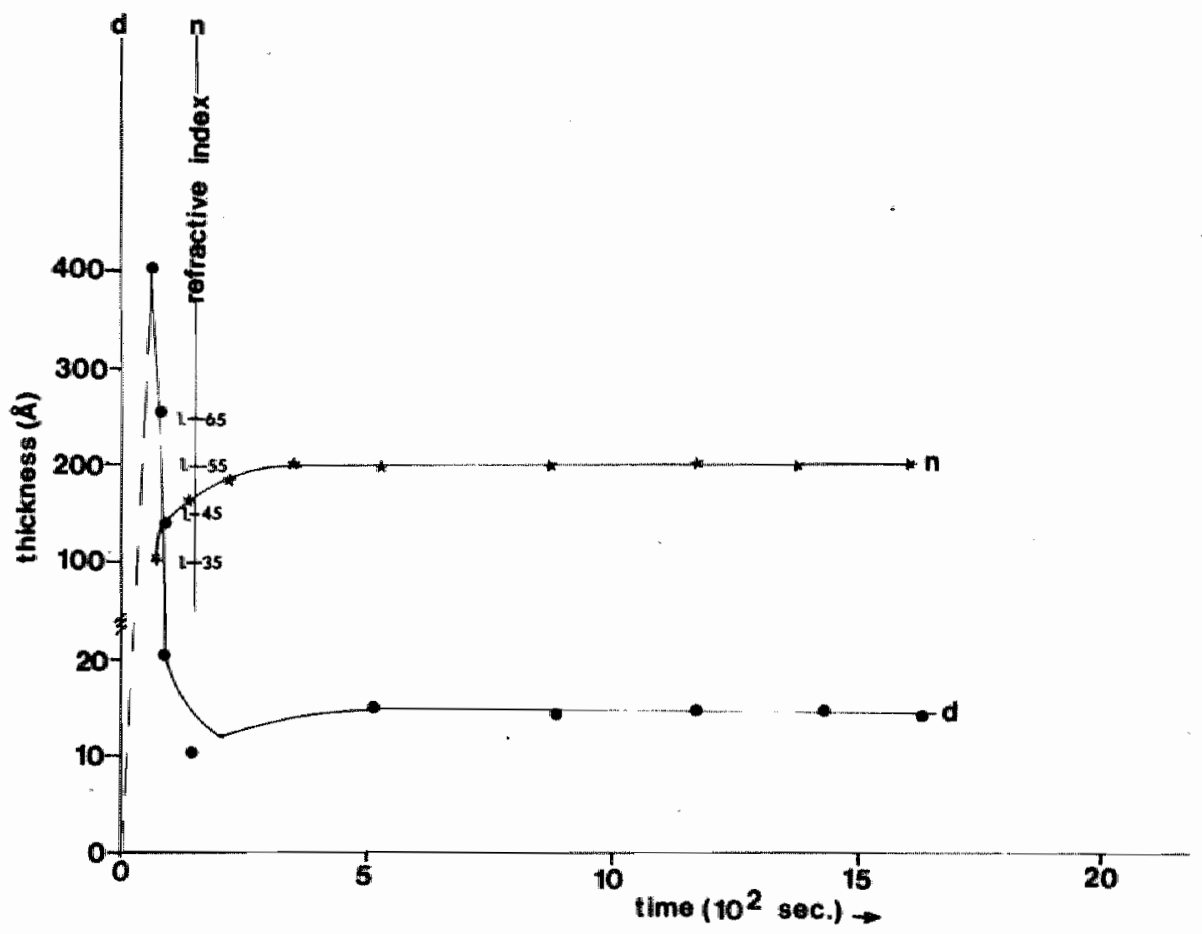

Fig. V1.8. Adsorption of albumin into a chromium (hydrophilic) surface. Concentration of albumin: $10 \mu \mathrm{g} / \mathrm{ml}$. Buffer $0.01 \mathrm{MTr}$ is HC $1 \mathrm{pH} 7.0$. 


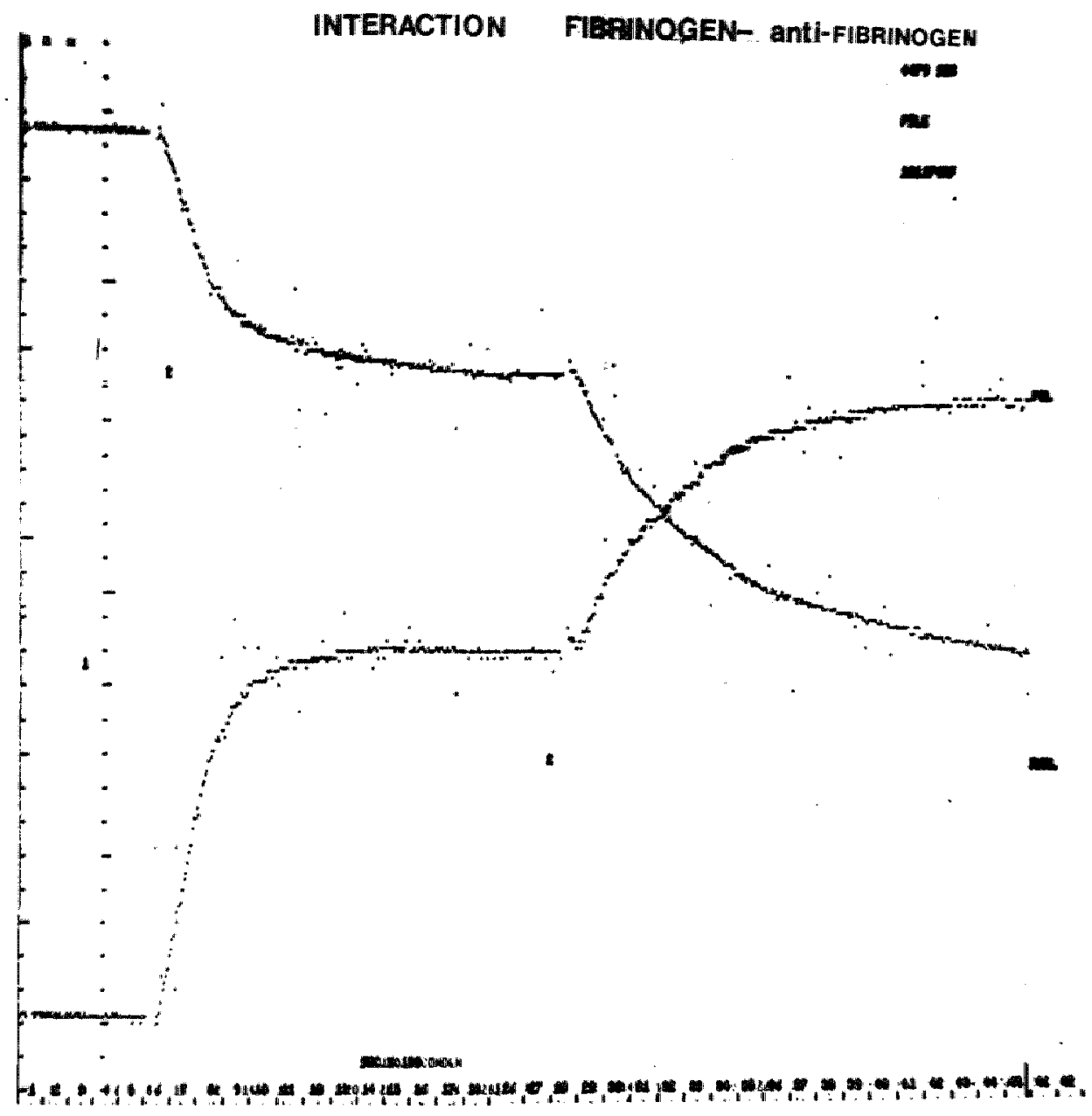

Fig. V1.9. Fibrinogen-antifibrinogen interaction (see text). 


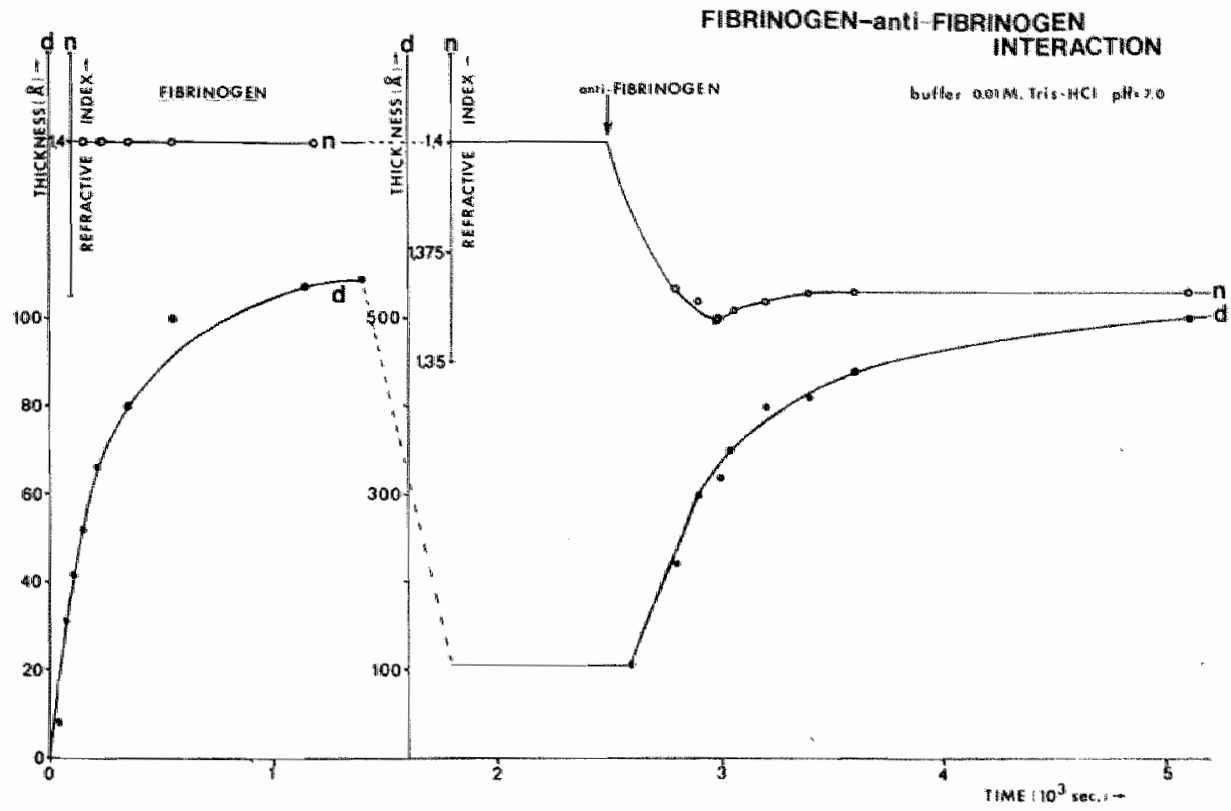

Fig. VI.10. Fibrinagen-antifibrinagen interaction (see text). 


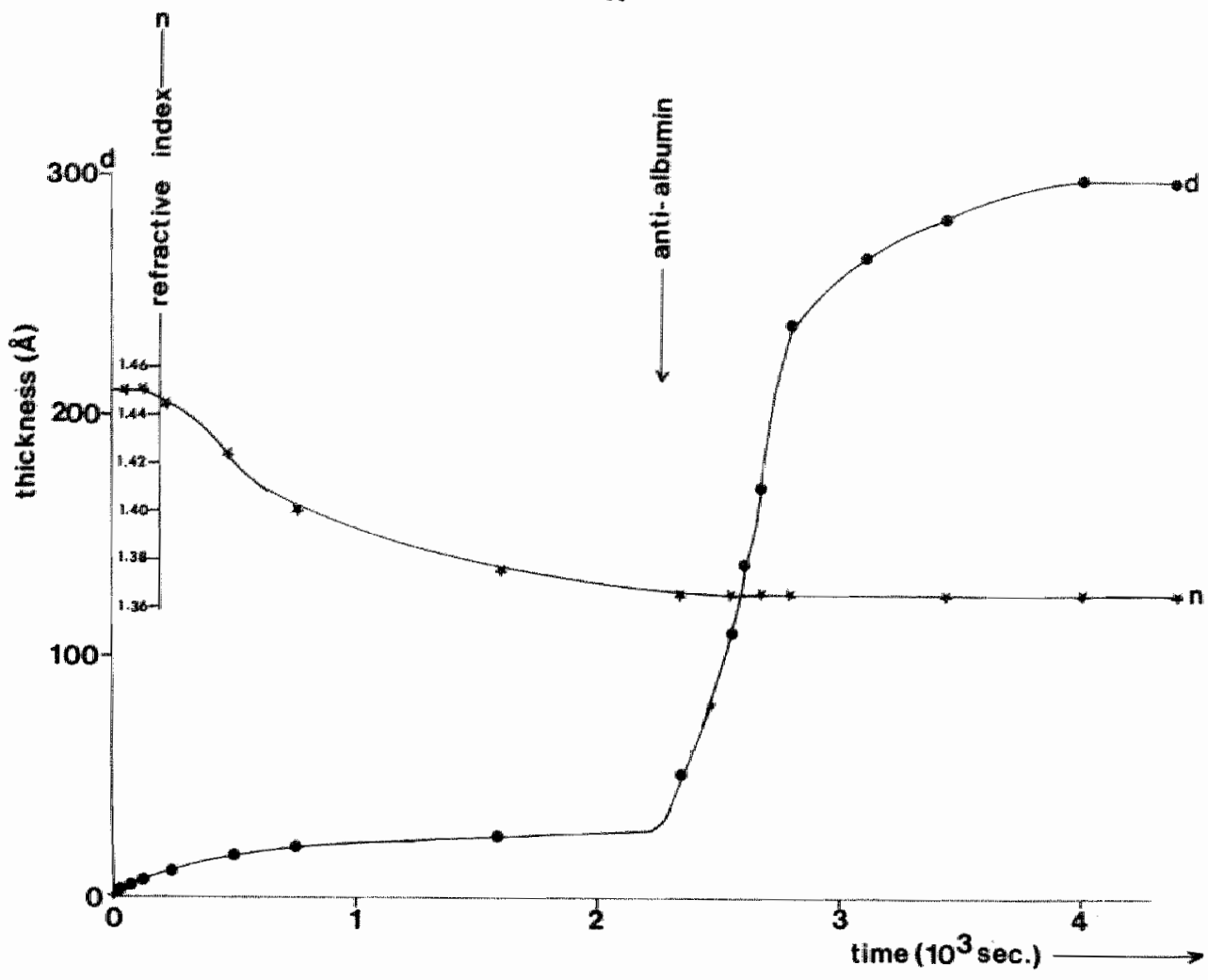

Fig. VI.11. Albumin-antialbumin interaction (see text).

6.5 .2 Albumin-antialbumin interaction

This experiment is exactiy comparable to the fibrinogen-antifibrinogen experiment in 6.5.1. Fimal albumin concentration was $10 \mu \mathrm{g} / \mathrm{ma}$. The result is shown in fig. YI.11. In this figure we see a thickness of the albumin layer of about 22 with a refractive index of $n=1,867$. After washing, addition of anti-albumin gives a Langmuir like adsorption with constant refractive index. The thickness in the end is $300 \AA$

6.6 Displacement of several proteins by fibrinogen

6.6.1 Displacement of albumin by fibrinogen on a chromium surface These experiments were carried out under the same experimental conditions as in 6.3.1. Final albumin concentration $10 \mu \mathrm{g} / \mathrm{m}$, final 
fibrinogen concentration $10 \% 9 / m 1$. After the first addition of albumin. a monolayer is formed. Further adition of albunin causes no further deposits. Addition of fibrimogen after washing gives a big change in polarizer and analyzer. After calculation we find a thickness of 80 with a refractive index of $\# 1,515$. These data are compatible with a fibrinogen monolayer. Addition of antifibrinogen caused a big change in thickness and refractive index as shown in fig. W.12. The layer thus presumably is fibrinogen that replaced the albumin. This is further supported by

1. addition of anti-albumin after the fibrinogen adsorption, which caused only a very small change, and

2. adsorption of albumin after a fibrinogen adsorption which gave no reaction at a 11 .

6.6 .2 Displacement af serum proteins by fibrinogen on a chromium surface

The serum protein was added to a final concentration in the cuwet of $10 \mu \mathrm{g} / \mathrm{ml}$. After the adsorption of serum, the fibrinogen was added. In fig. VI. 3 we see the changes in polarizer and analyzer. Fig. WI.14 shows the thickness and refractive index as a function of time. Addition of serum gives an adsorption of about $d=180 \AA$ and $n=1,36$. After refreshing the contents of the cuvet the optical constants remain the same. Addition of fibrinogen causes a change in polarizer and analyzer (fig. VI.13) that must be interpreted (fig. WI.14) as a change of the refractive index on 7 . After washing, addition of antifibrinogen causes a large change in thickness. This indicates that fibrinagen replaced the adsorbed serum proteims. This is further supported by the abservation that antifibrinogen does not interact with the adsorbed serum proteins (first layer) and anti-whole serum does not interact with the layer generated after addition of fibrinogen (second layer).

6.7 Relation between thickness and refractive index in a monolayer of protein

During the adsorption of albumin or fibrinagen onto different chromium-chromium oxide slides, monolayers of different thickness and refractive index are obla ined.

we have already seen in 6.3.1 and 6.3.2 that under experimental conditions differing on ly in the hydrofobicity of the chromium surface, layers of $d=130 \AA, n=1,38$ till $d=35 \& n=1,8$ are formed. 


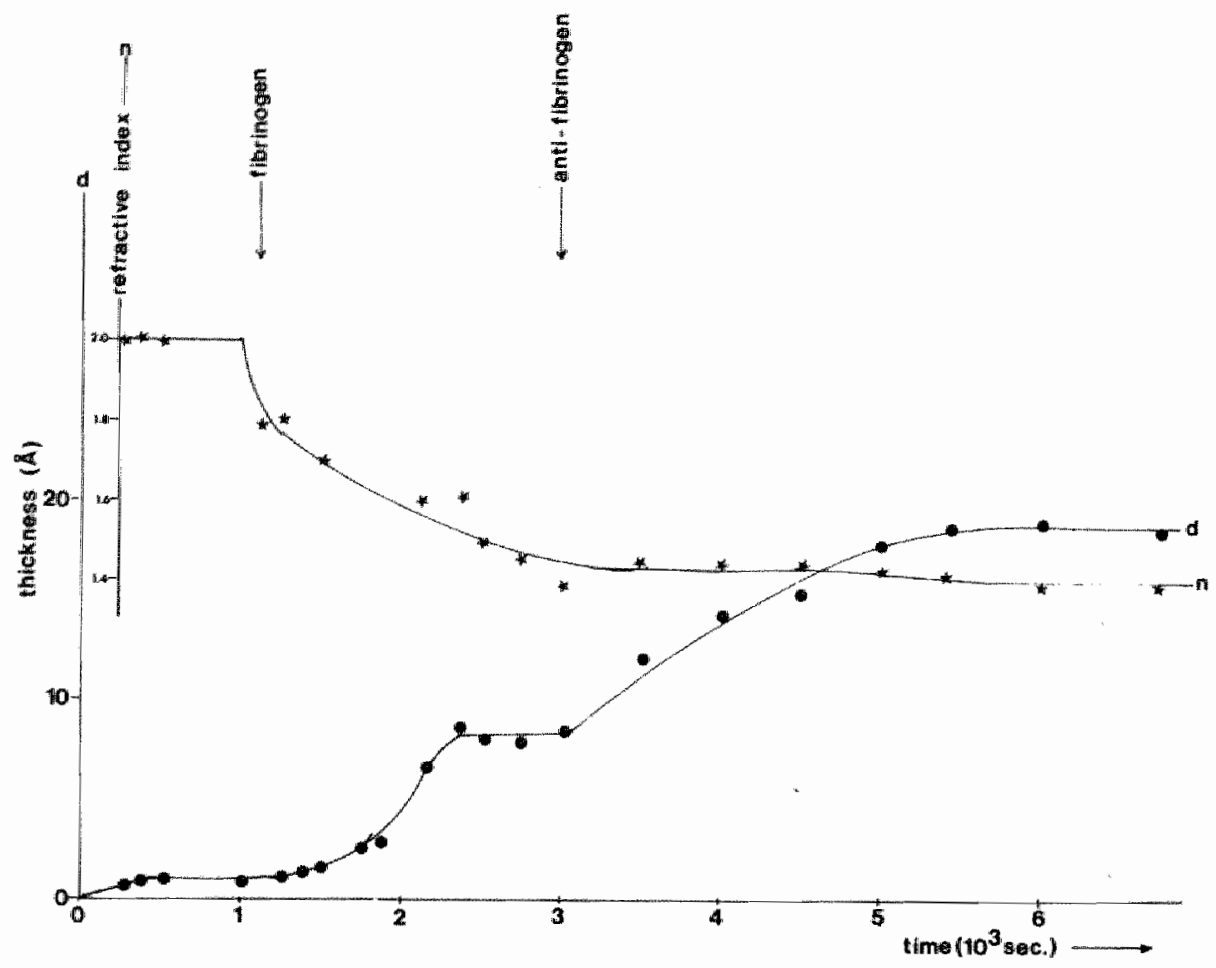

Fig. VI.12. Displacement af albumin by fibrinogen on a chromium surface. Fibrinogen-antifibrinogen interaction.

Concentration albumin $10 \mu \mathrm{g} / \mathrm{m} 1$.

Concentration fibrinogen $10 \mu \mathrm{g} / \mathrm{ml}$.

Buffer 0.01 M Tris-HCl, PH 7.0.

In Fig. VI.1S and VI.16 the relation between the values of the

thickness and refractive index of manolayers of albumin and fibrinogen are platted.

The curves resemble an orthogonal hyperbola with the refractive index of the medium as one asymptote. This is suggestive of a relation of the type $d . \Delta n=$ constant

where $\Delta n=n_{\mathrm{La}}-n_{m}$

$n_{\text {La }}=$ refractive index adsorbed layers

$n_{w}=$ refractive index medium. 


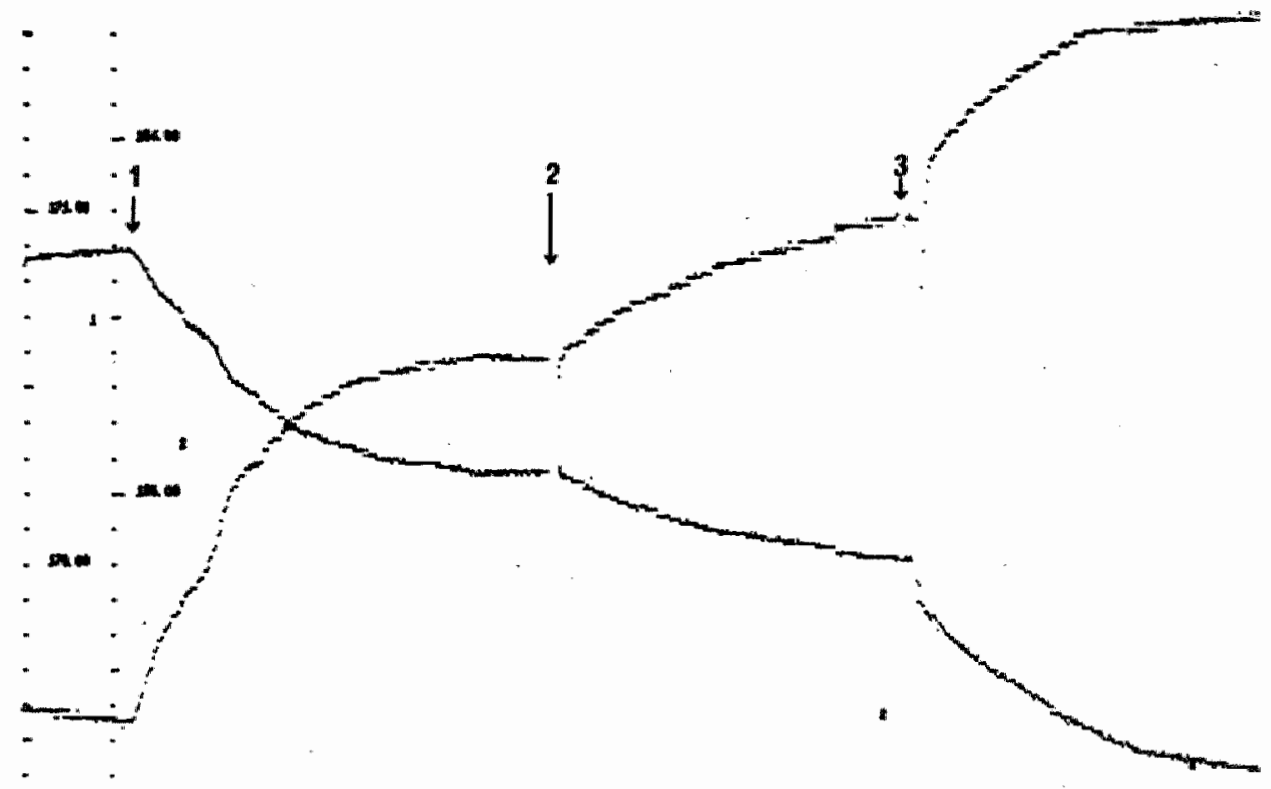

Fig.VI. 13. Displacement of serum proteins by fibrinogen

1. Hddition of serum proteins. Final conc. $10 \mathrm{wg} / \mathrm{ml}$.

2. Addition of fibringgen. Final conc. $10 \mu g / m l$.

3. Addition of antifibrinogen. 


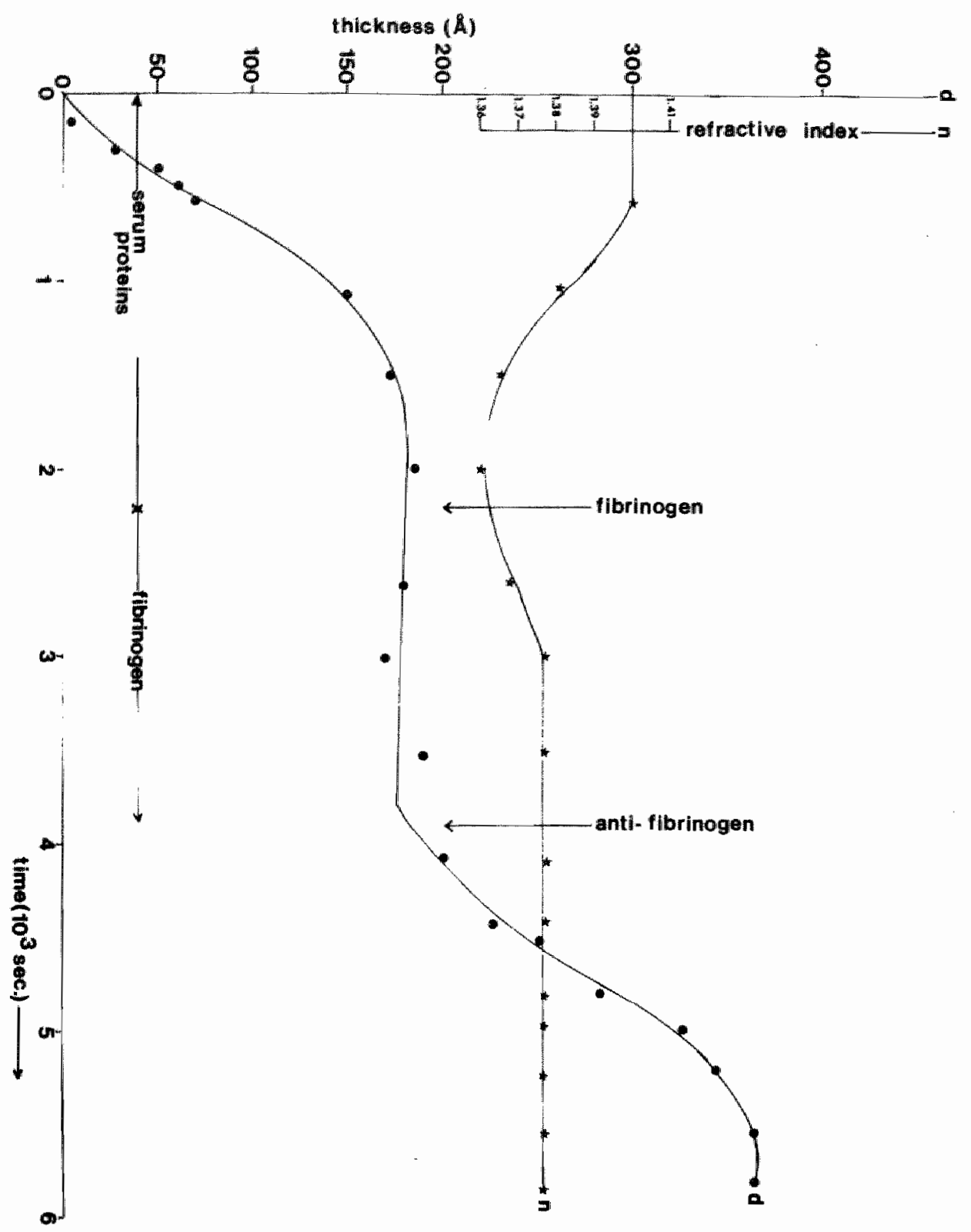

Fig.VI.14. Displacement of serum proteins by fibrinogen. 


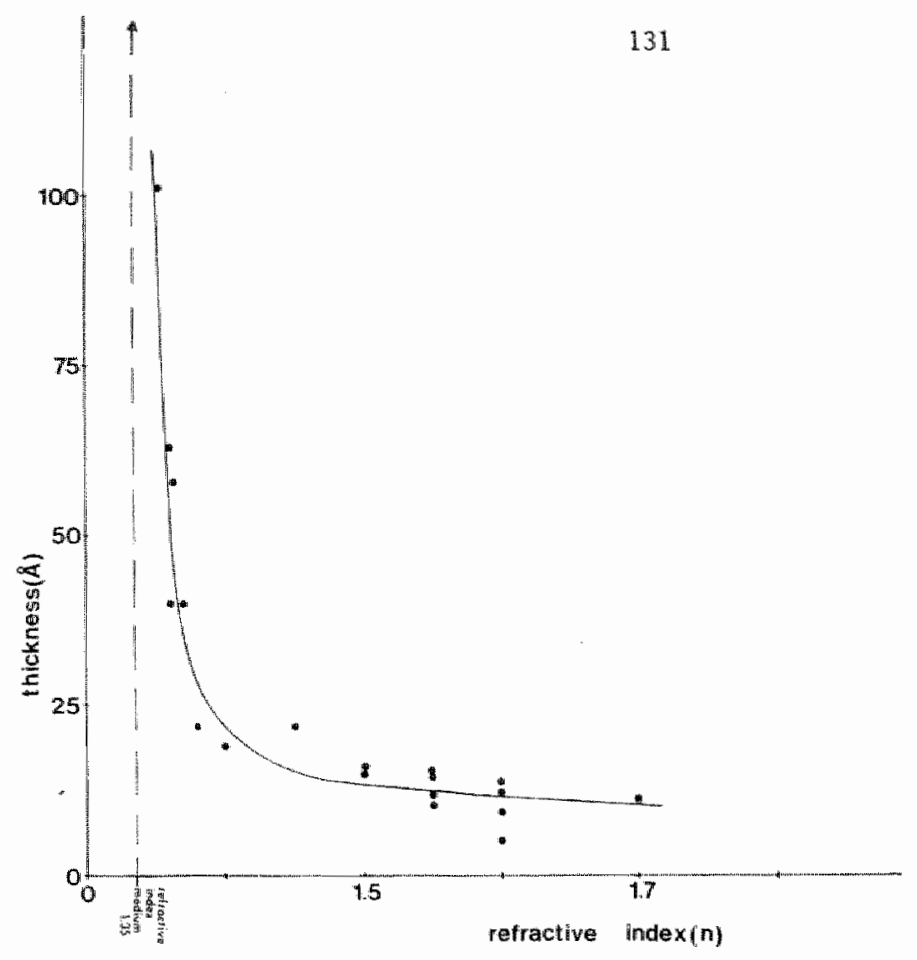

Fig. W. 15. Relation between $n$ and $d$ in a monolayer of albumin on chromium surfaces, differing in hydrophobicity.

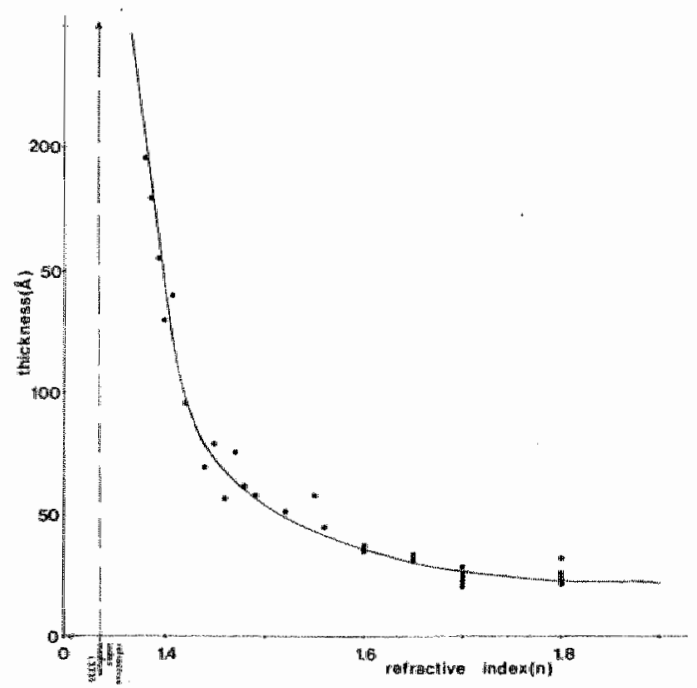

Fig. V1.16. Relation between $n$ and $d$ in a monolayer of fibrinogen on chrontum surfaces differing in hydrophobicity. 
To test the validity of this formull we plotted d against 1/An (Fig. VI.16; fig. (1.17).

The figures show that fomula (87) indeed can be taken as a first approxIndion of the relation between d and $\Delta n$. Further experiments are fuecessary.

\section{01 iscussion}

This last chapter shows a number of posstble applications of the technique. Some of these experiments have been done before by using the recording ellipsometer (6-9), hawever, in those cases it was not posstble to measure the effects in a quantitative way. The supposition in those experiments that the refractive index of the layer is a constant during the adsorption $(10,11)$ is valid only under very limited experimental conditions as is shown in this thesis. In our experiments we were able to quantitate protein adsorption. In this way we found a series of interesting phenomena like rearrangement af layers as discussed in 6.3.4, quantitation of protein-antibody interaction, and the meplacement of proteins by fibrinogen. Because of our possibilities to quantitate both $d$ and $n$ we found a possible relation between these parameters in adsorbed monolayers. A possible physical background may be the fact that in proteins the refractive index of the protein solution changes about 0.2 per gram protein per millilitre. So $\Delta$ n is something like concentration, d is a thickmess, consequently the product will be an amount of protein per surface unit. In all experiments done we presumably obtained a monolayer adsorption so in all those cases the amount of protein per surface unit has to be the same. To interprete these data in terms of the Lorenz-Lorentz equation (chapter III) or the other theories mentioned for the submonolayer systems, we have to wait until we have enough experimental data on different proteins. 


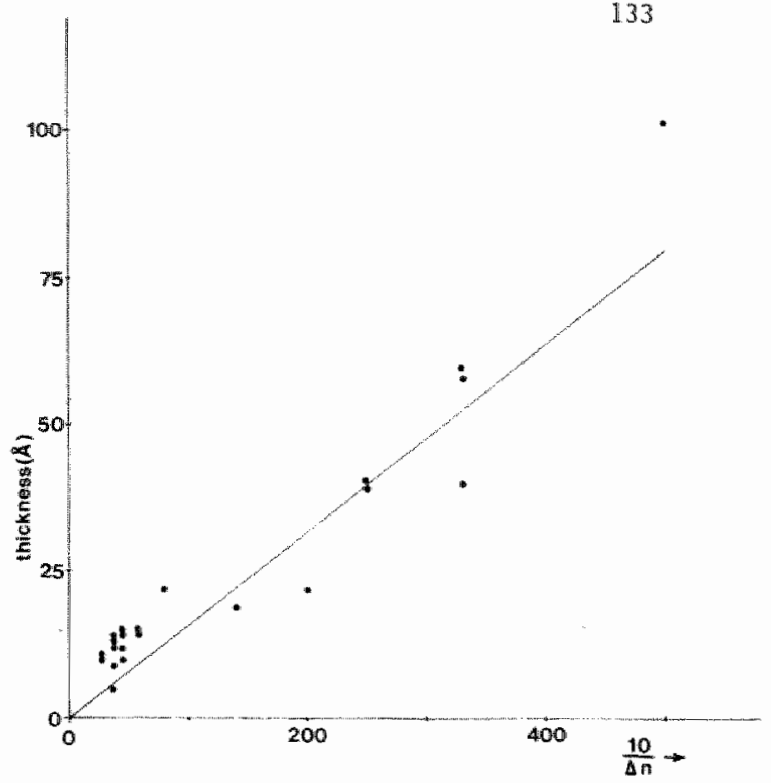

Fig $V \mathbb{1} .17$. Relation between $1 /{ }_{\Delta n}$ and $d$ of a monolayer of alburin (see text).

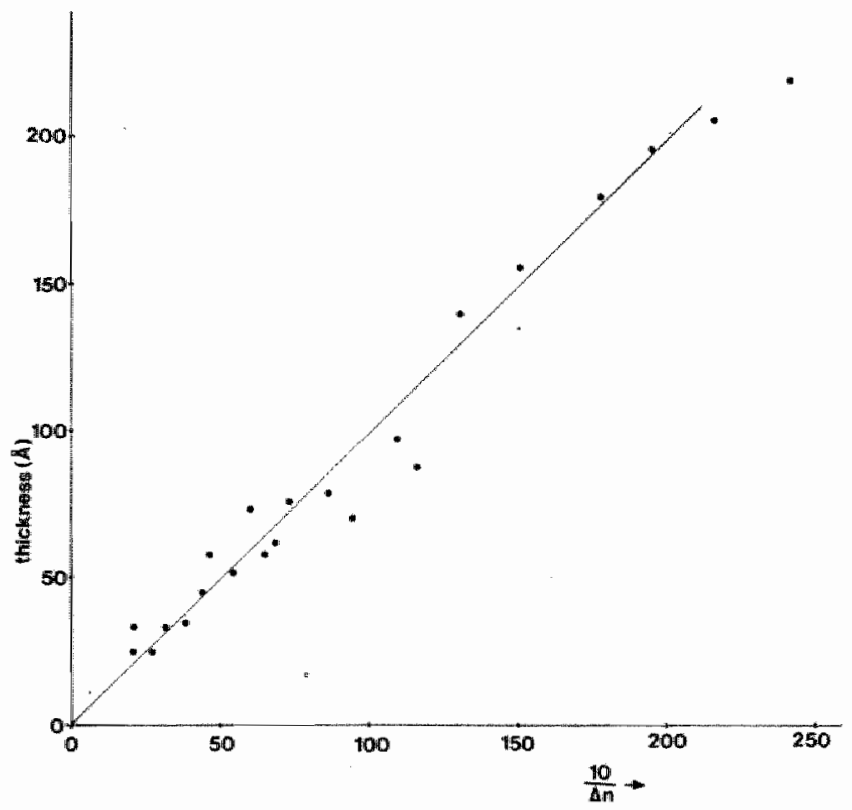

Fig. VI.18. Relation between $1 / \Delta n$ and $d$ of anolayer of fibrinogen (see text). 
Literature references

1. Winterbottom, A.B., (1946) Trans.Faraday Soc. 41,487

2. Bang, id. (1967) In Blood Clotting Enzymology. Ed. W. H. Seegers. Hcad.Press London, 487

3. HalT, C.E. and Slayter, H.S. (1959) d.Biophys.Biochem.Cyto1, 5, 11

4. Batemam, J.B. and Adams, E.D. (1957) J.Am.Chem.Soc.61, 1039

5. Mattuck, R.D.(1956) J.0pt.5oc.Amer. 46, 621

6. Wroman, L. (1964) Thrombos. Diathes.haemorth. 10, 455

7. Vroman, L. (1962) Nature 196, 476

8. Vroman, L. and Adams, A.L. (1967) Thrombos. Liathes haemorrh. 18, 510

9. Zucker, H. B. and Wroman, L. (1969) Proc.5oc. Exp.Biol. Hed. 131, 318

10. Poste, 6 . and Moss. C. In Progress in Surface Science. Vol. 2, Part 3 (1972) The study of surface reactions in biological systems by ellipsometry. Pergamon Press

11. Fenstermaker, C. H., Grant, H.H., Morrissey, B.W. Snith, L.E., and Stromberg, R.R. Interaction of Plasma Proteins with Surfaces. Nat1. Bur. of Stand. Washington. NBSIR. (1974) 74-470.

12. Bachmann, L., Schmitt-Fumian, W. W. Hammel, R. and Lederer, K. (1975) Die Makromolekulare Chemie 176, 2603

13. Lederer, K. and Hame1. R. (1975) Die Makromolekulare Chemie 176,2619 14. Lederer, K. (1975) Die Makromolekulare Chemie 176, 2641. 


\section{SUMMARY}

This thesis describes the development of an elipsometer useful for biochemical experiments.

The ellipsometer is an optical instrument that can be used to measure the thickness and the refractiwe index of thin transarant layers deposited on a reflecting surface. A big number of unsolved medical, biochemical and biophysical problems concemn processes occurring at interphases. Sone examples are membrane transport, nerve conduction, oxydative phosphorylation, thrombogenesis etc. Consequently it is very important to have an apparatus that can measure thickness and refractive index of layers of bialogical malecules t an interphase. The ellipsometric technique in principle allows such measurements, however, the major part af the apparatuses were until naw not able ta do so within 5 minutes. which is too slow far biochemical experiments. The developed recording ellipsoneter which could follow the change in light intensity reaching the photodiode continuously, could measure biachemical experiments fast enough but in this case it was not possible to. discrimimate between polarizer and analyzer changes, consequently these experiments can in general not be interpreted in terms of thickness or refractive index.

We developed a dymanic ellipsameter which follows both analyzer and polarizer automatically in time.

Chapter I summarizes the techniques available in the study of proteinprotein-and protein-lipid-interactions and reviews some of the obtaimed results.

Chapter II describes the measuring principle, electronic circuits and the computer steered stepping motors.

In Chapter II a general survey of the optical theory, necessary to understand the apparatus and the interpretation of the results. is given.

Subjects of Chapter IV are the thearetical analysis of the influence of the different parameters on the sensitivity of the measurements and the computerprogram for the interpretation of these experinemts.

Chapter $V$ gives the development of some standard experiments that cam be used to calibrate the instrument and to calculate the corrections. necessary to compensate the mon-ideal behaviour of the optical components. 
Chapter VI gives a number of illustrations of the technique applied for the unraveling of the following medical-biological problems:

1. Adsorption of a. a. fibrinagen and albumin onto different surfaces. All proteins tested adsorb onto chromium and silicon until a monolayer is obtained. The thickness of the layer varies with the water content.

The water content of the layer is influenced by the hydrophobicity of the surface. There is a relation between the thickness of the layer and the found refractive index. This relation is hyperbolic in a good approximation.

2. Interaction of prateins with their antibodies. By neans of ellipsometry it is possible to abserwe a reaction of a monolayer of protein $\left(<10^{-11}\right.$ grammoly with a momalayer of antibody $\left(<10^{-11}\right.$ grammol).

3. Fibrinogen displaces proteins adsorbed before, like albumin and serum proteins from chromium surfaces. 


\section{ZUSAMHENFASSUNG}

Diese Dissertation beschrébt die Entwickung eines Ell ipsoneters fur bachemische zwecke. Das Ellipsoneter ist ein optisches Instrument, das verwendet wird um die Dicke und den Brechungsindex düner durchsichtiger schichten auf einer reflektierenden oberflache zu messen. Viele ungelöste medizinische blochemische und biophysikalische Probleme betreffen Prozesse, die sich an Grenzflachenabspielen. Beispiele dafur sind Membrantransport, Reizleitung, oxydative Phosphorylierung. Thrombogenesis usw. Deshalb ist es sehr wichtig, ein Instrument zu haben, das Dicke und Brechungsindex bialogischer Molekulschichten auf einer Granzflache messen kann. Die ellipsometrische Technik ermöglicht dies. Die vorhandene Apparatur war aber nicht geeignet fü diese Zwecke. Man hatte nur ein statisches Ellipsometer zur verfügung, das genau dỉe Anderungen des Lichtpolarisationszustandes messen kann und in dieser Weise genaue Bestimmugen der Dicke und des Brechungsindexes ermöglicht, aber nur eine Messung pro 5 bis 10 Minuten durchführt, was für dynamische biochemische Prozesse nicht genügt. Daneben gab es ein Ellipsometer das kontinuierlich nur die Lichtintensitat des von dem Instrument durchgelassemen Lichtes mass, so dass nur ungefähre Schätzungen der Dicke oder des Brechungsindexes möglich waren. Wir entwickelten eim Instmument, das beide parameter automatisch misst mit Unterbrechungen von $2 \frac{1}{2}$ bis 5 sekunden.

Kapitel I beschreibt im kurzen die bis heute verwendeten Techniken zur Untersuchung wan Protein-Protein- und Protein-Lipid interaktionen und gibt eine vbersicht der damit erreichten Ergebnisse.

Wirkungsprinzip, elektronische Eigenschaften, Lenkung der Stufenmotoren und das vom Komputer gelenkte Messverfahren werden iff Kapitel I beschrieben.

Kapitel II gibt eine kurze Ubersicht der Theorie, die man braucht zur Deutung der Wirkung des Apparats, und der Ergebnisse. Die theoretische Analyse des Ejiflusses der verschiedenen Variablen auf die Empfindlichkeit der Messungen und der Komputerprogramme fü dite Be abachtungsdeutung findet man im Kapitell IV. Kapitel V beschreibt die Entwicklung von Normalversuchen zur Eichung des Instruments und zur Berechnung wan korrekturen für nicht-ideale Wirkungen der optischen Komponenten. 
Kapted VI beschreibt efne Anzahl von mit dieser Technik bearbeiteten biomedizischen Problemen 2.8 .

1. Adsorption von Fibrinagen und Abumin an verschiedenen oberflachen. Es stellt sich heraus dass alle gepruften proteine an Chrom oder sillicon adsorbiert werden, bis sich eime monomolekulären Schicht hergestellt hat. Die Schichticke varifert mit dem Hassergehalt. Der Wassergehalt der Schichten wird beedinflusst von der Hydrophilitä der oberflache. Zwischen der Schichtdicke und dem Brechungsindex besteht ein Zusamenhang der fast hyperbolisch ist.

2. Interaktionen von Proteinen mit ihren Antikörpern. Es ist möglich, mit Hife der Elipsometertechnik, unittelbar die Reaktion eirner Proteinmonoschicht $\left(<10^{-11}\right.$ Grammol) mit einer Antikörpermonoschicht (< $10^{-11}$ Gramma1) zu beobachten.

3. Fibrinogen verdrangt adsorbierte Proteine wie Albumin und Serumproteine von Chromoberflächen. 
RÉSUMÉ

L'objet de cette thèse est la description des modifications d'un ellipsomètre. Ces modifications ont été rendues nécessaires pour piermettre des êtudes biochimiques.

L"ellipsomẽtre est un instrument d"optique qui permet de mesurer 1 "épaisseur et I'indice de réfraction de couches minces et transparantes se trouvant sur des surfaces reflechissantes. De nombreux problèmes non résolus qui se posent dans les domaines mẻdicaux, biochimiques, biophysiques et biomedicaux, concernent des processus qui se passent au niveau des interfaces liquide - solide, par example: les transports tramsmembranaires, la canduction nerveuse, la phosphorilation oxydatiwe, la thronbogenèse. Il est donc important de posseder un instrument qui soit capable de mesurer l'épaisseur et l'indice de réfraction de cauche de molécules de substances biologiques se trouvant à ces interfaces.

La technique ellipsométrique permet de telles mesures. Cependant les appareils existants n'étalent pas aptes à le faire. En effet, on ne disposait que d'ellipsomètres statiques qui pouvaient mesurer exactement des madifications de lumière palarisée et permettaient ainsi de déterminer d"une manière précise l"épaisseur et l indice de rēfraction. Avec ces instruments le temps nécessaire pour effectuer une mesure êtait compris entre 5 et 10 minutes ce qui est beaucoup trop lang pour suivre un processus biochimique. Il était également possible d'effectuer des mesures d'une manière continue maís seulement de l'intensité lumineuse transmise par l'instrument de telle sorte

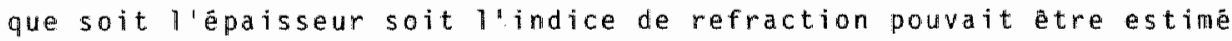
d'une manière grossî̀re.

Nous avons développé un instrument capable de suivre automatiquement ces 2 paramètres à des intervalles variant entre 2 let 5 secondes.

Le chapitre I résume les techniques utilisêes jusqu'à présent pour 1 "étude des interactions protéines-protéines et protéines-lipides aux interfaces et $i l$ donne également une vue gënérale des rêsultats obtenus.

La description de l'appareil en ce qui concerme son principe de fonctionnement, san schema êlectronique, son mode d'emploi et le procédë de mesure dirigé par computer est trailtẻ dans le chapitre Il. 
Le chaptere III donne une vue globale de la theorie nécessaire la comprênenston du fonctiannement de l"apparell et à l "interpretation des resultats. L'analyse theorique de i'influence des diffétentes variables sur la sensibilite des mesures et celles des programmes du computer pour l'interpretation des resultats est traltee dans le chapitre IV.

Uans le chapitre $V$ on dëveloppe des experiences standards qui permettent detalonner 1 "finstrument et de tenir compte de corrections nécessalles lors du comportement non idéal des composants optiques.

Le chaptre VI donne une sêrie dillustrations de l'application de cette technique aux problemes biologiques et médicaux suivants:

1. L'asorption du fibrinogème et de l'albumine sur differentes surfaces.

11 semble que toutes les pratéines testees s"adsarbent sur le chrome ou le silicium sous la forme d'une couche mononucleatre. L'epaisseur de la couche varie avec la teneur en eau.

La teneur en eau de la couche est influencëe par la nature hydrophyle de la surface. La relation entre l'épaisseur de la couche et 1 indice de refraction est de nature hyperbalique.

2. L'interaction entre les proteines et leurs anticorps.

Il semble possible à 1 "aide de 1 "ellipsamètre d"observer directement la réction entre une couche monomoléculaire de pratêine ( $<10^{-11}$ molêcule gramme) et une couche monomoléculaire $\left(<10^{-11}\right.$ molécule gramme).

3. Le fibrinogêne dêcolle d"une surface en chrome des protéines adsombées auparavant sur celle-ci telle l'albumine des protéines du sêrum. 
KOMPENOIUM

Dees dissertasie besjreif ie mèt vä̈l belump nen ellipsometer word ineingefisternold dee ziech lient weur biochenisch gebrukk. U n ellipsameter is " $n$ optisch instrumint wat in staot is de dikte en brekingsindex te mete van dun, doorziechtige laogskes die op e reflekterend oppervlak $z$ it te.

"n Groete struip oonopgellosde medische, biochemische, biofysische en biomedische prableme regardere processe die ziech aon grensvllakke aofspeule, zoe wie beveurbeeld membrantransport, de geleijing van steekskes door de zenuwbane, oxydatieve fosforylering, "t oontstoon van thromboos en zoe mie. "t Is dacrum varn importantie " $n$ instrumint te höbbe, wat dikte en brekingsindex (bezettingsgraod) waan lage vaan biologische molekule in e grensvlak kin mete. De ellipsometrische techniek mak dit in prinsiep meugelek. De bestaonde appretuur dougde dao evels neet veur. Ne had namelek wel de statische ellipsometer, dee puntelik de veranderinge in de polaristietowstand vaan " $t$ leech kin mete en zoe de eksakte bepaoling vaan dikte en brekingsindex meugelek mak, weh boe mer ein meting um de 5 a 10 menute mèt kós weure gedoon, wat veur dymamische biochemische processe neet genóg is.

Ouch had me ellipsometers die kantinu allein mèr de intensiteit mete van "t leech wat door "t instrumint weurd doargelaate, boedoor of vaan dikte of vaan brekingsindex allein mer groof taxaties meugelek zien.

Veer höbbe " $n$ instrumint oetgeprakkezeerd wat allebey de parameters otomatisch vervolg mèt intervalle vaan 2 tot 5 sekonde.

Hoofstök I gief " $n$ korte imventarisatie valu de technieke, die tot noe tow veurnamelek $z$ ien gebruuk veur 't bestudere vala eiwit-eiwit en eiwit-jipide interaksies aon interfases en gief " $m$ auverziech wa de rizzeltate die daomet zien behald. De besjreiving vaan " $t$ apperat wat betröf werrrekingsprinsiep, elektronische regelinge, 't sture wan de stepke-veur-stepke drejjende motors en de door de kompjoeter bestuurde meetproceduur weure in hoofstök II besjreve.

In hoofstök III weurd e kort globaal euverzlech gegeve vaan de theorie die nudig is um ' $n$ inziech te kinne krieve in de wèrreking vaan 't apperat en um de rizzeltaote te kinne interpreteere. 
De theoretische besjowing euver de inwerrreking van de versjeije variabele op de geveuligheid van de metinge en daobij ouch de kompjoeter-programa"s veur de fintempretasie van de observasies weure in hoofstok IV betrandeld.

In hoofstak $V$ weure standaardeksperiminte oet de deuk gedoon die goojen deens kinne doen bij"t ijke van de klonmel en bij de besiefering van de karrekties veur ' $t$ geval' $t$ gedrag van de optische komponente neet ideal is.

Hoofstók VI gief ' $n$ hamfel i1lustrasies wan d'm techniek, Howgepas op de volgende medisch-biologische probleme:

1. Adsorptie wan o.a. fibrinogeen en albumine a an versjeije oppervlakke. Dabij bliek tot alle beproofde eiwitte ap chroom- en siliciumoppervlakke weure wasgehawe totdat ' $n$ laog is oontstande die monomollekulair is. De dikte van de laog varieert nèt "t watergehalte. * Watergehalte vaan de laog weurd 0 . a. mètbepald door de wateraontrejkingskrach wan "t oppervlak. Dao is e verband töse laogdikte en brekingsindex, wat - es alles good zit - nyperbolisch is.

2. Interaksies vaan eiwitte mét hun anti-liechame. 't Bliek meugelek um m.b.v. ellipsometrie direk de reasie vaan "n monolaog eiwit (< $10^{-11}$ grammol) mèt "n monolaog antiliecham ( $10^{-11}$ grammol) te konstatere.

3. Fibrinogeen verdringk al ieder geadsombeerde eimitte, zoe wie albumine en serumeiwitte, wan chroomoperwlakke. 
Dit proefschrift beschrijft de ontwikkeling van een ellipsometer geschikt voor biochemisch gebruk. De ellipsometer h een optisch instrument dat in stat is de dikte en brekingsindex te meten van dunne doorzichtige lagjes die zich op een meflekterend oppervlak bevinden. Een groot antal onopgeloste medische, biochenische, biofysische en biomedische problemen betreffen processen die zich an grenswiaken afspelen. Hen denke b. an membrantransport, prikkelgeleiding, oxydatieve fosforyleming, thrombogenese etc. Het is darom van groot belang om te beschikken over een instrument dat dikte en brekingsindex (bezettingsgraad) van lagen van biologische molekulen in een grenswlak kan meten. De ellipsometrische techniek makt dit in principe mogelijk. De bestaande apparatur was echter niet geschikt. Wen beschikte nl. over de statische ellipsometer. die nawkeurig de veranderingen in de polarisatietoestand van het licht kan meten en zadaende exakte bepaling van dikte en brekingsindex mogelijk makt, maar slechts éên meting per 5 ả 10 mimuten toestaat, hetgeen woor dymanische biochemische processen onvoldoende is of over ellipsometers die kontinu \$lechts de lichtintensiteit van het door het instrument doorgelatem 1 icht meten wardoor of van dikte of van brekingsindex slechts ruwe schattingen mogelijk zijn. Wij ontwikkelden een instrument dat beide parameters automatisch vervalgt met interwallen van $2 \frac{2}{2}$ à 5 sekonden.

Hoofilstuk I somt in het kart de technieken voor het bestuderen op, die tot nu toe voornamelijk gebruikt zijn voor het bestuderem van eiwit-eiwit-en eiwit-1 jpide interakties aan interfases en geeft een overzicht van de daarmee bereikte resultaten.

De beschrijving van het apparaat wat betreft werkingsprincipe, elektronische regelingen, sturing van de stappenmotoren en de komputer gestuurde meetprocedure worden in hoofdstuk 11 beschreven.

In hoofdstuk III wordt een kort globaal overzicht gegever van de thearie die nodig is om een inzicht te kunnen kijgen in de werking wan het apparat en am de resultaten te kunnen interpreterem. De theoretische analyse wan de invloed van de verschillende variabelien op de gevoeligheud van de metingen en de komputerprograma's voor de interpretatie wan de warnemingen wordem in hoofdstuk IV behandeld. In hoofdstuk $V$ worden standaardeksperimenten ontwikkeld die kunnen dienen am het instrument te ijken en om korrekties voor niet-ideal gedrag van de optische komponenten te berekenen. 
Hoofdstuk VI geeft een antal 11 lustraties van de techniek toegepast op de walgende medisch-biologische problemen:

1. Hodsortie van a. a. fibrinogeen en albumine a an verschillende opperwlaken. Het blijkt dat alle geteste eiwiten op chroom en silicium adsorberen tot een momomolekulaire lag verkregen is. De dikte van de laag varieert met het watergehalte. Het wathergehalte van de laag wordt a.a. beinvloed door de hydrofiliteit wan het appervlak. Er is een verband tussen laggikte en brekingsindex dat in goede benadering hyperbolisch is.

2. Interakties van eiwitten met hun antilichamen. Het blijkt mogelijk om met behulp van ellipsometrie direkt de reaktie wan een monolaag eiwit $\left(<10^{-11}\right.$ grammol) met een monolaag antillicham (< $10^{-11}$ grammol) war te nemen.

3. Fibrinogeen verdingt reeds eerder geadsorbeerde eiwitten zoals al bumine en serumeit then van chroomoppervlakken. 
op verzoek wan de Faculteit der Geneeskunde wolgt hier een avenzicht van mijn akaderische studie.

Ik 1966 liet ik mij na het behalen van het ULO-B en HBS-B diploma inschrijwen aan de Gemeente Universiteit van Amsterdan. Dar behal. de $i k$ in 1969 het kandidatsexamen schelkunde letter $S_{2}$. De doctoralstudie verliep met hoofdwak biochemie onder leiding van de hoogleraar Dr.E.C.51ater. Het bijvak neurophysiologie werliep onder leiding van Prof.Dr.J.Ariens Kappers op het Mederlands centraal Instituut voor Hersenonderzoek. Als specialle richting werd wiskunde gedaan. In februari 1971 werd het doktoraal examen affelegd.

Van 1971 tot mart 1974 was ik als wetenschappelijk medewerker verbonden aan het Laboratorium voor Cardiobiochemie en Bloedstollingsbiochemie wan het Academisch Ziekenhuis in Leiden, onder leiding van Dr.H.C. Hemker. Vanaf 1973 werden door mij de colleges Pathologische scheikunde voor vijfde en zesde jaars studenten van de Vrije Universiteit Brussel gegeven. Sinds mart 1974 ben ik als wetenschappelijk medewerker verbonden an de Rijksuniversiteit Limburg. 


\section{DANKWORO}

Garne 11 ik op deze plats mijn dank betuigen a an een ieder die heeft bijgedragen an het tot stand komen van dit proefschrift en de ontwikkeling van de ellipsometer.

Prof.Dr.H.C. Hemker ben ik veell dank verschuldigd voor de begeleiding war dit onderzok.

Dr. Hermens, beste Wim. jouw inbreng in dit onderzoek heeft een grote invioed gehad op de inhoud van dit proefschrift. Hiervoor ben ik je zeer erkentelijk.

Prof.Dr.H.D. Ohlenbusch en Dr.L.Vroman wil ik danken voar hun bereidineid om als coreferent op te treden.

De heren J.Mooy en A.J.M.Alink dank ik woor de grote bijdragen op het gebied van de computerprogrammering en de elektronika.

ook dank ik de heer J.M.Q. v.d.Voort voor zijn bijdrage a an de mechanische ontwikkeling van het apparat.

Verder dank ik Dr.L.Wroman, Ir.V.J.G.Honderd, Drs.P. W. Hemker, Drs. D. Meyer, en Drs.R. ilarquet die allen in een zeer Vraeg stadium bij de ontwikkeling van het apparaat betrokken waren.

Verder gat mijn dank uit naar:

Mej.R.Jamssen die met veel geduld em toewijding de latste experimenten heeft uitgewoerd;

Mevr.H.Vermeer-Kmulst voor het typen van het manuscript;

ine Heer V.Dreessen voom de assistentie bij de computerprogramering; Mewr.L.Graeneweg-Wolfs die het engels van het grootste gedeelte van dit proefschrift heeft gekorrigeerd;

De Heer H.A.Essers voor zijn vertaling van de samenvatting in het mestmeechs;

De heer F. lleyer van het Natuurkundig Laboratorium van Philips in Eindhoven voor het beschikbaar stellen van siliciumplakken:

Mej.A.D.Muller vaop het vervaardigen wan de tekeningen: Het Nederlands Astmafonds, de Nederlandse Hartstuchting, de Stichting Scheikundig onderzoek Nederland en het Ministerie van sactale zaken en Valksgezomdhejd voor hun financièle siteun. 